\title{
Management Concepts and Safety Applications for Nuclear Fuel Facilities
}

Manuscript Completed: January 1995

Date Published: May 1995

Prepared by

H. Eisner, R. S. Scotti, The George Washington University

W. S. Delicate, The KEVRIC Company, Inc.

The George Washington University

School of Engineering and Applied Science

Center for International Training and Education

Washington, DC 20052

Under Contract to:

The KEVRIC Company, Inc.

8401 Colesville Road, Suite 610

Silver Spring, MD 20910

Prepared for

Division of Fuel Cycle Safety and Safeguards

Office of Nuclear Material Safety and Safeguards

U.S. Nuclear Regulatory Commission

Washington, DC 20555-0001

NRC Job Code J5030 



\section{DISCLAIMER}

This report was prepared as an account of work sponsored by an agency of the United States Government. Neither the United States Government nor any agency thereof, nor any of their employees, make any warranty, express or implied, or assumes any legal liability or responsibility for the accuracy, completeness, or usefulness of any information, apparatus, product, or process disclosed, or represents that its use would not infringe privately owned rights. Reference herein to any specific commercial product, process, or service by trade name, trademark, manufacturer, or otherwise does not necessarily constitute or imply its endorsement, recommendation, or favoring by the United States Government or any agency thereof. The views and opinions of authors expressed herein do not necessarily state or reflect those of the United States Government or any agency thereof. 


\section{DISCLAIMER}

Portions of this document may be illegible in electronic image products. Images are produced from the best available original document. 


\begin{abstract}
This report presents an overview of effectiveness of management control of safety. It reviews several modern management control theories as well as the general functions of management and relates them to safety issues at the corporate and at the process safety management (PSM) program level. Following these discussions, a formal and structured technique for assessing management of the safety function is suggested.
\end{abstract}

ABSTRACT

Seven modern management control theories are summarized, including business process reengineering, the learning organization, capability maturity, total quality management, quality assurance and control, reliability centered maintenance, and industrial process safety. Each of these theories is examined for its principal characteristics and implications for safety management.

The five general management functions of planning, organizing, directing, monitoring, and integrating, which together provide control over all company operations, are discussed. Under the broad categories of Safety Culture, Leadership and Commitment, and Operating Excellence, key corporate safety elements and their subelements are examined. The three categories under which PSM program-level safety issues are described are Technology, Personnel, and Facilities.

Using the general management functions and the key safety elements, evaluation matrices for the corporate and PSM program levels are established in order to assess the ability of the organization under scrutiny to manage safety. For each cell of the matrix, a list of typical questions is provided that permits an evaluator to rate the success of the organization in management of that aspect of safety. 



\section{CONTENTS}

Section

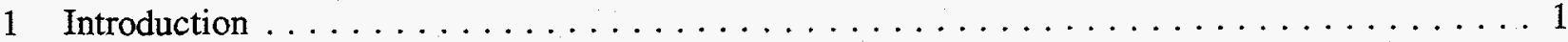

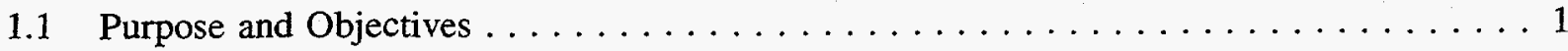

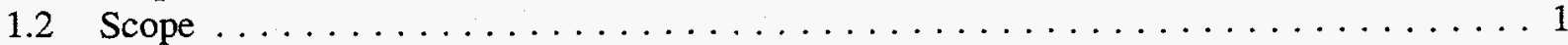

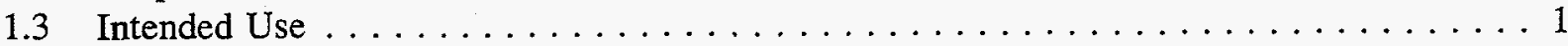

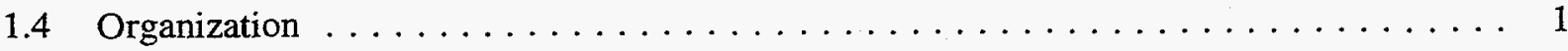

2 Modern Management Control Theories $\ldots \ldots \ldots \ldots \ldots \ldots \ldots \ldots \ldots \ldots \ldots$

2.1 Introduction $\ldots \ldots \ldots \ldots \ldots \ldots \ldots \ldots \ldots \ldots \ldots \ldots \ldots \ldots \ldots$

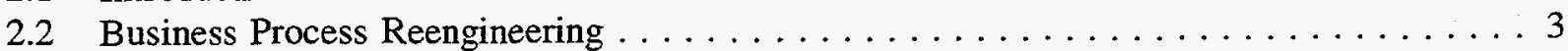

2.3 The Learning Organization $\ldots \ldots \ldots \ldots \ldots \ldots \ldots \ldots \ldots \ldots \ldots \ldots \ldots \ldots$

2.3 .1 Personal Mastery . . . . . . . . . . . . . . . . . . . . . . . . 4

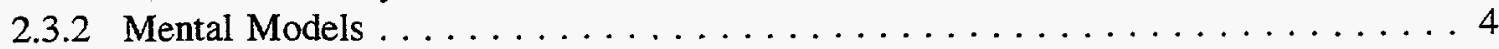

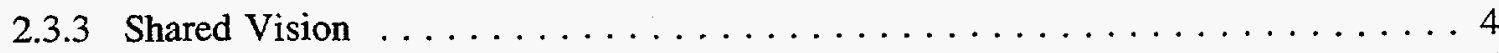

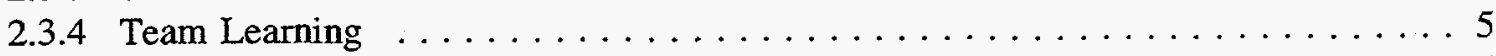

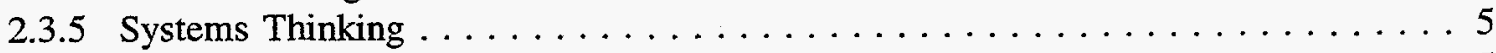

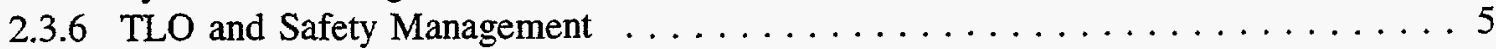

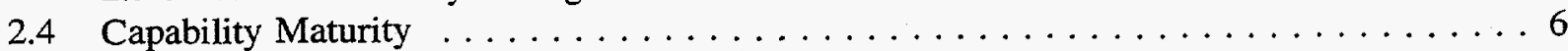

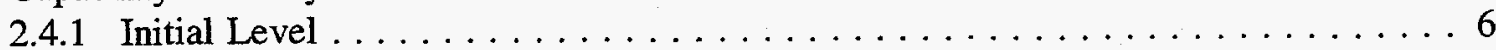

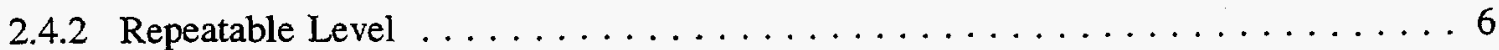

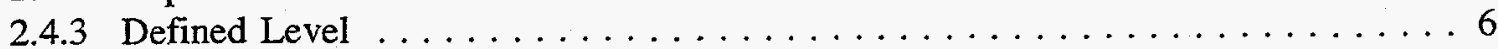

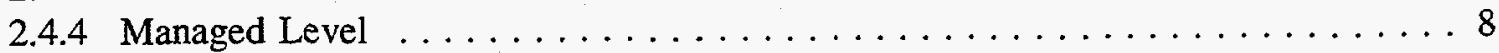

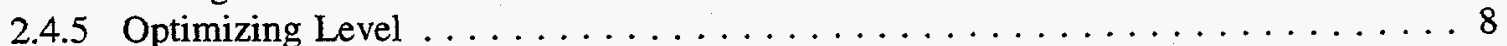

$2.4 .6 \mathrm{CM}$ for Safety Management $\ldots \ldots \ldots \ldots \ldots \ldots \ldots \ldots \ldots \ldots \ldots$

2.5 Total Quality Management $\ldots \ldots \ldots \ldots \ldots \ldots \ldots \ldots \ldots \ldots \ldots \ldots \ldots$

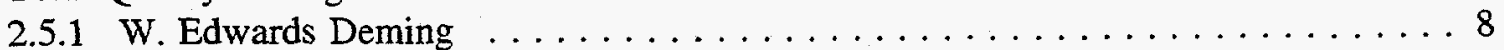

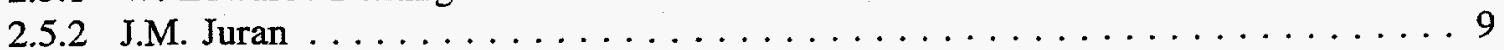

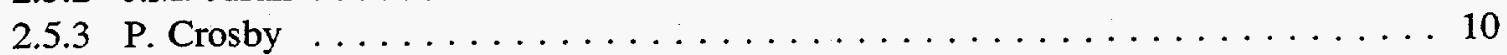

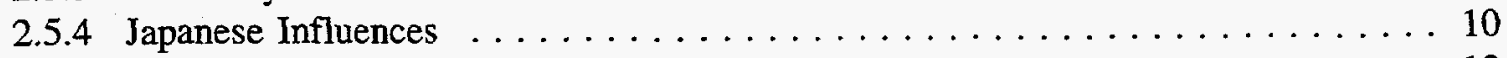

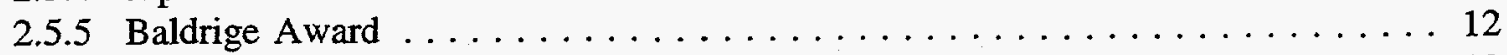

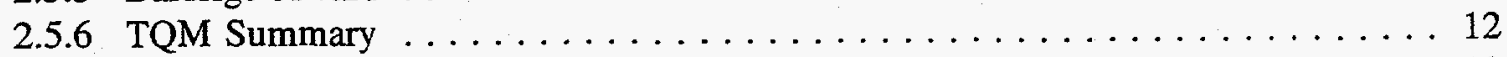

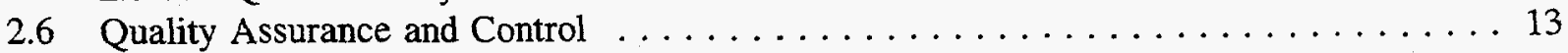

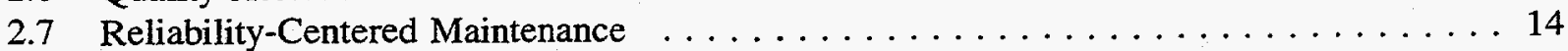

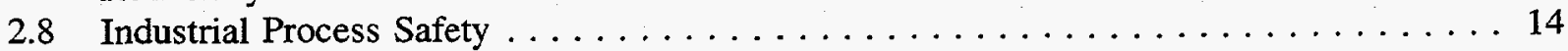

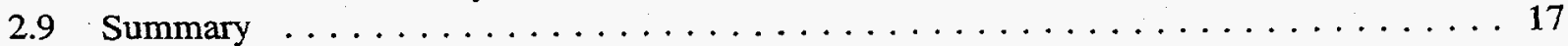

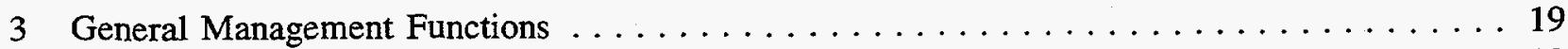

3.1 Introduction . . . . . . . . . . . . . . . . . . . . . . . . . 19

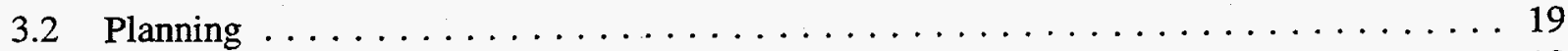

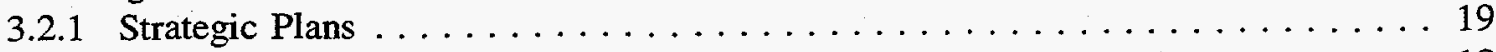

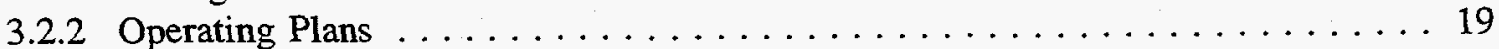

3.2 .3 Tactical Plans . . . . . . . . . . . . . . . . . . . . 19

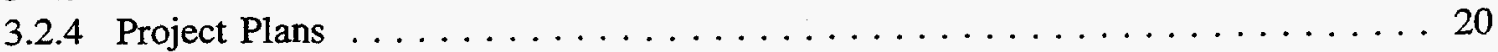

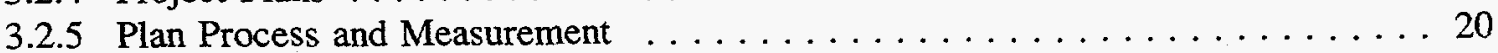

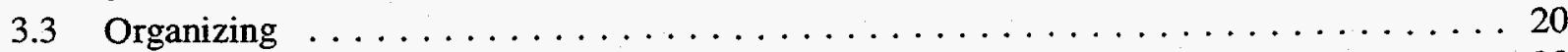

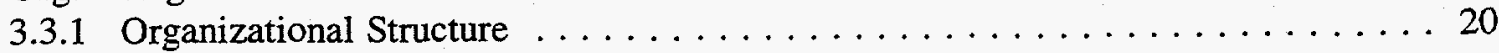


Section

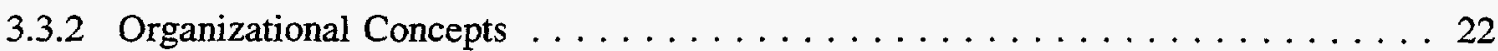

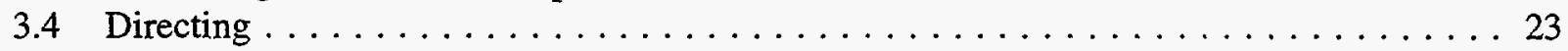

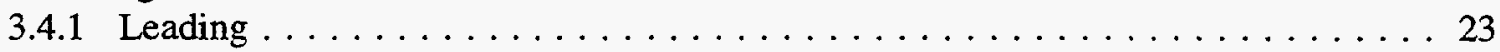

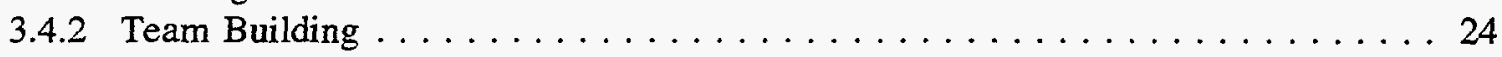

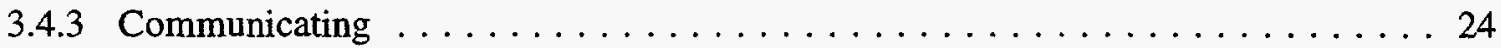

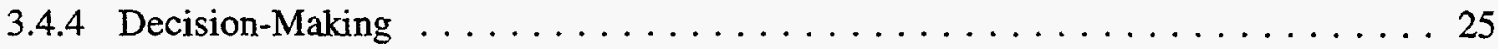

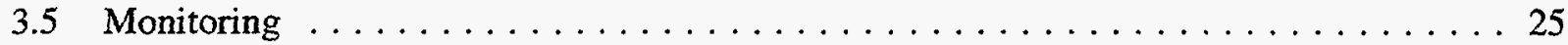

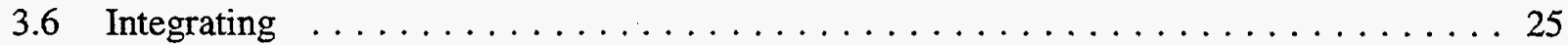

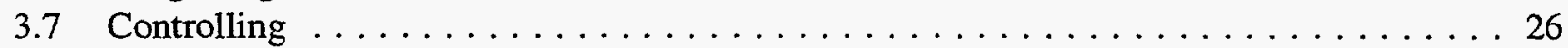

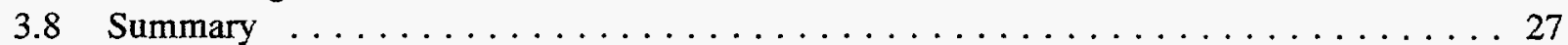

4 Process Safety Management and Its Elements . . . . . . . . . . . . . . . . . . 29

4.1 Introduction . . . . . . . . . . . . . . . . . . . . . . . . . . 29

4.1 .1 Regulatory Background . . . . . . . . . . . . . . . . . . 29

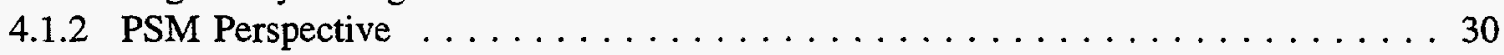

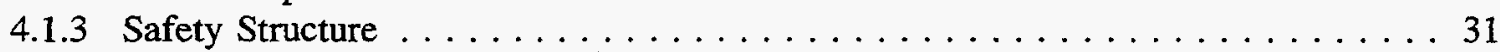

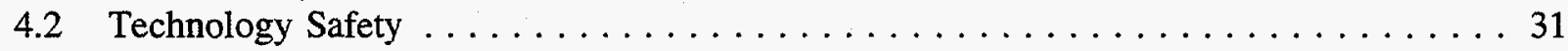

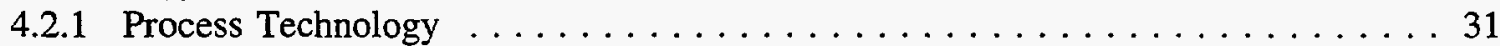

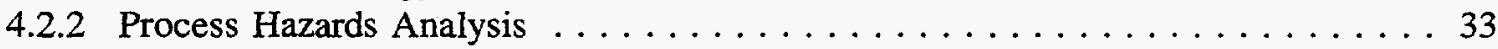

4.2.3 Operating Procedures and Safe Work Practices $\ldots \ldots \ldots \ldots \ldots \ldots \ldots$

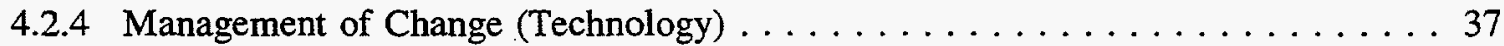

4.3 Personnel Safety . . . . . . . . . . . . . . . . . . . . . . . . 39

4.3.1 Personnel Training and Performance . . . . . . . . . . . . . . . 39

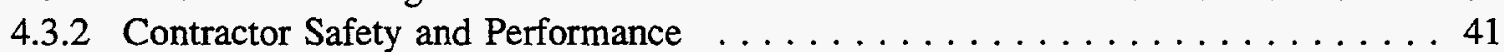

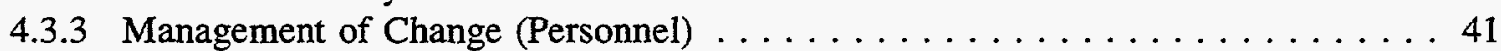

4.3.4 Incident Investigation and Communication $\ldots \ldots \ldots \ldots \ldots \ldots \ldots \ldots$

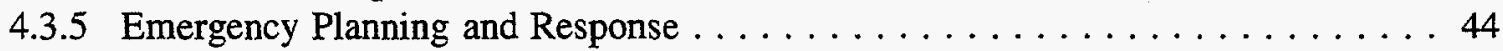

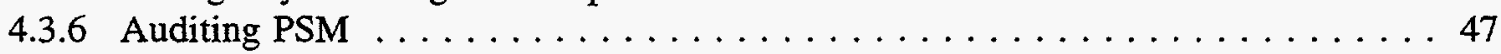

4.4 Facilities Safety . . . . . . . . . . . . . . . . . . . . . 49

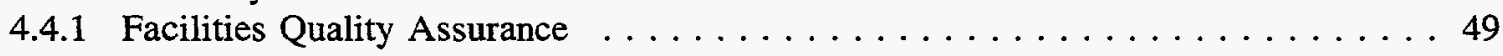

4.4 .2 Facilities Mechanical Integrity . . . . . . . . . . . . . . . . 49

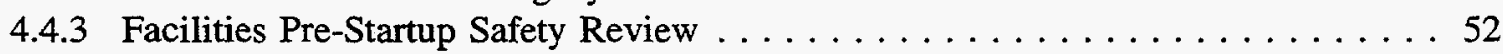

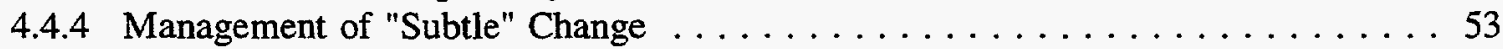

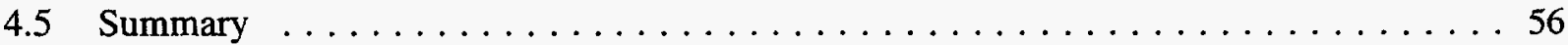

5 Corporate Issues and Concerns in Regard to Process Safety Management . . . . . . . 57

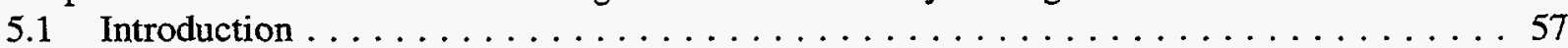

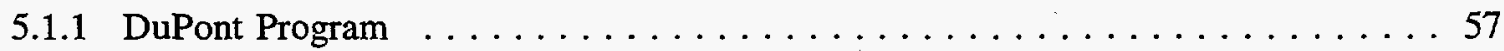

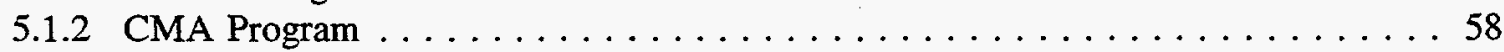

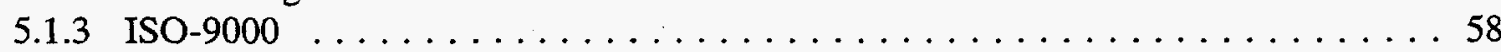

5.1 .4 Corporate Culture . . . . . . . . . . . . . . . . . . . 59

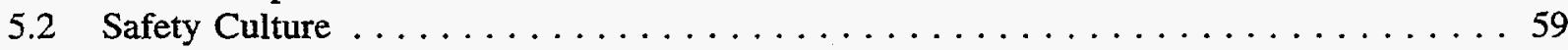

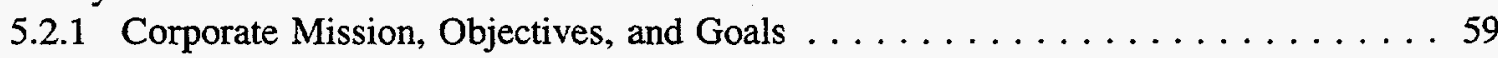

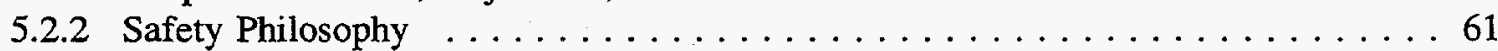




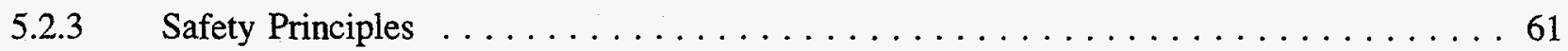

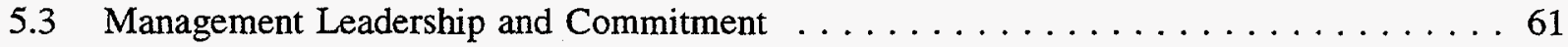

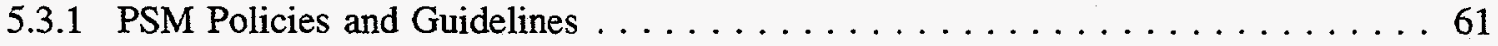

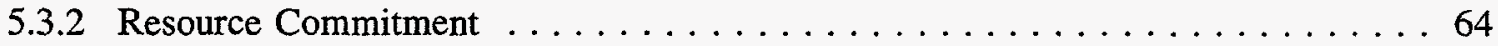

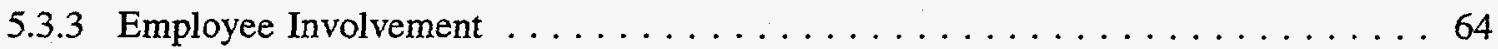

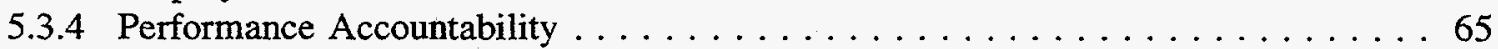

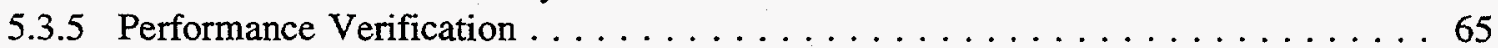

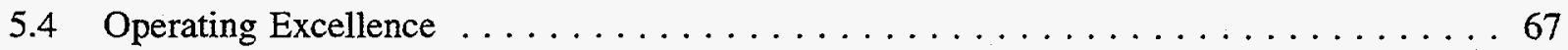

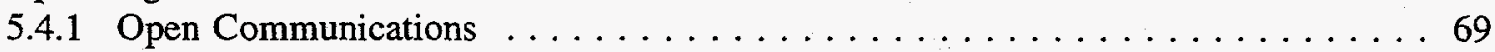

5.4 .2 Teamwork . . . . . . . . . . . . . . . . . . . . . . 69

5.4 .3 Common Shared Values $\ldots \ldots \ldots \ldots \ldots \ldots \ldots \ldots \ldots \ldots \ldots \ldots \ldots$

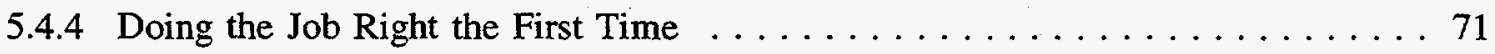

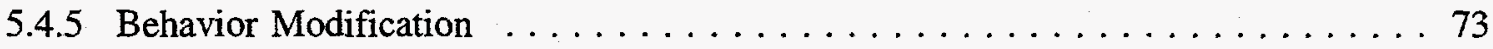

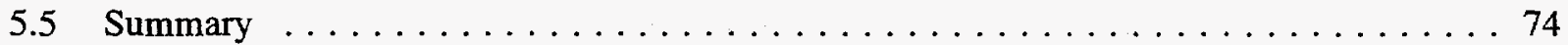

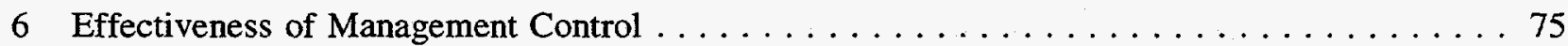

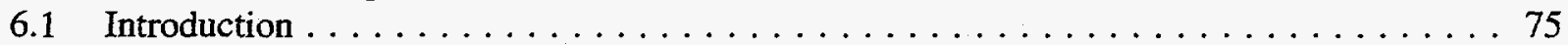

6.2 Corporate-Level Evaluation Matrix $\ldots \ldots \ldots \ldots \ldots \ldots \ldots \ldots \ldots \ldots$

6.3 Process Safety Management Program-Level Evaluation Matrix . . . . . . . . . . 75

6.4 Effectiveness Evaluations $\ldots \ldots \ldots \ldots \ldots \ldots \ldots \ldots \ldots \ldots \ldots \ldots$

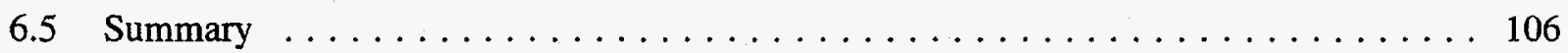

7 Issues for Putting Theory Into Practice $\ldots \ldots \ldots \ldots \ldots \ldots \ldots \ldots \ldots \ldots \ldots \ldots \ldots$

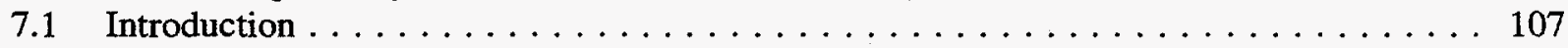

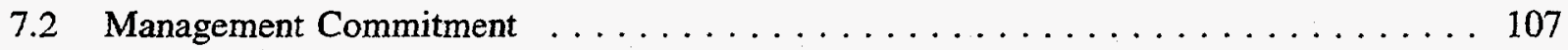

7.3 Management Awareness . . . . . . . . . . . . . . . . . . . . 107

7.4 Management Policies . . . . . . . . . . . . . . . . . . . . . . . . . . 107

7.5 Procedures and Procedure Control $\ldots \ldots \ldots \ldots \ldots \ldots \ldots$

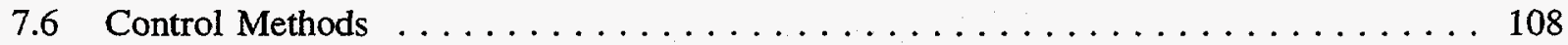

7.7 Integrated System Approach $\ldots \ldots \ldots \ldots \ldots \ldots \ldots \ldots$

7.7.1 Models . . . . . . . . . . . . . . . . . . . . . . . . . . . 109

7.7.2 Information Systems . . . . . . . . . . . . . . . . . . . . 109

7.8 Configuration and Records Management $\ldots \ldots \ldots \ldots \ldots \ldots \ldots \ldots \ldots \ldots$

7.9 Safety Committees . . . . . . . . . . . . . . . . . . . . . . . . . . . 110

7.10 Performance, Financial, and Safety Management $\ldots \ldots \ldots \ldots \ldots \ldots \ldots \ldots$

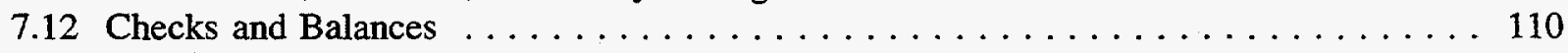

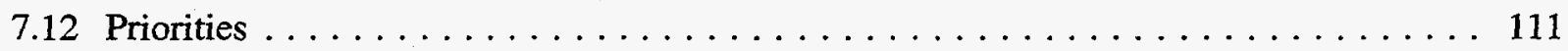

7.13 Business and Regulator Perspectives $\ldots \ldots \ldots \ldots \ldots \ldots \ldots \ldots \ldots \ldots \ldots$

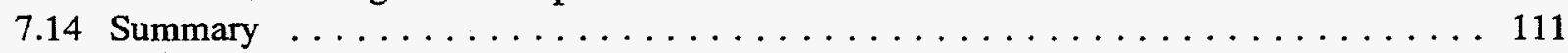

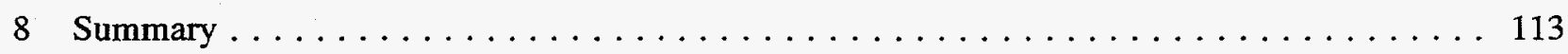

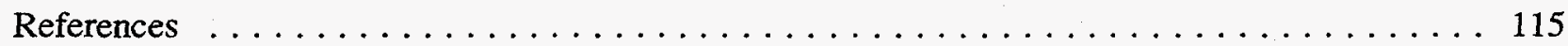

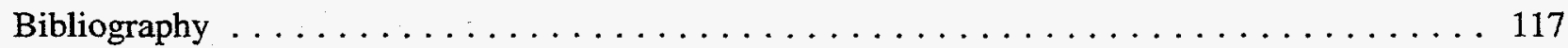




\section{Figures}

Figure Number

Page

1-1 Location of text disucssion and interaction of safety elements $\ldots \ldots \ldots \ldots \ldots$

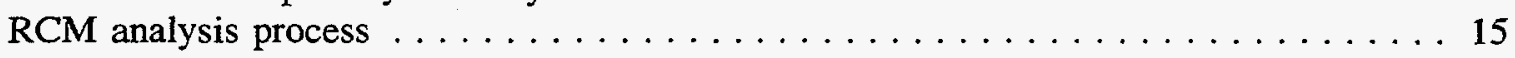

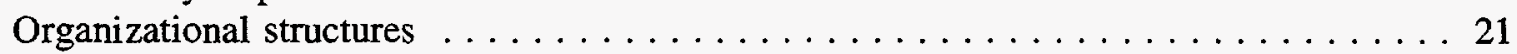

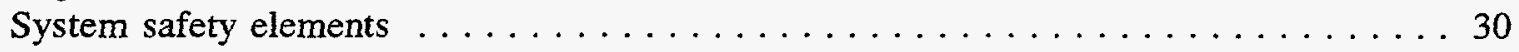

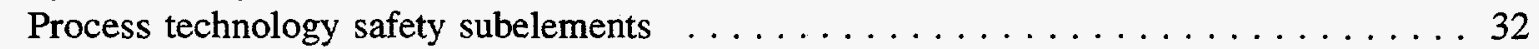

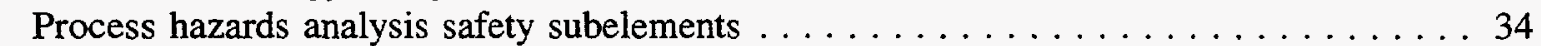

Operating procedures and safe work practices safety subelements $\ldots \ldots \ldots \ldots \ldots$

Management of change (technology) safety subelements $\ldots \ldots \ldots \ldots \ldots \ldots$

Personnel training and performance safety subelements $\ldots \ldots \ldots \ldots \ldots \ldots \ldots$

Contractor safety and performance safety subelements $\ldots \ldots \ldots \ldots \ldots \ldots \ldots$

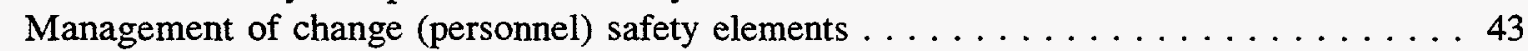

Incident investigation and communication safety subelements $\ldots \ldots \ldots \ldots \ldots$

Emergency planning and response safety subelements $\ldots \ldots \ldots \ldots \ldots \ldots \ldots$

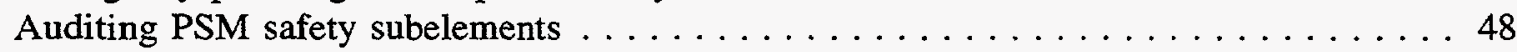

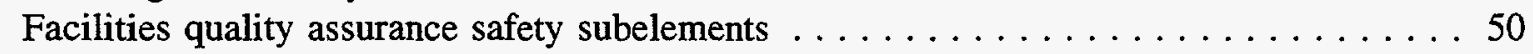

Facilities mechanical integrity safety subelements $\ldots \ldots \ldots \ldots \ldots \ldots \ldots \ldots$

Facilities pre-startup safety review subelements $\ldots \ldots \ldots \ldots \ldots \ldots \ldots \ldots \ldots$

Management of subtle change safety subelements $\ldots \ldots \ldots \ldots \ldots \ldots \ldots$

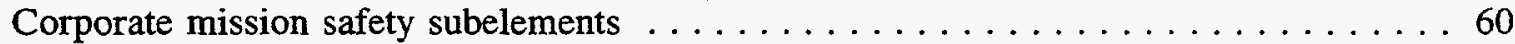

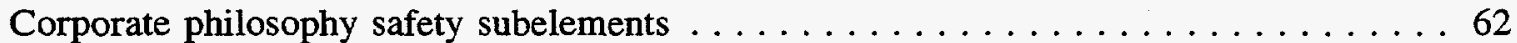

Performance accountability safety subelements $\ldots \ldots \ldots \ldots \ldots \ldots \ldots \ldots \ldots$

Performance verification safety subelements $\ldots \ldots \ldots \ldots \ldots \ldots \ldots \ldots \ldots \ldots \ldots$

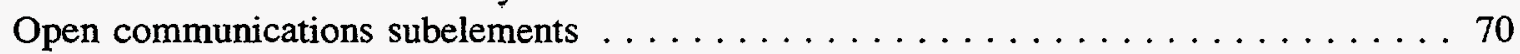

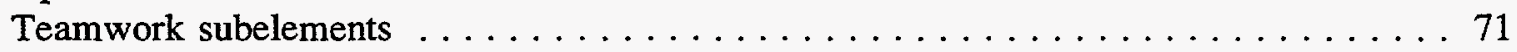

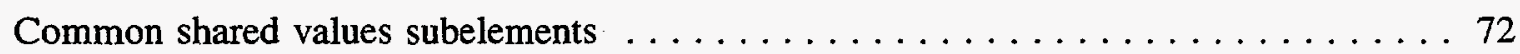

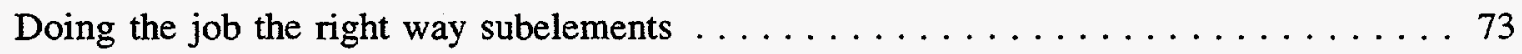

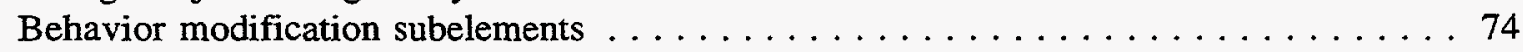

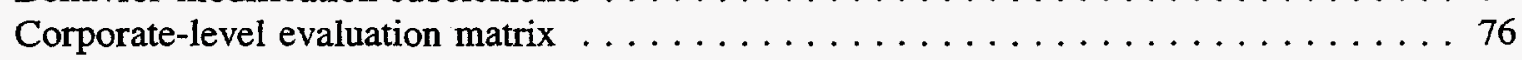

Process Safety Management program-level evaluation matrix $\ldots \ldots \ldots \ldots \ldots$ 


\section{Tables}

Table Number

Page

4-1 Some recent major process safety incidents . . . . . . . . . . . . . . . . . . . . 29

5-1 Chemical Manufacturers Association safety principles $\ldots \ldots \ldots \ldots \ldots \ldots \ldots$

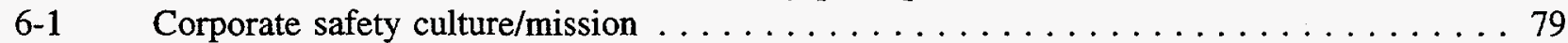

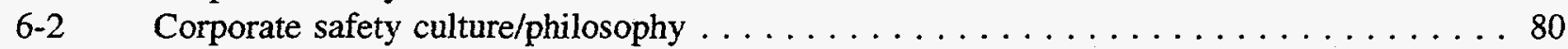

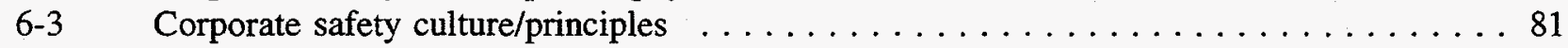

6-4 Corporate leadership and commitment/PSM policies and guidelines $\ldots \ldots \ldots \ldots 2$

6-5 Corporate leadership and commitment/resource commitment $\ldots \ldots \ldots \ldots \ldots$

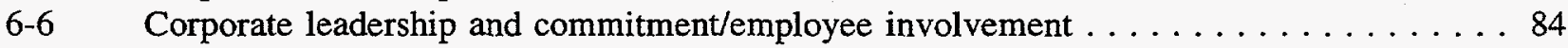

6-7 Corporate leadership and commitment/performance accountability $\ldots \ldots \ldots \ldots$

6-8 Corporate leadership and commitment/performance verification $\ldots \ldots \ldots \ldots \ldots$

6-9 Corporate operating excellence/open communications $\ldots \ldots \ldots \ldots \ldots \ldots \ldots$

6-10 Corporate operating excellence/teamwork $\ldots \ldots \ldots \ldots \ldots \ldots \ldots \ldots \ldots \ldots \ldots$

6-11 Corporate operating excellence/common shared values $\ldots \ldots \ldots \ldots \ldots \ldots$

6-12 Corporate operating excellence/do the job the right way $\ldots \ldots \ldots \ldots \ldots \ldots$

6-13 Corporate operating excellence/behavior modification $\ldots \ldots \ldots \ldots \ldots \ldots \ldots$

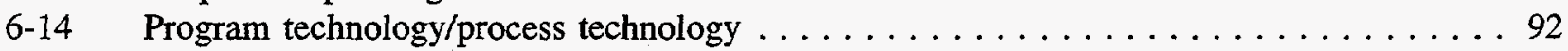

6-15 Program technology/process hazards analysis $\ldots \ldots \ldots \ldots \ldots \ldots \ldots \ldots \ldots$

6-16 Program technology/operating procedures and safe work practices . . . . . . . . 94

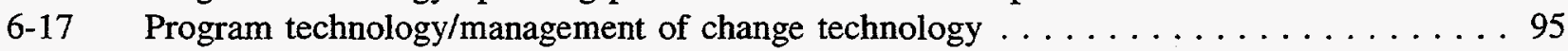

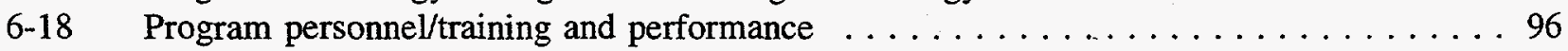

6-19 Program personnel/contractor safety and performance $\ldots \ldots \ldots \ldots \ldots \ldots \ldots \ldots$

6-20 Program personnel/management of change personnel . . . . . . . . . . . . . . 98

6-21 Program personnel/incident investigation and communication . . . . . . . . . . 99

6-22 Program personnel/emergency planning and response $\ldots \ldots \ldots \ldots \ldots \ldots$

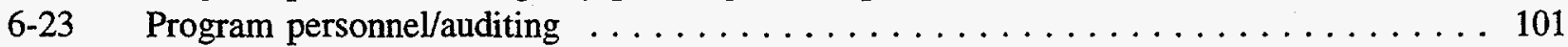

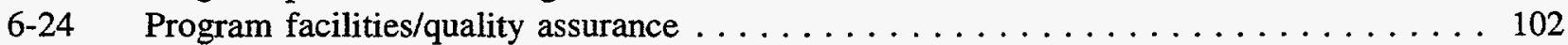

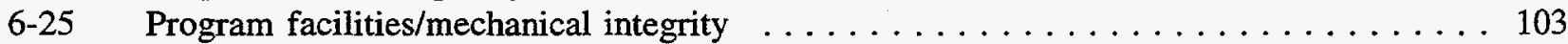

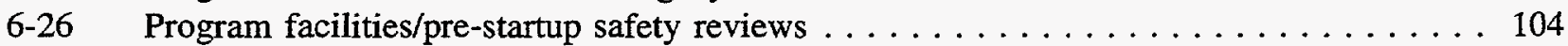

6-27 Program facilities/management of "subtle" change $\ldots \ldots \ldots \ldots \ldots \ldots \ldots$ 


\section{ACRONYMS}

BPR business process reengineering

CM capability maturity

CMA Chemical Manufacturers Association

CS\&P contractor safety and performance

EP\&R emergency planning and response

II\&C incident investigation and communication

IPS industrial process safety

ISO International Organization for Standardization

MC management control

MOC management of change

NRC U.S. Nuclear Regulatory Commission

OSHA Occupational Safety and Health Administration

PHA process hazards analysis

PHR process hazard review

P\&ID piping and instrument design

PSM process safety management

PT process technology

QA quality assurance

QAC quality assurance and control

RCM reliability centered maintenance

SHE safety, health, and environmental

SOC standard operating condition

SOW statement of work

TLO the learning organization

TQM total quality management

WBS work breakdown structure 


\section{SECTION 1 INTRODUCTION}

\subsection{Purpose and Objectives}

This report describes selected modern management control theories and functions and shows how these may be related and applied to the issue of safety. The basic purpose is to demonstrate relationships between management control theories and functions of an organization and the ways in which that organization can control safety.

The objectives of this investigation and report are to-

(1) articulate selected modern management control theories and general management functions

(2) describe safety elements, both in terms of corporate-level concerns and of programlevel issues

(3) provide a structure for evaluating the effectiveness of management control of safety

\subsection{Scope}

This report covers modern management control theories, general management functions, program-level safety issues, corporate-level safety issues, and an evaluation structure to assess the effectiveness of management control of safety. Finally, the report discusses issues not necessarily revealed through the effectiveness evaluation.

In terms of evaluating the effectiveness of management control of safety, an evaluation structure and procedure are suggested. This procedure involves a series of questions, but the specific questions and number of questions should be considered illustrative and subject to further testing and modification. In the current format, the questions are, however, immediately usable.
Because this report focuses on how management deals with-or fails to deal with-safety issues, it does not examine detailed engineering and technical control matters with respect to safety. It also does not explore in any detail technical control methods such as statistical process control, design of experiments, and other related procedures that are currently used for safety, quality control, and quality assurance.

\subsection{Intended Use}

The U.S. Nuclear Regulatory Commission (NRC) sponsored preparation of this report to establish a management-oriented perspective regarding how industry might approach the issue of controlling safety. To this end, this report has developed procedures for evaluating the effectiveness of management control of safety. Following refinement and testing of these procedures, the report will ultimately become the basis of a course that will train a group of NRC personnel to use established procedures in order to assess management's control of safety in selected segments of the nuclear industry.

\subsection{Organization}

Section 2 reviews the key aspects of selected modern management control theories. Section 3 provides an overview of the five general management functions: planning, organizing, directing, monitoring, and integrating. Under the three main categories of Technology, Personnel, and Facilities, Section 4 reviews the structure and content of Process Safety Management (PSM) program issues and discusses 14 safety elements. Section 5 examines corporate-level safety issues under the three categories of Safety Culture, Leadership and Commitment, and Operating Excellence in terms of 13 safety elements. Sec- 
etion 6 introduces the recommended structure for assessing the effectiveness of management control, namely, matrices that map the general management functions (Section 3) against the corporate-level (Section 5) and PSM program-level (Section 4) safety issues. The location of the text discussion and the interaction of these safety elements are shown as a schematic (Figure 1-1).
Section 6 further provides a series of questions for each of the cells defined by the two matrices. The last section discusses a number of practical issues, from management commitment and awareness to the different perspectives of a business organization compared with that of a regulator.

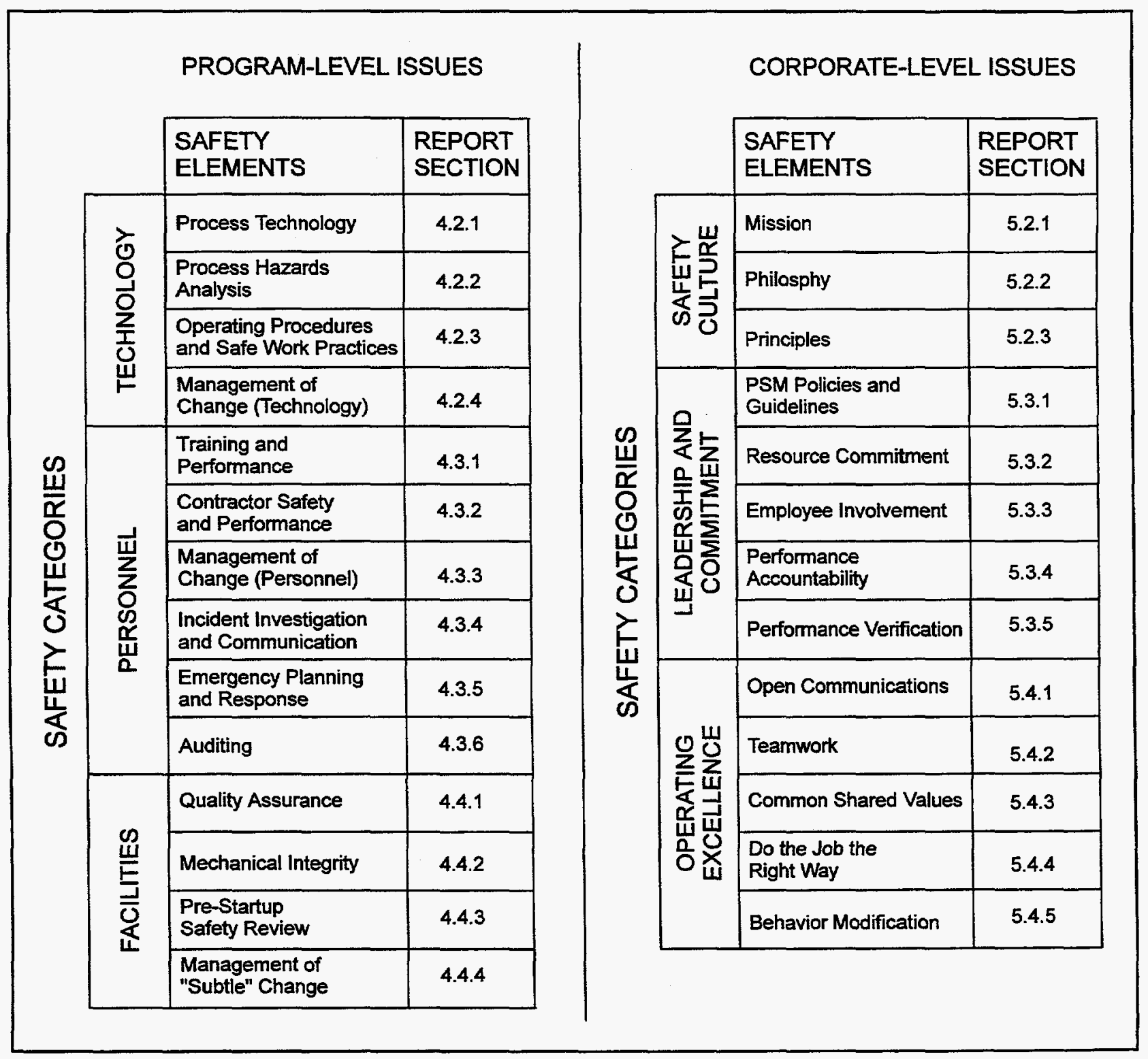

Figure 1-1. Location of text discussion and interaction of safety elements 


\section{SECTION 2 MODERN MANAGEMENT CONTROL THEORIES}

\subsection{Introduction}

This section briefly discusses seven modern management theories and emphasizes how an organization might better focus on control of a significant parameter, such as safety programs in the nuclear field. The theories covered in this section are business process reengineering (BPR), the learning organization (TLO), capability maturity $(\mathrm{CM})$, total quality management (TQM), quality assurance and control (QAC), reliability centered maintenance (RCM), and industrial process safety (IPS). The first two theories are rather broad; the other five have a focus that can be easily extrapolated and related to the issue of safety.

\subsection{Business Process Reengineering}

In broad terms, BPR involves modifying or redoing any and all processes that are not as efficient and effective as desired. Therefore, in a safety management program, any and all processes that affect safety are examined and reengineered so that they optimally support safety. Thus, the expected steps are to (1) identify all significant business processes that affect the goal of safety and (2) change, improve, and reengineer these processes. The steps apply to providing both products and services.

Hamner and Champy (1993), leading proponents of BPR as opposed to TQM, which is discussed in Section 2.5, emphasize words like fundamental, radical, and dramatic in terms of the recommended approach to reengineering. The BPR view is that incremental changes have minimal effect and more significant changes have a greater likelihood of success. In terms of safety, reengineering of safety-related processes is necessary whenever and wherever safety goals are not likely to be achieved.
Examples of changes that commonly occur under BPR include-

- combining several jobs into one

- having workers make more of the decisions

- ensuring that process steps are performed in their natural order

- establishing single points of contact and responsibility

- $\quad$ reducing checks and controls

In the context of safety management, the last two examples of change require closer examination. Single points of contact and responsibility make sense as long as backup positions are available when the single points are not available. But single points are unacceptable when only one point of contact lies between standard operation and potential disaster. More important, reducing checks and controls is not recommended in the context of ensuring safety.

In the context of BPR, Hamner and Champy, cite some of the "ways to fail":

- fail to focus on processes

- try to fix the process rather than change it

- neglect people's values and beliefs

- be willing to settle for minor results

- allow attitudes to scuttle reengineering

- try to make things happen from the bottom up

- $\quad$ assign a leader who does not understand reengineering or who lacks process knowledge 
- bury or overlook the corporate agenda

- fail to carry out root cause analysis

- $\quad$ skimp on resources

- $\quad$ quit too early

Although there is a large and growing body of knowledge and experience with respect to BPR, the following five points seem to be most appropriate in terms of the issue of ensuring safety:

(1) Reengineer any and all processes that fail to achieve required levels of safety.

(2) Do not settle for minor improvements when such improvements do not lead to appropriate safety levels.

(3) Clearly and continuously support BPR at the top levels of the organization.

(4) Select "champions" who fully understand the goals as well as the process reengineering discipline.

(5) Ensure that points of contact exist with related responsibility and accountability.

\subsection{The Learning Organization}

One of the first to set forth the concept of TLO, Senge, in his 1990 book, focused on five disciplines that lead to TLO. These disciplines are

(1) personal mastery, (2) mental models,

(3) shared vision, (4) team learning, and

(5) systems thinking.

\subsubsection{Personal Mastery}

Personal mastery refers to the mastery of one or more disciplines at the personal level on the part of each and every person in an organization.
This means that individual skill levels should not only be high but also be continuously improved in response to changes in technology and the world. At least one implication of this part of TLO theory is that if all people in the organization should be able to demonstrate personal mastery, the organization should share some of the responsibility for providing continuous training and learning in order to ensure that mastery is up to date.

\subsubsection{Mental Models}

Mental models, according to Senge (1990, p. 8), are "deeply ingrained assumptions, generalizations, or even pictures or images that influence how we understand the world and how we take actions." Senge goes on to point out that "insights into...many outmoded organizational practices fail to get put into practice because they conflict with powerful, tacit mental models." In terms of safety matters, this could mean that ingrained mental models held by top management personnel might prevent sweeping away outmoded organizational structures and practices.

\subsubsection{Shared Vision}

Senge $(1990$, p. 9) states that when there is a genuine shared vision, "people excel and learn, not because they are told to, but because they want to." Clearly, this is a complex matter of formulating a vision that is strong enough for people to support. Shared vision relates to issues of motivation and how top management can attain high levels of motivation to support the goals of the organization. If brought into the domain of safety, the following question might be posed: How can top management adopt and convey a shared vision of high levels of safety that all personnel will buy into? Such a question strongly relates to matters of leadership on the part of the company's management. 


\subsubsection{Team Learning}

Team learning recognizes the dominant force of teams in today's businesses. Most significant advances in a corporate context are carried out by teams. As Senge (1990, p. 10) points out, "When teams are truly learning, not only are they producing extraordinary results but the individual members are growing more rapidly than could have occurred otherwise." The implication, with respect to safety, is that management should regard establishing high-performance teams that are focused on matters of maintaining and enhancing high levels of safety as a priority agendum item. Teamwork and explicit team building then become the order of the day.

\subsubsection{Systems Thinking}

Systems thinking is the capstone of Senge's view of TLO. Indeed, systems thinking is the fifth discipline that serves to integrate the other four, by "fusing them into a coherent body of theory and practice" (Senge, 1990, p. 12). Systems thinking involves seeing the interaction between one part of a system and all other parts, so work on a task requires maintaining the relationship between that task and all other tasks. Systems thinking is closely related to the disciplines of systems theory and systems engineering in that if one is able to understand and master systems theory and systems engineering, then it is likely that systems thinking will occur. In the context of safety issues, the systems thinker will see how changes in one part of a safety "system" will affect other parts of that system. Changes in a system are not made in isolation; they should always be considered in terms of interactions, effects, and consequences with respect to other parts of the system.

Systems thinking, when appropriately applied, leads to synergism. In such a case, parts of processes tend to be structured in a mutually supportive manner. Because people are part of the processes and the overall system, they will tend to support one another and the overall achievement of the system goals. Synergism implies this mutual support and is more likely to take place when systems thinking is the rule rather than the exception.

\subsubsection{TLO and Safety Management}

Senge's theory argues that if the five basic disciplines are highly functional, then the organization is likely to be a "learning organization." With respect to safety, a learning organization is always moving forward and growing and is, therefore, continuously learning from mistakes so as to improve and enhance safety.

In summary, it is important for an organization to ensure that it is a "learning organization." Some ways in which the five TLO disciplines may be achieved include-

- massive amounts of training and retraining in the domains of interest (e.g., safety, personal mastery areas)

- $\quad$ support for team definition and team building, to include training in how to build and manage teams

- programs that are sponsored by management to build a shared vision that emphasizes safety

- training that will emphasize systems thinking and how systems and their component elements interact 


\subsection{Capability Maturity}

The concept of $\mathrm{CM}$ emerged in response to one of the major problems that exists todaydeveloping quality software within specified cost, time, and performance constraints. As software has become a larger and larger part of our complex systems, it has dominated the development of these systems because it has been a factor in numerous cost and schedule overruns. The $\mathrm{CM}$ paradigm was developed largely as a means of solving some of these problems.

Basically, the idea is that it is possible to define and measure the $\mathrm{CM}$ of a development team and ultimately correlate this $\mathrm{CM}$ with the success of a software development effort. Initially formulated by the Software Engineering Institute associated with Carnegie-Mellon University, this rather simple idea has enjoyed wide acceptance. It has already had a significant influence on the way in which Government agencies procure software.

Figure 2-1 shows the five levels of the CM model-initial, repeatable, defined, managed, and optimizing. Moving from the initial level to the optimizing level increases the likelihood that the software developer will achieve consistently improved project results.

\subsubsection{Initial Level (Level 1)}

At the initial level, the software development process is ad hoc and is likely to continue in this fashion unless management realizes that some type of upgrading is necessary. On small projects, an ad hoc process may turn out to be adequate. On complex software developments, an ad hoc process is very likely to lead to disaster. Therefore, the focus for management's commitment to move beyond the initial capability is largely in the areas of requirements, planning, performance tracking, subcontractor management, change control, and quality assurance.

\subsubsection{Repeatable Level (Level 2)}

At this level, success largely depends on working on software that is similar to that previously encountered. That is, if a new project is similar to a previous one (in the sense of using the same people and operating in the same application domain), it is possible to obtain reasonable results. However, if a significant number of new people are added, or the application domain differs, the probability of success drops drastically. Moving on to the next level requires (1) process standards for the business organization and dedicated process resources and (2) established and practiced methods for requirements analysis, design, inspection, and test.

\subsubsection{Defined Level (Level 3)}

At the defined level of $\mathrm{CM}$, success depends on managing the process as well as the product. At this level, five areas have been mastered-

(1) the nature and significance of the operational process

(2) provision of process support for all people on the project

(3) empowerment of people with respect to project management

(4) achievement of reliable costs and schedules

(5) an understanding of the relationship between process and product

Achieving the managed level of capability (Level 4) requires improvements in establishing process measurements, having quantitative quality goals, and planning and tracking based on explicit measurements. 

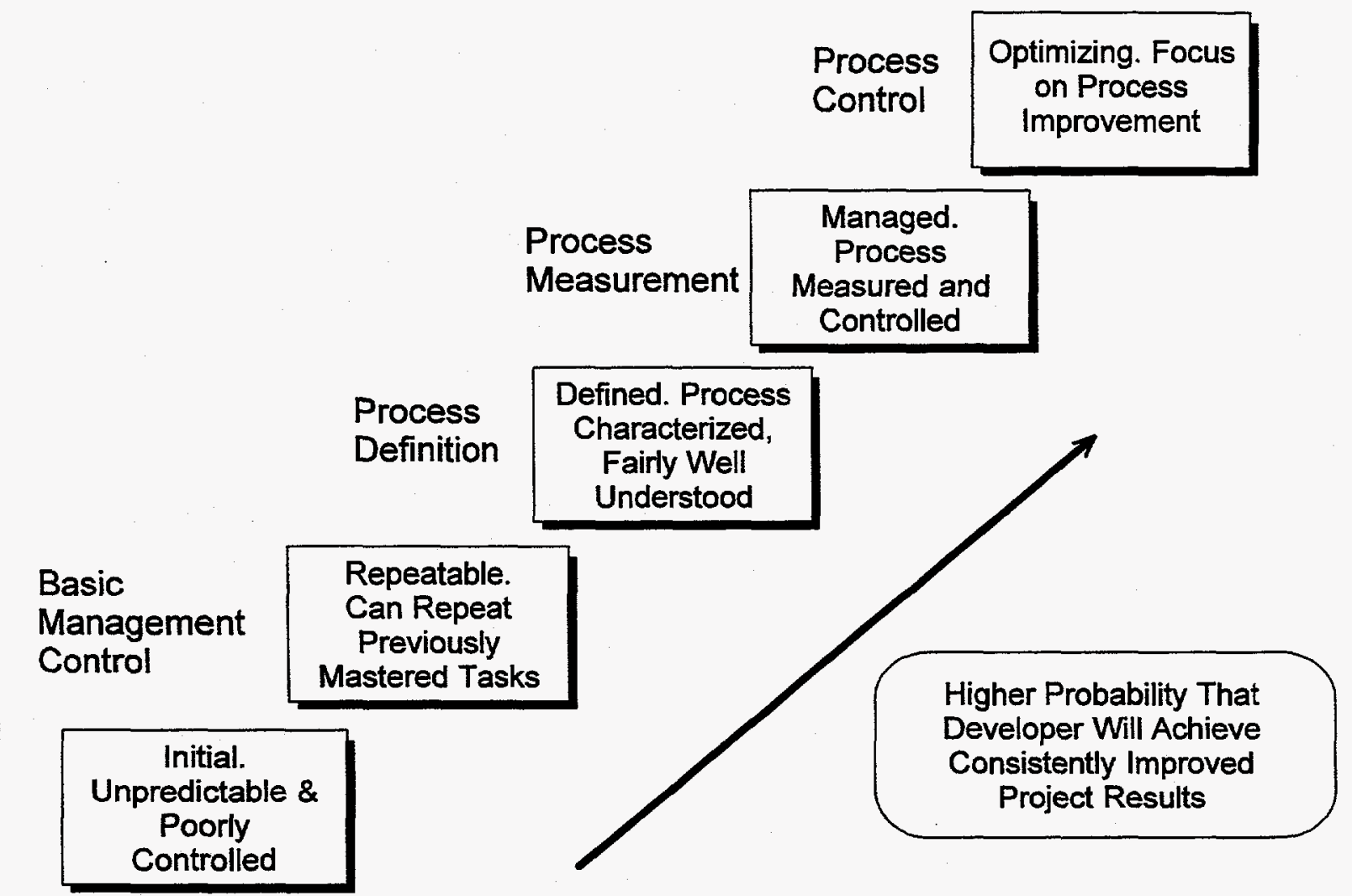

Figure 2-1. Five levels of capability maturity 


\subsubsection{Managed Level (Level 4)}

Level 4 emphasizes quantitative measurements and process assessments. New project targets and goals are based on quantified past performance. Management methods are well defined and clearly based on quantitative assessments. Advancing to the optimizing level (Level 5) requires management to achieve quantitative process monitoring, improvement based on actual performance, and economically justified technology improvements.

\subsubsection{Optimizing Level (Level 5)}

At this, the final and most advanced capability, the project is continually modified in response to measured needs. But the continuous improvement is a standard process that is procedurally controlled. Technology is integrated so that all project personnel know how to utilize this technology. Technical people manage their own processes, which are standardized and well understood. Management stays in touch with technological change that can be effectively integrated into the development process and continues to measure progress against goals. Tradeoff studies are routine during process improvement.

\subsubsection{CM for Safety Management}

Implementation of the CM model has been broken down into a software process assessment and a software capability evaluation. Although the implementation methods are not discussed here, the levels of CM show that by achieving higher levels of capability, there is a greater probability of being able to develop quality software. By inference, it is possible to assess an organization's capability to control safety to acceptable levels, leading to a formal "safety maturity" model. Such a model might contain any number of levels with respect to safety. A rating system might mirror the factors set forth for the
Baldrige Award (Section 2.5.5), whereby an organization is evaluated in regard to a fixed and known set of evaluation criteria.

\subsection{Total Quality Management}

Since the early 1980 s, TQM has been a strong influence on how companies operate. TQM principles and programs have been embraced in an attempt to improve the quality of both products and services. If the concept of safety is, along with quality, a corporate goal, there are direct analogies between how to improve safety and how to approach the matter of quality. The following sections highlight significant concepts and themes of TQM.

\subsubsection{W. Edwards Deming}

There have been several leaders in the TQM thrust, perhaps the most well known being $W$. Edwards Deming, who has been credited with helping the Japanese achieve quality in several of their industries. In his 1986 book, Walton discusses Deming's well-known 14 points dealing with quality:

(1) Create a constancy of purpose toward improvement of product and service.

(2) Adopt the philosophy that acceptance of poor products and service is a roadblock to productivity.

(3) Cease dependence on mass inspection; replace it with improved processes.

(4) End the practice of awarding business on the basis of price alone

(5) Find problems and fix them; continually reduce waste and improve quality. 
(6) Institute modern methods of training on the job.

(7) Institute modern methods of supervision.

(8) Drive out fear.

(9) Break down barriers between departments and locations.

(10) Eliminate posters, exhortions, and slogans.

(11) Eliminate work standards and numerical quotas.

(12) Remove barriers that stand between the worker and his/her right to pride of workmanship.

(13) Institute a vigorous program of education and training.

(14) Create a structure in top management that will push every day on the above 13 points; take action to accomplish the transformation.

\subsubsection{J.M. Juran}

J.M. Juran, another leader in the field of TQM, basically defined TQM as "fitness for use" (1989, p. 15). Juran is well known for defining the Juran Trilogy (a trademark of the Juran Institute) as quality planning, quality control, and quality improvement. The recommended actions under each follow.

\subsubsection{Quality Planning}

(1) Determine who the customers are.

(2) Determine the needs of the customers.
(3) Develop product features that respond to customers' needs.

(4) Develop processes that are able to produce those product features.

(5) Transfer the resulting plans to the operating forces.

\subsubsection{Quality Control}

(1) Evaluate actual quality performance.

(2) Compare actual performance with quality goals.

(3) Act on the difference.

\subsubsection{Quality Improvement}

(1) Establish the infrastructure needed to secure annual quality improvement.

(2) Identify the specific needs for improvement (the improvement "projects").

(3) For each project, establish a project team with clear responsibility for bringing the project to a successful conclusion.

(4) Provide the resources, motivation, and training needed by the teams to diagnose the causes, stimulate establishment of a remedy, and establish controls to hold the gains.

Juran has been an important force in the TQM arena and his concepts of strategic quality management have been embraced by many industrial organizations. 


\subsubsection{P. Crosby}

Philip Crosby (1984), another TQM practitioner, identified the following tenets as important.

- The definition of quality is conformance to specifications.

- The system of quality is prevention.

- The performance standard can be zero defects.

- The measurement of quality is the price of nonconformance.

Of particular interest with respect to Crosby is his profile of a problem organization. This profile includes-

- Product/service normally contains deviations from agreed-upon requirements.

- There is an extensive field network for corrective actions.

- There is no clear performance or quality definition or standard.

- Management does not know the cost of nonconformance.

- Management denies that it is the cause of the problem.

Finally, Crosby identifies 14 steps for quality improvement:

(1) management commitment

(2) quality improvement teams

(3) measurement

(4) knowing the cost of quality

(5) quality awareness

(6) corrective action

(7) "zero defects" planning

(8) "zero defects" day
(9) goal setting

(10) employee education

(11) error-cause removal

(12) recognition

(13) quality councils

(14) do it all over again

\subsubsection{Japanese Influences}

The Japanese have demonstrated that they are able to consistently produce high-quality products, so considerable attention has been paid to the notions set forth by some of their quality practitioners, including Genichi Taguchi (Roy, 1990) and Kaoru Ishikawa (1985), as well as principles identified under the title "Kaizen" (Imai, 1986).

\subsubsection{Taguchi}

Taguchi methods tend to focus on the statistical design of experiments that would reveal deviation and variability in products. Implicitly, measurements are the core of the methods proposed by Taguchi. Beyond that, Taguchi's key concepts are-

- Design quality into the product/process.

- Quality cannot be "inspected in."

- Minimize product deviation from the target.

- Design to be immune from uncontrollable environmental factors.

- The cost of quality is to be measured as a function of the deviation from a standard.

- Losses are measured by all costs in excess of a perfect product. 


\subsubsection{Ishikawa}

Ishikawa developed a philosophy regarding TQM as well as a focus on tools that would help to implement his philosophy. The essence of Ishikawa's approach is-

- Know the requirements of the customers and what they will buy.

- Quality cannot be defined without knowing the cost of quality.

- Quality control without action is mere avocation.

- Anticipate potential defects and complaints.

- Quality should be built into each design and process.

- Quality control begins with education and ends with education.

- Quality control brings out the best in everyone.

- Implement statistical methods.

The following statements summarize Ishikawa's approach to total quality. Total quality-

- is the responsibility of all workers/divisions

- cannot fail if all cooperate

- is a group activity requiring teamwork

- involves quality control circles

- is one of the company's major objectives

- requires top management support and leadership

- will contribute to the overall health and character of the company
- utilizes statistical methods

With respect to the last point, seven elementary statistical tools supported by Ishikawa are the Pareto chart, the cause-effect (Ishikawa) diagram, stratification, checklists, histograms, scatter diagrams, and graph and control charts.

As with Taguchi, Ishikawa tends to rely on quantitative methods and various diagramming procedures to provide insight into a quality problem.

\subsubsection{Kaizen}

Kaizen is not a person but rather a word that means improvement. It is viewed as the overriding concept behind good management. Kaizen is a process-oriented way of thinking as opposed to a results-oriented way of thinking. Results are expected within a 3-5 year timeframe; earlier expectations are likely to lead to counterproductive results. Kaizen favors the gradualist approach.

\section{Under Kaizen-}

- People grasp the issues more quickly.

- The planning process is emphasized and embraced.

- A process-oriented approach is encouraged and accepted.

- A focus is maintained on the most important issues.

- Everyone participates in making changes and improvements.

A summary of the Kaizen implementation method follows.

- Speak with data.

- $\quad$ Put quality, not profit, first. 
- Manage the previous process.

- Be customer-oriented, not manufactureroriented.

- Start with training and end with training.

- Utilize cross-functional management and facilitation.

- Follow the "plan-do-check-act" cycle.

- $\quad$ Standardize the favorable result.

\subsubsection{Baldrige Award}

Last to be discussed under the subject of TQM are the factors used in evaluating nominees for the Baldrige Award. This award, given by the U.S. Commerce Department, is named after Malcolm Baldrige, the Secretary of Commerce from 1981 to 1987 . Categories that are used to evaluate industry from the point of view of their quality programs are-

- leadership —senior management's success in creating quality values and in building the values into the way the company operates

- information and analysis-effectiveness of the company's collection and analysis of information for quality improvement and planning

- $\quad$ strategic quality planning-effectiveness of the company's integration of the customer's quality requirements into its business plans

- human resources utilization-success of the company's efforts to realize the full potential of the workforce for quality

- quality assurance of products and services -effectiveness of the company's systems for assuring quality control of all its operations and in integrating quality control with continuous quality improvement

- quality results-company's improvements in quality and demonstration of quality excellence based upon quantitative measures

- customer satisfaction-effectiveness of the company's systems to determine customer requirements and demonstrated success in meeting them

\subsubsection{TQM Summary}

Although the forgoing descriptions of some of the activities in the field of TQM are brief, they do provide sufficient information with which to identify the main common themes with respect to this significant and well-accepted corporate area. These common themes may be summarized as-

Quality improvement through prevention Understand customer needs and requirements Accept continuous improvement concept for product/service

Launch focus on change of process

Infrastructure development utilizing teams

Training and more training

Yes to special recognition and rewards

Multifunctional/interdepartmental

Generate pride of workmanship

Measure quality performance vs. goals

Top management commitment

In all the TQM areas discussed, it is possible to substitute the word safety in place of the word quality. In that context, many-if not all-of the concepts apply to the problem of how to improve safety. Although the translation is not necessarily one-to-one, there is much to gain from adapting TQM precepts to the matter of ensuring safety in organizations. 


\subsection{Quality Assurance and Control}

The terms quality assurance and quality control have been used for many years, and, consequently, a great deal of literature has developed on these subjects. This section reviews some of the perspectives of Armand Feigenbaum, one of the leading proponents of quality assurance and control. In Total Quality Control (1991, p. 7), Feigenbaum covers most of the aspects of quality assurance and control. He defines product and service quality as-

The total composite product and services characteristics of marketing, engineering, manufacture, and maintenance through which the product and services in use will meet the expectations of the customer.

Feigenbaum (1991, p. 59) further identifies the "9 Ms," as the fundamental factors that affect quality:
(1) markets
(2) money
(3) management
(4) men
(5) motivation
(6) materials
(7) machines and mechanization
(8) modern information methods
(9) mounting product requirements

His 10 "benchmarks" (1991, p. 828-9) for achieving total quality control for the 1990 s follow.

(1) Quality is a companywide process.

(2) Quality is what the customer says it is.

(3) Quality and cost are a sum, not a difference.
(4) Quality requires both individual and teamwork zealotry.

(5) Quality is a way of managing

(6) Quality and innovation are mutually dependent.

(7) Quality is an ethic.

(8) Quality requires continuous improvement.

(9) Quality is the most cost-effective, least capital-intensive route to productivity.

(10) Quality is implemented with a total system connected with customers and suppliers.

Feigenbaum (1991, p. 147) also pays explicit attention to what he calls "management strategies for quality"-what management can and should be doing to achieve QAC. Some of the points he makes in this regard include the subjects of -

- managerial responsibilities for planning, organizing, integrating, and measuring

- accountability

- work activities for quality engineering, quality information equipment engineering, and process-control engineering

- centralization vs. decentralization

- $\quad$ structure of the quality control component

- organizing and problems in organizing

- a behavioral science view of the quality control organization

As with TQM, it is possible to view the QAC concepts and methods as directly applicable to dealing with the subject of safety. Most of the recommended procedures and actions apply to quality and safety. 


\subsection{Reliability-Centered Maintenance}

RCM is a term coined by the U.S. Navy as it grappled with issues of how to maintain equipment and related processes so as to achieve reliability, availability, and readiness goals. Experiments and analyses performed in the mid-sixties by the airlines and the Air Transport Association represented a precursor to the Navy's development of RCM. At that time, the airlines discovered that scheduled overhaul of complex equipment had little or no effect on the reliability of equipment in service. These early tests led to the development of a new concept in preventive maintenance, as well as new philosophies and procedures.

As the Navy moved forward in the area of RCM, it ultimately produced Military Standard 2173 (Mil-Std-2173) in 1986. In the context of this report, RCM is directly related to the problem at hand in that control of reliability and readiness is related to the issue of control of safety.

The application of Mil-Std-2173 (1986, p. 1) is stated as follows-

This standard is to be used by contractors during development of new systems and equipment, and by analysts and auditors...for determining preventive maintenance requirements and developing age exploration requirements.

The goals of the standard are to analyze the maintenance requirements, objectively justify every maintenance requirement, and enforce the performance of only the justified maintenance actions.

Figure 2-2 shows the RCM analysis process in Mil-Std-2173. Following the process shown helps to ensure that the RCM concepts are faithfully executed and that the appropriate mainte- nance activities are carried out so as to control reliability.

RCM procedures focus on the tasks to be performed as part of the process. Effectiveness criteria are developed not only for reliability but also for safety and hidden safety consequences.

The basic ideas of RCM that might be brought into the domain of safety and its management and control include-

- Safety is a feature or characteristic that can be controlled through the proper application of management and technical principles.

- Specific procedures can be developed that will control safety with respect to stated goals.

- Effectiveness as well as cost-effectiveness of a control process can be determined.

- $\quad$ Aspects of the conventional wisdom (e.g., scheduled overhaul of complex equipment) with respect to control of a parameter such as safety may need to be challenged and modified.

\subsection{Industrial Process Safety}

IPS refers to a theory that has, over the years, been adopted by the larger companies through associations, conferences, meetings, and the inevitable transfer of personnel from one company to another. These companies are typically those with significant manufacturing processes that involve issues of safety for the public as well as safety for their employees and customers. The DuPont Company has been in the forefront of carrying out IPS and therefore is used in this section as an example of how to execute a comprehensive safety program. 


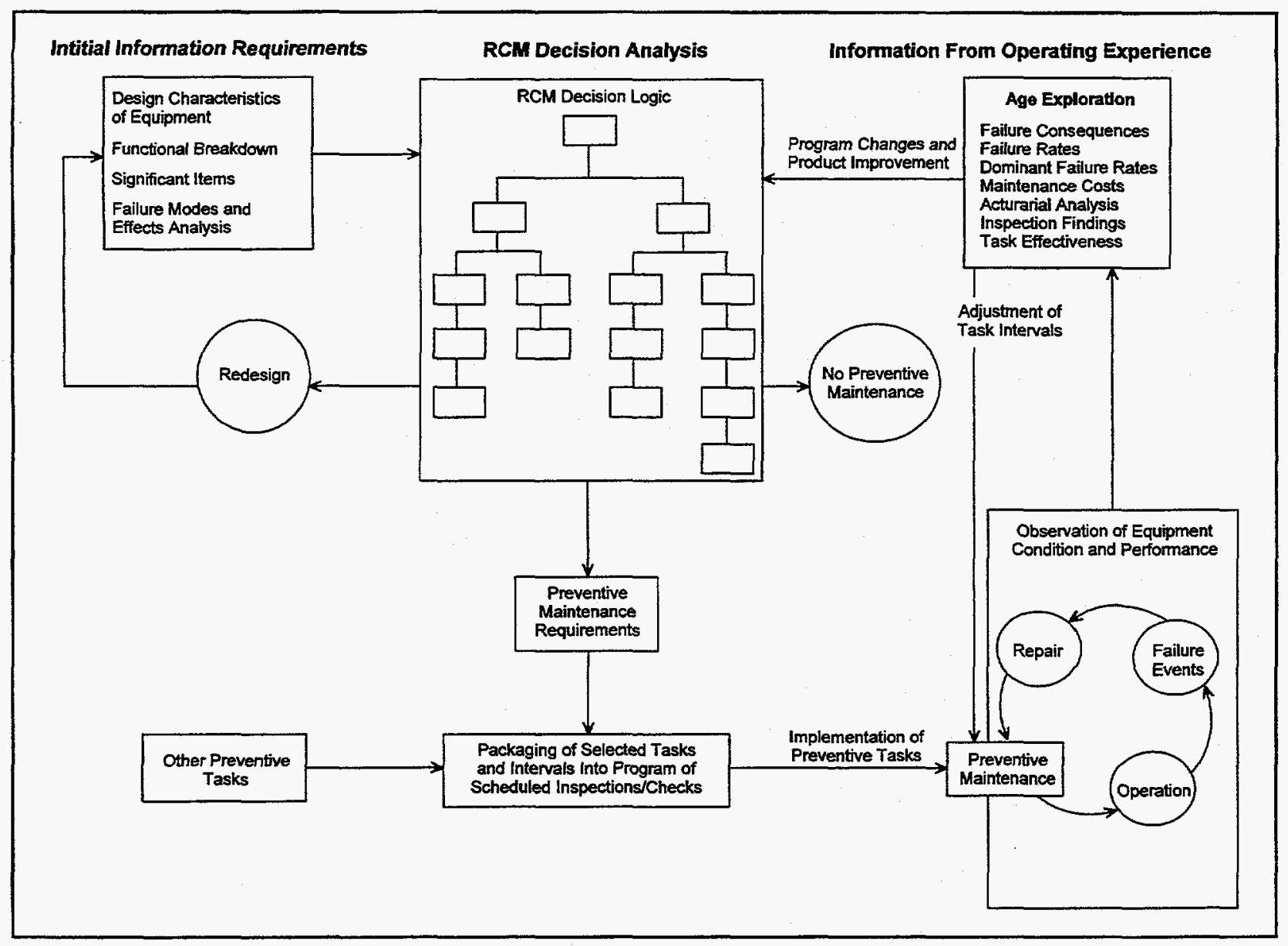

Figure 2-2. RCM analysis process 
DuPont has been at the leading edge of understanding how to achieve excellence in process safety management (PSM). Support for that statement lies in the record that DuPont has compiled in the areas of safety and health in the workplace. In a 1993 paper he delivered and in personal communications (1994), Arthur F. Burk, principal safety consultant to DuPont, provided much of the information presented in this section and in Section 5.1.1.

At DuPont, PSM is defined in terms of four steps and the key points needed to achieve the steps.

(1) Establish the safety culture. The safety culture includes the safety mission, the safety philosophy, and safety principles.

(2) Provide management leadership and commitment.

(a) Establish PSM policies and guidelines.

(b) Commit resources to implement PSM policies and guidelines.

(c) Involve employees.

(d) Establish clear accountability for performance against specific process safety goals and/or objectives.

(e) Verify (via measurement) the degree of compliance with established PSM policies and guidelines.

(f) Participate personally in activities that visibly demonstrate process safety commitment.

(3) Define the comprehensive PSM program in terms of technology, personnel, and facilities. Three key questions should be addressed.

(a) What is the principle involved? (b) Why is that element important?

(c) What are the essential features that need to be in place?

(4) Achieve operating excellence. The means to achieve operating excellence are as follows.

(a) Base management on "leadership by example."

(b) Encourage a high degree of employee involvement.

(c) Establish open and active lines of communication.

(d) Build a strong sense of teamwork.

(e) Promulgate common shared values.

(f) Commend those jobs being stopped for safety reasons.

(g) Provide recognition for absence of "short cuts."

These four steps are considered fundamental with respect to establishing and maintaining a highquality PSM program. The Step 3 elements -technology, personnel, and facilities-are discussed in some detail in Section 4.

Several common themes relate PSM to "business excellence":

- $\quad$ sound and up-to-date technology

- trained and qualified personnel

- $\quad$ equipment that is maintained and reliable

- effective management of change

- $\quad$ audits to provide feedback and control

- a focus on "doing each task the right way"

The DuPont PSM program represents a model that has achieved real-world results. The management practices that are part of that program 
should therefore be examined in more detail in terms of their applicability to the issues of this report (see Section 5).

\subsection{Summary}

In the aggregate, the seven management control theories discussed in this section provide guidance as to how to deal with establishing, controlling, and maintaining appropriate levels of safety in an organization. The following two dozen points summarize the main features of these theories, and, taken together and specifically, can be applied to the issue of safety.

(1) Reengineer and establish control processes focused on preventing problems of safety.

(2) Ensure commitment, leadership, and support from top management.

(3) Empower champions dedicated to the safety program and its goals.

(4) Establish cross-functional cooperative teams for problem solving.

(5) Ensure personal mastery of all safetyrelated tasks.

(6) Build a "learning organization."

(7) Establish a safety vision, culture, and ethic.

(8) Provide appropriate motivation, recognition, and rewards.

(9) Set qualitative and quantitative safety goals.

(10) Establish the means of measurement, evaluation, and tracking of safety goals.
(11) Ensure corrective actions when measurements indicate deficiencies in meeting goals.

(12) Maintain a program and perspective of continuous improvement.

(13) Provide the resources necessary to have a vigorous safety program that meets goals.

(14) Ensure accountability, responsibility, and authority.

(15) Standardize and institutionalize processes that have been demonstrated to work.

(16) Continuously evaluate adequacy of facilities and equipment to carry out all safety-related tasks.

(17) Know the cost of lack of safety.

(18) Embrace and utilize appropriate statistical methods.

(19) Ensure that safety-related matters and activities are viewed and assessed as a system.

(20) Employ the Pareto principle to apply resources and problem solving to highpriority areas.

(21) Continuously assess new technology and apply appropriately to matters of measuring and ensuring safety.

(22) Establish capability levels and measures.

(23) Take the time to determine who the customers are as well as their needs and requirements.

(24) Provide training and more training in all of the above. 


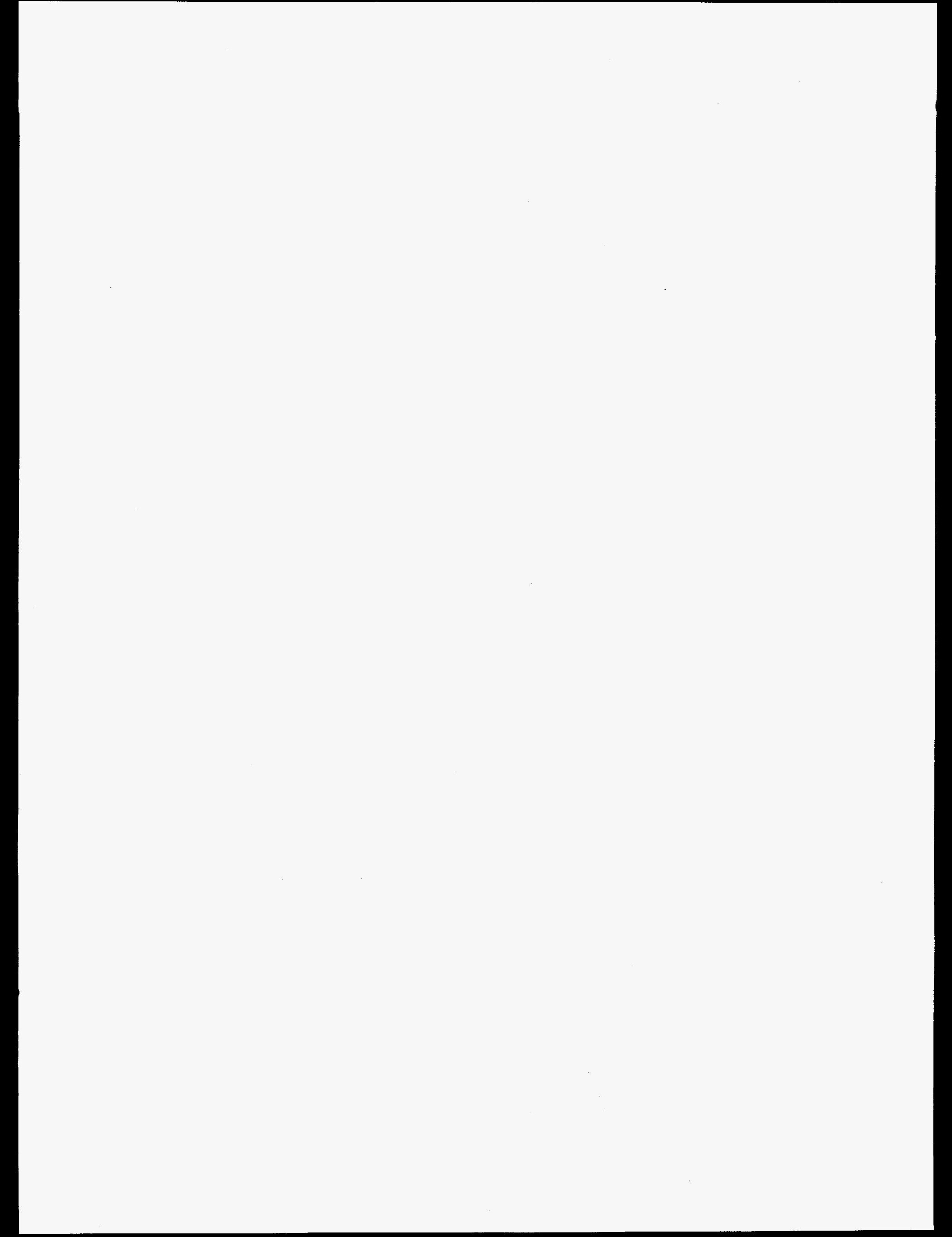




\section{SECTION 3 GENERAL MANAGEMENT FUNCTIONS}

\subsection{Introduction}

Consensus exists as to the definition of the general management functions in an organization, but there are some minor differences in the way these functions are viewed. Broadly, the key functions are variously defined by the terms planning, organizing, influencing, motivating, leading, staffing, evaluating, directing, implementing, and controlling. The general management functions used in this report are planning, organizing, directing, monitoring, and integrating.

In the aggregate, these five functions provide the overall "control" necessary to achieve the goals and objectives of an organization. Each of these functions is described and discussed, and their synthesis is examined in Section 3.7, Controlling. Examination of these management functions in the context of safety and safety-related issues appears in Sections 4 and 5.

\subsection{Planning}

\subsubsection{Strategic Plans}

An important function of management, planning is carried out at different levels in an organization. At the top level, management is concerned with strategic planning, which Mondy and Premeaux (1993, p. 164) define as "the process by which top management determines overall organizational purposes and objectives and how they are to be achieved." Such plans cover all aspects of an organization. If an important aspect is safety, then there will be special places in the strategic plan, such as in the mission statement and in the goals and objectives section, where safety issues are addressed. Strategic plans cover such matters as-

- mission statement
- vision for the organization

- goals and objectives

- strengths

- weaknesses

- opportunities

- threats

- broad implementation plans

The strategic plan is often referred to as the 5-year plan so that the planning horizon is explicitly understood. Some organizations look beyond 5 years, but they are probably the exception. Organizations that deal with 10 -year time horizons and longer believe they need this type of lead time despite the rapid advances in technology and a world characterized by rapid change. Numerical goals such as revenues and projected profits are almost always part of a strategic plan.

\subsubsection{Operating Plans}

The first year of a 5-year strategic plan is addressed in a great deal of detail. This activity is then converted into the operating plan for the next year for the organization. Key elements in operating plans are projections of revenues, profit and loss, budgets and schedules, and resources required in order to satisfy the plan's goals.

\subsubsection{Tactical Plans}

Strategic and operating plans in an organization are responded to by the tactical plans of the divisions within that organization. Tactical plans, sometimes also called functional-level strategic plans, might show how the facility managers' plans fit into the overall corporate strategy and describe implementation steps in detail. Thus, strategic and tactical plans should fit together and should be in harmony with the corporate view of both internal and external environments of the 
organization. If a key strategic goal is safety, then matters of safety should be addressed in the divisional plans so that it is clear how safety will be addressed in the organization.

\subsubsection{Project Plans}

Another important level of planning is the project plan. Projects are normally executed within divisions, and a series of projects, more or less on the same or related subjects, is called a program. But the essential unit in which work is accomplished is the project.

There are different types of projects, but most project plans have essentially the same elements-

- statement of project requirements

- $\quad$ statement of goals and objectives

- $\quad$ statement of work or task statements

- work breakdown structure

- $\quad$ schedule

- organization chart and staffing plan, including a task responsibility matrix

- budget or cost estimate

- risk assessment

Often, a company's safety program will be embodied in a series of projects, all of which have safety as their primary focus. Each project should be documented in a plan that includes all of the above elements.

\subsubsection{Plan Process and Measurement}

The processes of planning are usually viewed as very important. Most organizations pay a great deal of attention not only to the plan but also to the process by which the plan is produced. The process is important in that it helps to achieve "buy-in," whereby all members of an organization commit to the plan's goals and objectives as well as the implementation details. This commitment is crucial to ultimately achieving the desired corporate results.

The best plans have no real impact on an organization unless there is a measurement aspect to the plan. This subject-the monitoring function of management-is dealt with in Section 3.5.

\subsection{Organizing}

Organizing is the next major function in an organization. In broad terms, after a plan has been devised, the next logical step is to figure out how to organize in order to carry out the plan in the context of the different levels-strategic, operating, tactical, and program/project-of plans. The organizational structure is normally illustrated by a chart showing the various positions and the reporting structure and hierarchy.

\subsubsection{Organizational Structure}

The three fundamental types of company organization are the functional, the project, and the matrix structures. Each of these three structures is depicted in Figure 3-1.

\subsubsection{Functional Structure}

The functional, or line, structure breaks down the organization into the major functions that are 


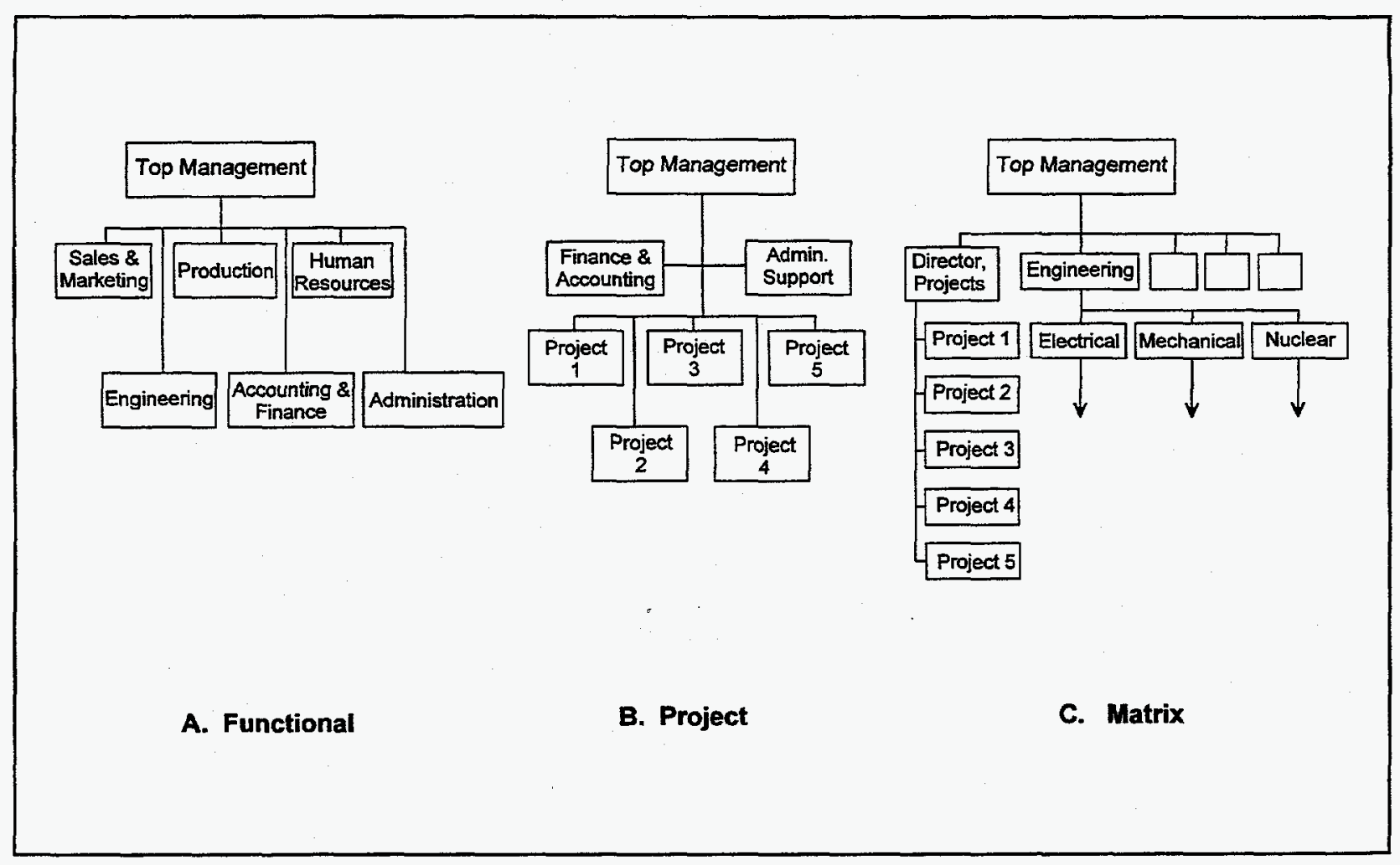

Figure 3-1. Organizational structures 
necessary in order to provide the products and services. Typical functions include-

- $\quad$ sales and marketing

- engineering

- production

- administration

- accounting and finance

- human resources

When products or services "cut across" several functions, as they usually do, then assignments are made from the different functional areas to support that product or service. Conventional wisdom today formalizes some of these assignments, as well as special assignments, into crossfunctional or interdepartmental teams.

\subsubsection{Project Structure}

In a project-oriented structure, the basic organization is broken down into numerous projects. Projects of a similar kind are grouped into organizational units, as illustrated in Figure 3-1. Projects are managed by project leaders or managers, and each project is able to access personnel, by transfer or hire, in order to execute the project. A project organization is often adopted by services companies that do not have a need for manufacturing facilities. When a project is completed, the company pays a great deal of attention to making the people available to other projects rather than releasing them from the company.

\subsubsection{Matrix Structure}

In a matrix organization, a combination of functional and project organizations exists simultaneously. The project manager obtains the services of personnel, who may be participating in a number of projects in parallel, from the functional, or line, organization. When the project is over, the project manager is assigned to another project and the support personnel remain in their functional groups. Projects can also be carried out completely within a functional group. This "hybrid" type of organization requires a great deal of communication and coordination as the functional organization personnel working on the project my be located in different line organizations and even in different geographic locations.

\subsubsection{Organizational Concepts}

There is no real conventional wisdom as to which of the three organizational structures is best. All three exist in companies today and all three can be made to work. If management is poor, then all three can also be dismal failures. Significant and well-meaning communication between groups and avoidance of the "we" and "they" syndrome will support any of the three organizational structures.

With the advent of practices known as "downsizing" and "right sizing" in companies that feel compelled to reduce staff, there has been a tendency toward reducing the layers of middle management. This has had the general effect of increasing the span of control and flattening organizational structures. From a safety point of view, this can reduce response times to potential problems and keep management closer to the personnel carrying out the safety programs. However, if "right sizing" reduces the numbers of personnel carrying out safety-related functions, the overall safety program and its goals may be in danger of being compromised.

There is little conventional wisdom as to whether centralization or decentralization is best as an organizational concept. Perhaps the best that can be said is that in the move toward empowerment, there may be a tendency to decentralize. As a rule, decentralization and organizational flattening go hand in hand. 
Many companies have adopted a table tennis approach to organizational structuring. That is, if the company is not meeting its goals, it will reorganize, often moving more toward decentralization if it is centralized, or vice versa. This forces change but can also create instability.

Kezsbom et al. (1989) cite the following basic requirements when considering an organizational structure-

- clarification of roles and relationships

- efficiency and economy

- classification of objectives, goals, and mission

- clarification of individual and organizational tasks

- encouragement of decision-making and rapid response

- provision of a sense of stability and a high degree of adaptability

- encouragement of innovation and personnel development

Several principles that are usually part of the overall notion of organizing are advanced by Mondy and Premeaux (1993) -

- unity of command

- equal authority and responsibility

- the scalar principle

- span of management

- division of labor

Unity of command refers to the idea that a person should report to only one boss. The second principle is that when assigning responsibility, the authority should be provided that will enable that responsibility to be carried out. Many people complain that they do not have the requisite authority to execute all of their responsibilities.
The scalar principle deals with the clarity of definition of authority in the organization and the need, in general, to "go through channels."

Span of management (or span of control) refers to the number of direct subordinates who report to any manager. This number has apparently been increasing as our Nation's companies have experienced downsizing. Finally, division of labor accepts the notion that work specialization can bring about increases in efficiency.

\subsection{Directing}

Directing refers to the active management function that involves performing the various work assignments. It therefore deals with such complex activities as-

- leading

- team building

- communicating

- coordinating

- motivating

- delegating

- resolving conflicts

- problem solving

- decision-making

\subsubsection{Leading}

Probably the most important aspects of directing have to do with leading and team building. Indeed, if the requirements for a leader are examined in detail, they include essentially all the other aspects of directing. For example, in a study of leadership, Eisner (1993) examined the various attributes of a leader. The basic conclusions were that 13 attributes could be ranked in three major categories-

\section{Most Important Attributes}

(1) empowering/supporting/motivating/trusting 
(2) having vision/long-term viewpoint

(3) cooperating/sharing/team playing and building

(4) renewing/learning/growing/educating

Very Important Attributes

(5) communicating

(6) serving as a model for corporate culture and values

(7) being productive/efficient/determined

\section{Important Attributes}

(8) exemplifying time management/prioritization skills

(9) being action-oriented

(10) offering contributions/commitment/legacy

(11) being innovative/imaginative

(12) having integrity/morality

(13) exhibiting skill/knowledge/substance

If a manager has all these 13 attributes, that person is a leader.

Leaders can and do operate at all of the various levels in an organization. Thus, leaders can be found in the executive suite as well as at the level of project manager or team leader. Failure to find and develop such leaders often leads to the ineffectiveness of an organization. Leadership skills are necessary at all levels in order to carry out all of the dimensions of a coherent and effective safety program.

\subsubsection{Team Building}

A number of company activities depend on the formulation of high-performance teams. Team building is therefore a key element of directing, especially as teams have evolved from single function to multifunctional entities dealing with issues that cross all organizational boundaries. Teams address issues that are believed to be of special significance to the company, including such matters as quality and safety. Essential aspects of team building may be summarized as follows-

- develop and execute plan for team operation and growth

- carry out periodic and special team meetings

- clarify goals and roles

- run team in participative, possibly consensual, manner

- involve the team in situation analysis and problem solving

- $\quad$ give credit to active, positive team members and contributions

- ensure team efficiency and productivity

- communicate

\subsubsection{Communicating}

A leader in today's organization is a superb communicator, coordinator, and resolver of conflict. Conflicts arise essentially every day in the affairs of a company, and a leader is able to confront such conflict and wind up with a successful resolution. Conflict can occur in many dimensions, two of the most important being (1) conflict over the control and use of resources and (2) interpersonal conflict. In the first case, there is always 
the vying for funding to allow people to carry out programs and projects. In the second case, some people simply do not get along with each other. It is up to the leader to address such matters and issues in real time and move the organization and its units beyond the conflict to successful team operations. Communication skills are invaluable in carrying out this difficult task.

\subsubsection{Decision-Making}

Finally, a last important aspect of directing is decision-making. The leader should be able to come to closure on all important issues. The preferred style is participative or consensual, but the leader should also be prepared to make a decision that is contrary to the advice of the majority. Implicit in the decision-making process is the definition and evaluation of alternative courses of action. Team involvement in these steps is crucial. Failure to clearly articulate alternatives or to seriously consider new and different ways to solve problems leads to less than true decision-making. The evaluation of alternatives often involves considerable analysis so that the process may be drawn out over a period of time. However, the true leader knows when it is time to stop analyzing and make a decision.

\subsection{Monitoring}

The management function of monitoring deals with such elements as progress reviews, measurement, evaluation and assessment, and feedback.

The two key elements of monitoring are measurement and feedback. Feedback is required for the directing function so that corrective action can be taken to solve the various problems as they arise or are foreseen. Measurement is important so that all evaluations are made with the best possible data.
Essentially all large organizations have adopted the monitoring function known as monthly measurements. During such sessions, the senior managers, as a minimum, report progress to the corporate executives. If goals are not being met, then corrective action may be required. These monthly measurements are less prevalent as one moves down an organization. Project managers should continually assess progress, but some fail to do so on a fixed periodic schedule. This will often lead to significant problems. The concept of periodic measurements should be adopted across all levels of an organization.

In addition to measurements that occur on a fixed schedule, measurements and progress reviews need to be carried out in special circumstances, such as a significant failure in plant operations or whenever acceptable performance boundaries are crossed. Successful programs have strong qualitative and quantitative measurement components and respond to the results of these measurements quickly and efficiently.

Novice managers make the assumption, often incorrectly, that once plans and schedules are in place, there is little need to monitor progress. This can lead to disastrous results. Whether one adopts "management by walking around" or a more formal monthly measurements process, explicit monitoring of progress is essential to the success of an organization, at all levels.

\subsection{Integrating}

The integrating function makes clear that other functions do not operate successfully without considering how they need to interrelate. Examples of such interactions include the need to-

- convert plans into actions

- provide appropriate feedback from the monitoring function to the directing function 
- change organizational structures when the monitoring function indicates there are fundamental or structural problems

- provide timely information across and between all management functions

- $\quad$ practice systems thinking

For an organization to maintain proper control, all plans need to take form through action. Plans that are simply "put on the shelf" are not particularly useful. Therefore, all plans should be living documents and should serve as blueprints for the actions taken, especially in the directing and monitoring functions.

Feedback from the monitoring to the directing function is important and should be timely so as to facilitate corrective action. Lack of such feedback will sabotage any and all control.

Changes in organizational structures, from the corporate to the project levels, are standard methods of problem solving. Often, the need is for streamlining and breaking down of bureaucratic behavior.

With the advent of the "information age," information represents the lifeblood of most organizations. Clearly, companies cannot operate without accurate and timely information. Today's modern companies rely on information systems with a wide variety of capabilities, including, as a minimum-

- database management systems

- spreadsheets

- graphics packages

- executive information systems

- geographic information systems

- word processing

- image processing systems

- project management systems
Information is the "glue" that holds many organizations together and enables them to function at high levels of performance and responsiveness.

Another key aspect of the integrating function, delineated in Senge's The Fifth Discipline (1990) and discussed in Section 2, involves "systems thinking," which recognizes that all management functions are part of the larger system known as the corporate organization. Likewise, systems engineering focuses on the interfaces and interactions between the elements of systems engineering as well as the components of a large-scale system. If companies are organized by function, and both product and service development are multifunctional, then it is clear that interactions between functions are crucial to the operation of the overall organization. In carrying out programs, it is often at the organizational interface that the problems occur. Information is not passed on because people do not understand the requirements for effective communication across such boundaries.

An effective integrating function will ensure that when important decisions are under evaluation, there is also due consideration given to any and all influences such decisions might have on the systems within the company as well as outside the company. A straightforward example is in the area of resource allocation. If funds are provided in order to improve one area, such as safety, then funds may not be available to upgrade other areas, such as a financial control system. Integration is also supported by utilizing crossfunctional teams that can represent all of the relevant functions in an organization.

\subsection{Controlling}

As defined here, control is achieved when and if the other five functions of planning, organizing, directing, monitoring, and integrating are operating in harmony. In this context, the "controlling" 
function is viewed as the appropriate synthesis and balance among the other major functions.

Many companies install control systems in order to manage special parts of their operations. Some of these systems are listed below-

- $\quad$ safety control

- quality control

- maintenance control

- financial control

- contracts control

- configuration management and control

- $\quad$ process control

These systems all require inputs and consideration by each of the general management functions delineated in this section.

\subsection{Summary}

This section has defined the major general functions of management as planning, organizing, directing, monitoring, and integrating. These functions have been discussed only briefly, inasmuch as there is a vast body of literature on each of these functions.

The ultimate objective of this report is to relate management theories (Section 2) and organizational functions (Section 3) to matters and issues of safety. The elements of safety, per se, are articulated in Section 4. Section 5 examines the elements of corporate culture that are necessary to consider in evaluating safety programs. 


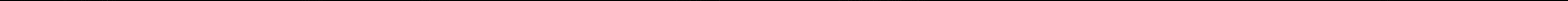




\section{SECTION 4 PROCESS SAFETY MANAGEMENT AND ITS ELEMENTS}

\subsection{Introduction}

\subsubsection{Regulatory Background}

In the last decade, a series of major international disasters occurred for which systems and personnel were neither adequately prepared nor fully ready for an appropriate response (see Table 4-1 for some examples). These disasters stimulated an intense cooperative effort by safety regulators, managers, and engineers from many countries worldwide. This international community comprises organizations and individuals from governments, commercial industries, trade associations, and professional societies and institutes. The intent of this spontaneous effort was to develop new perspectives on safety to ensure that process hazards be identified, understood, and controlled to prevent their occurrence, and, moreover, to mitigate the impacts of all accidents and incidents that do occur.

The principal end products of this work, including technologies and new management strategies, are the statutes, regulations, and industry standards that have been developed in industrial nations around the world. Regulations are meant to provide the boundaries and guidelines for safety of hazardous processes. Process safety management (PSM) regulations in the United States were written over an 8-year development period and included extensive and repeated professional and industrial input. The first regulation was the Occupational Safety and Health Administration's (OSHA) PSM Final Rule, published February 24, 1992; the second, OSHA's PSM Directive, 29 CFR 1910.119, dated September 28,1992 . Following the standard provided by the OSHA PSM Directive, new families of PSM programs have been and are being developed, particularly in the nuclear, chemical, and petroleum refining industries.

\section{Table 4-1. Some recent major process safety incidents}

\begin{tabular}{|c|c|}
\hline $\begin{array}{l}\text { Place, (date), } \\
\text { type of incident }\end{array}$ & $\begin{array}{l}\text { Monetary and } \\
\text { human loss and } \\
\text { other conse- } \\
\text { quences }\end{array}$ \\
\hline $\begin{array}{l}\text { Mexico City } \\
(11 / 84) \\
\text { Liquid petroleum } \\
\text { gas explosion }\end{array}$ & $\begin{array}{l}\$ 20 M \\
300+\text { fatalities }\end{array}$ \\
\hline $\begin{array}{l}\text { Bhopal, India } \\
(12 / 84) \\
\text { Toxic gas release }\end{array}$ & $\begin{array}{l}\$ \text { (undisclosed) } \\
2,800 \text { fatalities } \\
200,000 \text { affected }\end{array}$ \\
\hline $\begin{array}{l}\text { Chernobyl, USSR } \\
\text { (4/86) } \\
\text { Nuclear materials } \\
\text { release }\end{array}$ & $\begin{array}{l}\$ \text { (undisclosed) } \\
31 \text { fatalities } \\
\text { (short term) } \\
300 \text { square miles } \\
\text { evacuated }\end{array}$ \\
\hline $\begin{array}{l}\text { Pasadena, Texas } \\
(11 / 89) \\
\text { Chemical plant } \\
\text { explosion }\end{array}$ & $\begin{array}{l}\$ 750 \mathrm{M} \\
23 \text { fatalities }\end{array}$ \\
\hline
\end{tabular}

29 CFR 1910.119 provides a performance-based standard that specifies requirements for what needs to be accomplished without mandating how. As a Directive, it addresses the full range of issues that impact process safety and its management under three main areas: technology, personnel, and facilities. 29 CFR 1910.119 first establishes requirements for a thorough documentation of the technology utilized in a process. It then requires extensive formal hazards analysis and specifies activities that relate process technology to operating procedures and to the management of change. Operating procedures are also tied to training requirements for operating 
personnel. Redundant engineering, administrative controls, and compliance audits are interlinked and woven throughout the various elements and activities specified by the Directive. Overall, each of the elements of PSM is linked and skillfully intertwined with all the other elements in 29 CFR 1910.119.

The importance of 29 CFR 1910.119 in regard to this report is that it provides a safety model on which to base discussions of safety elements and PSM issues. This OSHA PSM Directive has, in effect, become an internationally accepted standard for PSM programs.

\subsubsection{PSM Perspective}

Safety (i.e., freedom from harm) is the primary goal of every safety management program.

However, the number and complexity of safety issues associated with development, operation, and maintenance of hazardous processes such as nuclear fuel or chemicals production make this a difficult goal. From a systems perspective, the primary elements of these processes include (1) people, (2) facilities, (3) procedures, (4) associated tasks, and (5) the work environment (see Figure 4-1). Safety in regard to hazards (i.e., things that can go wrong) concerns not only the elements themselves but also interactions among all of them, throughout the entire processing system life cycle. Hazardous process safety entails the capability to (1) predict everything that can cause illness, injury, or death to personnel or damage to a facility or the environment; (2) control to avoid occurrences; and (3) provide for mitigation of unexpected occurrences. The following questions are fundamental to PSM.

- What can go wrong?

- What are the expected consequences?

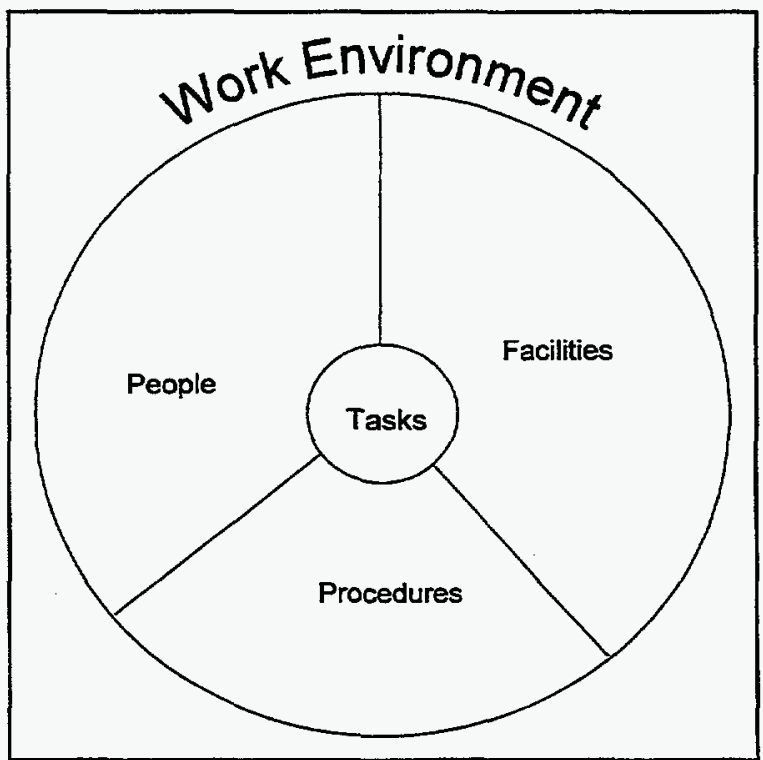

Figure 4-1. System safety elements

- What can be done to preclude accidents or negative events?

- What can be done to mitigate the consequences if an accident occurs?

- Are the risks associated with feasible accidents acceptable?

Primary and never-ending concerns of a PSM program include questions of completeness of understanding and of preparedness for the unexpected.

- Have all possible accidents and/or occurrences been identified, understood, and accounted for?

- Are the responsible personnel and systems adequately prepared and fully ready, should one or more accidents occur?

The approach selected to address and resolve such questions constitutes the basis of PSM, the focus of this section. 


\subsubsection{Safety Structure}

The purpose of this section is to identify and briefly describe a safety structure or taxonomy to represent the important safety elements for hazardous processes. This taxonomy will also be used in Section 6.3, the PSM Program-Level Evaluation Matrix, to show the relationships between the safety elements and management controls necessary for effective oversight and evaluation of PSM programs. The safety taxonomy selected for the matrix is based on OSHA PSM Directive, 29 CFR 1910.119. Among the many reasons for following this Directive and adopting its safety taxonomy are that it is-

- the principal PSM regulation for the hazardous materials industries

- a product of the efforts of the worldwide safety community

- professionally recognized as being comprehensive and complete

- followed and supported by industrial firms as well as professional societies and trade associations throughout the world

As in the OSHA PSM Directive, this report classifies all PSM issues under the three main areas of Technology, Personnel, and Facilities. These areas are further defined by 14 discrete safety elements. Then, within each of these elements, the inherent safety principles, constituent safety subelements, and essential features of the subelements that pertain to the management of process safety are described. These safety subelements may be used to support evaluation of PSM systems and management controls to facilitate the PSM oversight responsibility at the NRC.

\subsection{Technology Safety}

\subsubsection{Process Technology}

\subsubsection{Principles of Safety}

The process technology (PT) safety element involves operations associated with the nuclear fuel production process itself, from the perspective that the process is the foundation for both identification and understanding of all safety hazards. Three basic safety subelements-hazards associated with materials, hazards associated with the basic process design, and hazards associated with the basic equipment design-of the PT safety element are discussed next. The PT safety element is shown expanded into its subelements as a tree diagram in Figure 4-2.

\subsubsection{Materials}

Hazards of materials are those safety issues related to the materials being processed or being utilized in the nuclear fuel production processes. These hazards concern the basic physical, chemical, and nuclear properties of each chemical or material involved. Throughout the life cycle of nuclear fuel production operations, PSM depends on the availability of accurate and current physical, chemical, and nuclear material property data, including -

- boiling points

- $\quad$ freezing points

- vapor pressure

- $\quad$ flash points

- flammability limits

- ignition temperatures 
Physical Properties

\begin{tabular}{|l|l}
\cline { 2 - 2 } Materials & Chemical Properties \\
\hline & Nuclear Properties \\
\hline
\end{tabular}

Simplified Process Flow Diagrams

Process Chemistry

Process

Technology

Process Chemistry

\begin{tabular}{l|l}
$\begin{array}{l}\text { Process } \\
\text { Design }\end{array}$ & Process Nuclear Physics
\end{tabular}

Maximum Inventory Levels

Process Steps and

Standard Operating

Conditions

Safety, Health, and Environmental

Consequences of Deviations

\begin{tabular}{|c|c|c|}
\hline \multirow[b]{2}{*}{$\begin{array}{l}\text { Equipment } \\
\text { Design }\end{array}$} & $\begin{array}{l}\text { Equipment } \\
\text { Design Bases }\end{array}$ & \multirow[b]{3}{*}{ Design } \\
\hline & $\begin{array}{l}\text { Equipment Configuration } \\
\text { Management }\end{array}$ & \\
\hline & Equipment Compliance & \\
\hline & & Installation \\
\hline
\end{tabular}

Human Factors

Figure 4-2. Process technology safety subelements 
- thermal and chemical stability

- corrosion data

- criticality data

- toxicity data

- exposure limits

- hazardous effects of inadvertent mixing/combining of different materials

\subsubsection{Process Design}

The process design subelement concerns hazards associated with the "as-designed" nuclear fuel production process. PSM depends on readily available information describing the basis of the process design, including-

- $\quad$ simplified process flow diagrams

- process chemistry

- process nuclear reactions

- $\quad$ maximum inventory levels of hazardous substances

- $\quad$ process steps and standard operating conditions (SOCs) at each step

- $\quad$ safety, health, and environmental (SHE) consequences of deviations from the SOCs

\subsubsection{Equipment Design}

The design basis for the equipment utilized by the nuclear fuel industry is also of extreme importance. PSM depends on readily available information, grouped under equipment configuration management in Figure 4-2, that describes the equipment design basis, such as-
- equipment descriptive files

- materials of construction

- $\quad$ process flow diagrams for new facilities

- protective safety systems

- design codes

A second grouping, under equipment compliance in Figure 4-2, includes

- design and installation compliance with applicable laws, regulations, and generally accepted engineering practices

- human factors design

- relief system design

- electrical classification

- $\quad$ piping and instrument diagrams (P\&IDs)

In the late 1970 s, the nuclear industry recognized that the man-machine interface was an important component of safe process/equipment operation. The equipment designed to operate and control the process should be designed with an awareness of the operator's physical limitations and required work load (human factors engineering).

\subsubsection{Process Hazards Analysis}

\subsubsection{Principles of Safety}

A process hazards analysis (PHA) is necessary to identify, evaluate, and provide effective approaches for the control of hazards associated with the nuclear fuel production process so that injuries and process-related incidents can be prevented. Analyses should utilize an organized, methodological approach; seek out and be based on multidisciplinary consensus; and provide documented results for further future analysis and personnel training. The PHA safety element is shown expanded into its subelements as a tree diagram in Figure 4-3. 


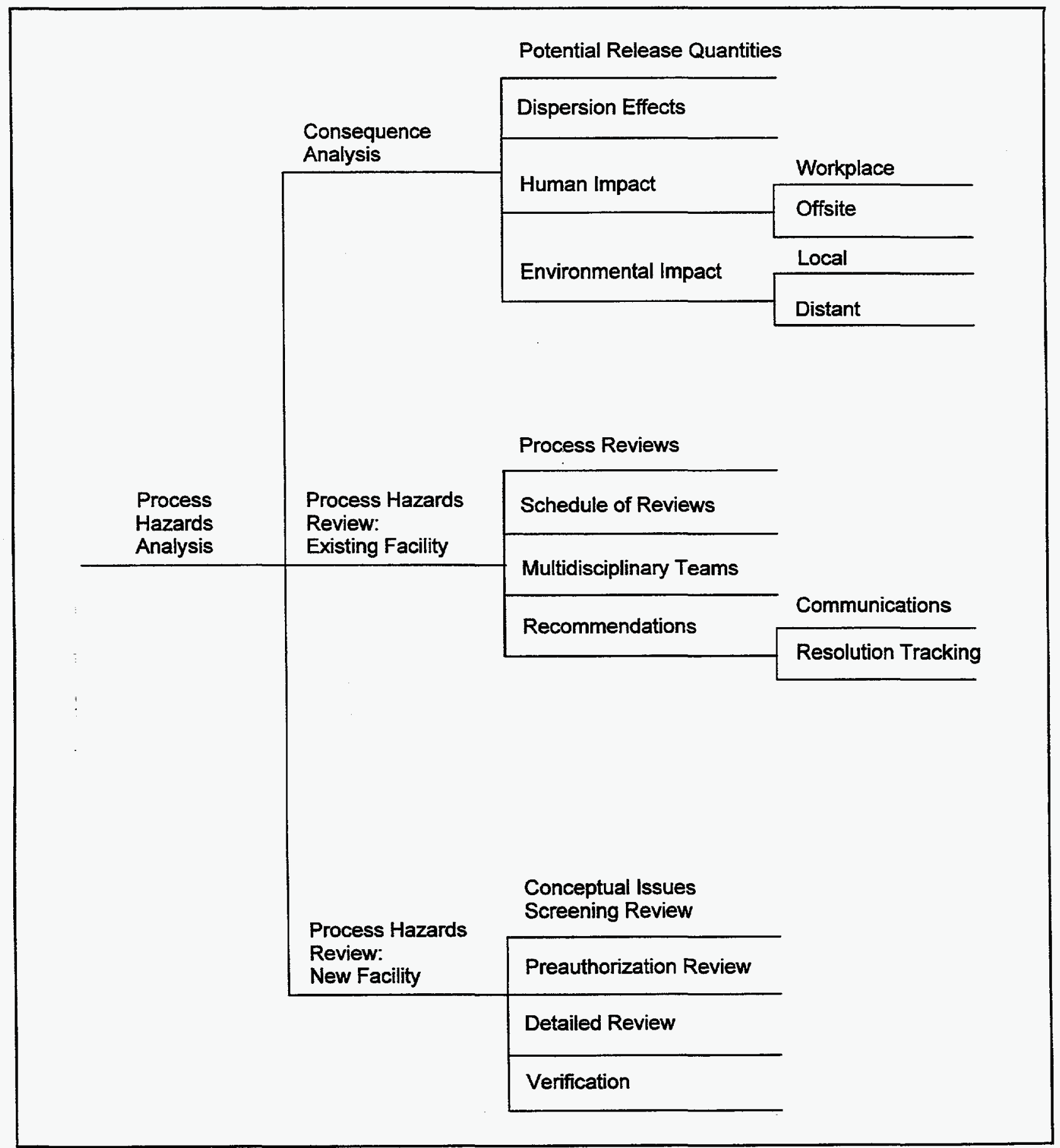

Figure 4-3. Process hazards analysis safety subelements 


\subsubsection{Consequence Analysis}

PSM depends on readily available information, generated by appropriate hazards analysis, that describes the consequences of credible accidents and includes estimates of-

- potential release quantities

- downwind dispersion effects

- $\quad$ impacts on surrounding populations (workplace and offsite)

- impacts on the environment (local and distant)

\subsubsection{Process Hazards Review: Existing Facility}

Periodic process hazard reviews (PHRs) are necessary to ensure process safety. The entire process should be reviewed for the purpose of identifying potential hazards during operations or maintenance of existing facilities. The PHRs should use methodologies that have been established as appropriate for the process or subprocess under study and that have been recognized as effective by Process Safety Boards. The PHRs should be carried out in accordance with existing PSM program schedules, using multidisciplinary teams of trained personnel who are outfitted with all necessary resources and with clearly defined roles and responsibilities. Moreover, recommendations resulting from PHRs should be logged, adequately communicated to the appropriate management and plant personnel, and tracked to completion.

\subsubsection{Process Hazards Review: New Facility}

PHRs for new facilities should be carried out at four distinct but related stages of the design and development effort.
(1) A screening PHR should be carried out at the basic data stage of development, focusing on conceptual issues.

(2) A preauthorization PHR should be carried out at the architecture and engineering stage of development, after the scope of the development project has been defined.

(3) A detailed PHR should be carried out at the final design stage, just after authorization to build.

(4) Following construction and prior to operation, the PHR should be reviewed to verify that the as-built facility conforms to the analyzed facility.

\subsubsection{Operating Procedures and Safe Work Practices}

\subsubsection{Principles of Safety}

The operating procedures for hazardous processes should detail operating parameters and their limits for safe operations so that those responsible have a clear understanding of the process. Also, there should be clear definitions of the consequences of operating outside these limits, and the steps required to correct or avoid out-of-limit deviations should be listed. Safe work practices comprise a carefully planned system of procedures and permits involving checks and authorizations prior to performing nonroutine work in process areas. The operating procedures and safe work practices safety subelements are shown in Figure 4-4.

\subsubsection{Operating Procedures}

To ensure effective PSM, the following requirements and conditions are among those that should be imposed on operating procedures. The requirements should- 


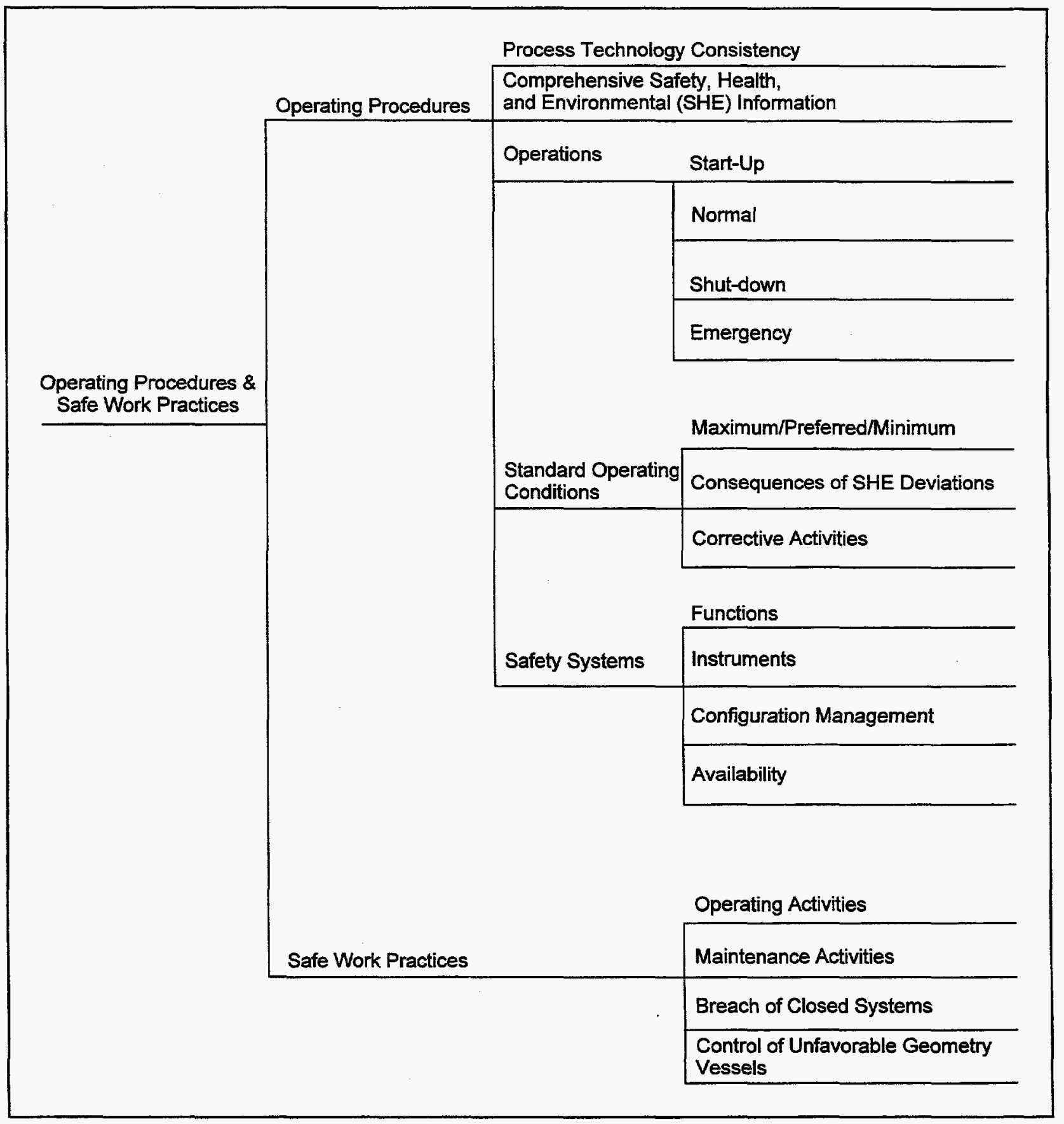

Figure 4-4. Operating procedures and safe work practices safety subelements 
- be consistent with the process technology

- include comprehensive and complete SHE information

- address start-up, normal, shut-down, and emergency operations

- list SOCs for each process step, including

- maximum, preferred, and minimum conditions

- consequences of SHE deviations

- steps necessary to correct or avoid deviations

- $\quad$ provide descriptions of safety systems and their functions

- $\quad$ specify predetermined inventory limits for all materials handled

- provide descriptions of all instrument controls

- be under configuration management and maintained up to date

- be readily available to all relevant employees

\subsubsection{Safe Work Practices}

Safe work practices pertain to safe operating and maintenance activities during the conduct of nonroutine work, and include the following-

- $\quad$ opening of process equipment and piping

- lockout/tag-out of hazardous energy sources

- confined space entry
- movement of heavy equipment (in contrast to equipment containing hazardous substances)

- integrity check of process equipment at time of shift changes or personnel turnover

- $\quad$ entry to and exit from a facility by support and contract personnel

- control of ignition sources

- breach of closed systems containing hazardous materials

- control of unfavorable geometry vessels

\subsubsection{Management of Change (Technology)}

\subsubsection{Principles of Safety}

Changes to the documented technology database potentially invalidate prior hazard assessments. All changes to the documented technology should, therefore, be subjected to rigorous review. The management of change in this case should be controlled by means of a documented authorization activity prior to the changes and a documented closing activity following the change. The management of change (technology) safety subelements are shown in Figure 4-5.

\subsubsection{Authorization Document}

An authorization document should be prepared to describe and to manage the required changes. Written documentation and a tracking system should cover the following-

- $\quad$ purpose of changes

- technical basis 


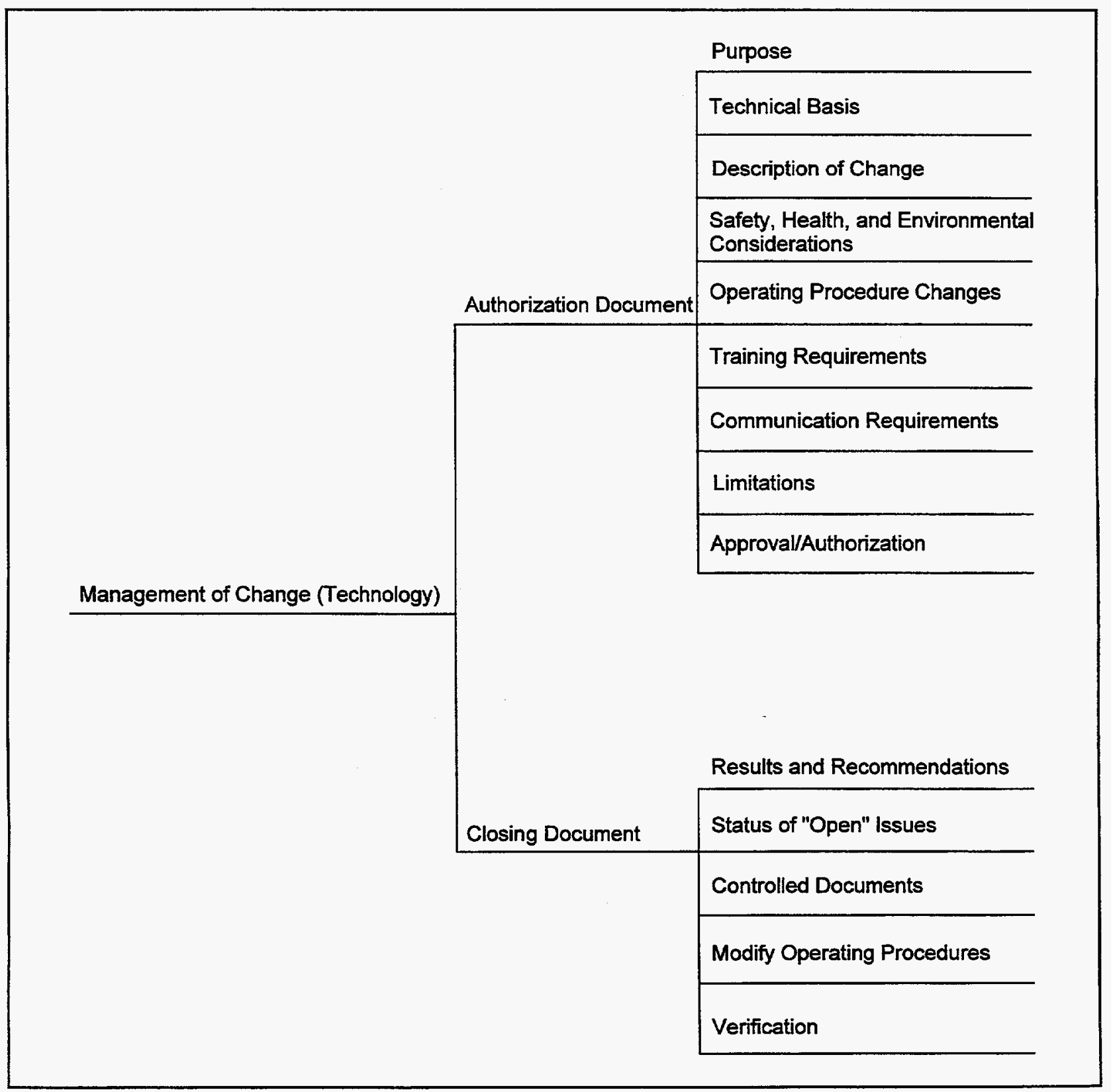

Figure 4-5. Management of change (technology) safety subelements 
- change description

- SHE considerations

- $\quad$ modifications to operating procedures

- $\quad$ training and communications requirements

- time and quantity limitations imposed on change

- approval and authorization requirements

Use of controlled documents includes-

- $\quad$ PHRs

- operational procedures

- P\&IDs

\subsubsection{Closing Document}

The closing document should include-

- summary of results and recommendations

- $\quad$ status of "open" PHR recommendations

- controlled documents (PHRs, operational procedures, P\&IDs)

- modifications to operating procedures

- verification that changes have been implemented as described in controlled documents

A tracking system is necessary to provide closure for both authorization and closing documents.

\subsection{Personnel Safety}

\subsubsection{Personnel Training and Performance}

\subsubsection{Principles of Safety}

Safe handling of hazardous materials and safe operations with hazardous processes depends on personnel performance. Facility personnel should be fully dedicated to following documented policies and procedures with accuracy and consistency. Personnel should not only be knowledgeable and well trained but also be physically able, mentally alert, and capable of using good judgment to properly follow prescribed practices. The personnel training and performance safety subelements are shown in Figure 4-6.

\subsubsection{Training}

The essential features of training should include (1) training resources to develop, document, and implement training policies and to address both initial training and refresher courses or retraining and (2) training policies to address the following basic subject areas-

- personnel requirements both to receive and to provide training

- qualifications of instructors

- basic skills training

- $\quad$ job task training

- emergency response and control training

- $\quad$ refresher and supplemental training

- basic elements of effective training

- $\quad$ record keeping 


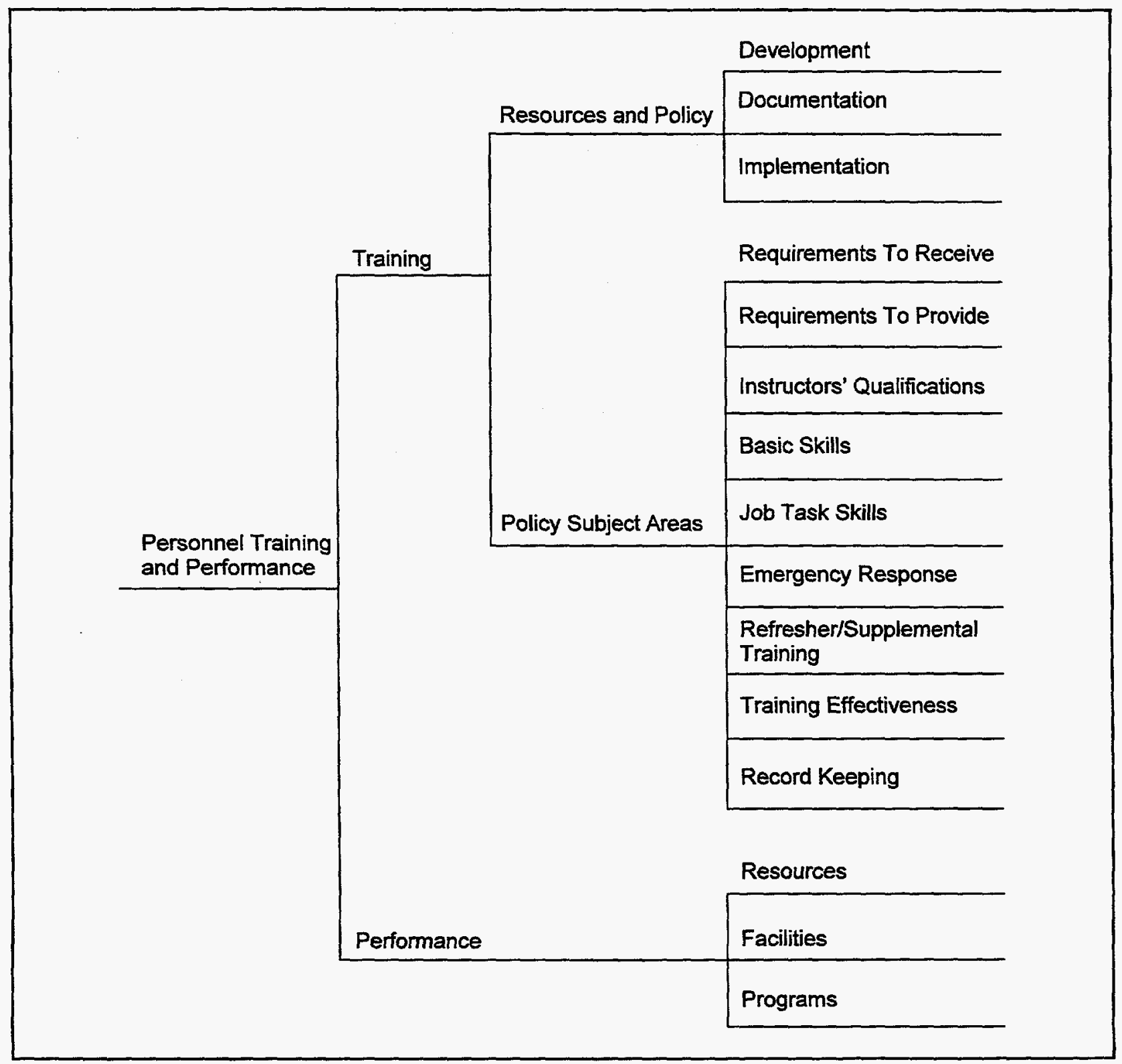

Figure 4-6. Personnel training and performance safety subelements 


\subsubsection{Performance}

The essential features of training performance include facilities and other resources to develop and implement a training program. These are necessary to ensure personnel fitness for duty.

\subsubsection{Contractor Safety and Performance}

\subsubsection{Principles of Safety}

Contractor personnel should adhere to the same safety principles and practices of the PSM program as do other facility personnel to ensure that all tasks and processes are completed safely. The responsibility for safety should be widely accepted and shared by the site and contractor personnel. Contractor safety and performance subelements are shown in Figure 4-7.

\subsubsection{Site Management}

The essential features of site management in regard to safety of contractor operations include the following issues-

- Consider safety evaluations as a part of contractor selection process.

- Ensure clear lines of communications between contractor administrator and contractor.

- Inform contractor of known potential hazards.

- Inform contractor and provide training on applicable rules, work practices, and sitespecific safety requirements.

- Explain emergency response/control plans to contractor.
- Maintain a contractor personnel injury and illness log.

- Periodically reevaluate contractor's overall and safety performance.

\subsubsection{Contractor Management}

In addition to monitoring employees and reporting to site management, the essential features of the contractor's responsibilities in regard to safe operations include ensuring that each contractor employee has job skills training and necessary qualifications, is instructed in known hazards, and receives and understands proper training. The contractor should maintain accurate records of its training programs and include verification of employee understanding.

\subsubsection{Management of Change (Personnel)}

\subsubsection{Principles of Safety}

Although personnel movements and organizational changes are inevitable, it is essential to retain a minimum level of experience and knowledge in order to maintain the "corporate" or "process" knowledge base in regard to

(1) specific direct process knowledge and

(2) knowledge and skill in managing process safety. Loss of minimum levels of experience during changes in technology or facilities potentially invalidates prior hazard assessments, which are based on knowledgeable people being present and in charge. Personnel changes at all levels should satisfy preestablished criteria to ensure that minimum levels of experience and expertise are maintained. 


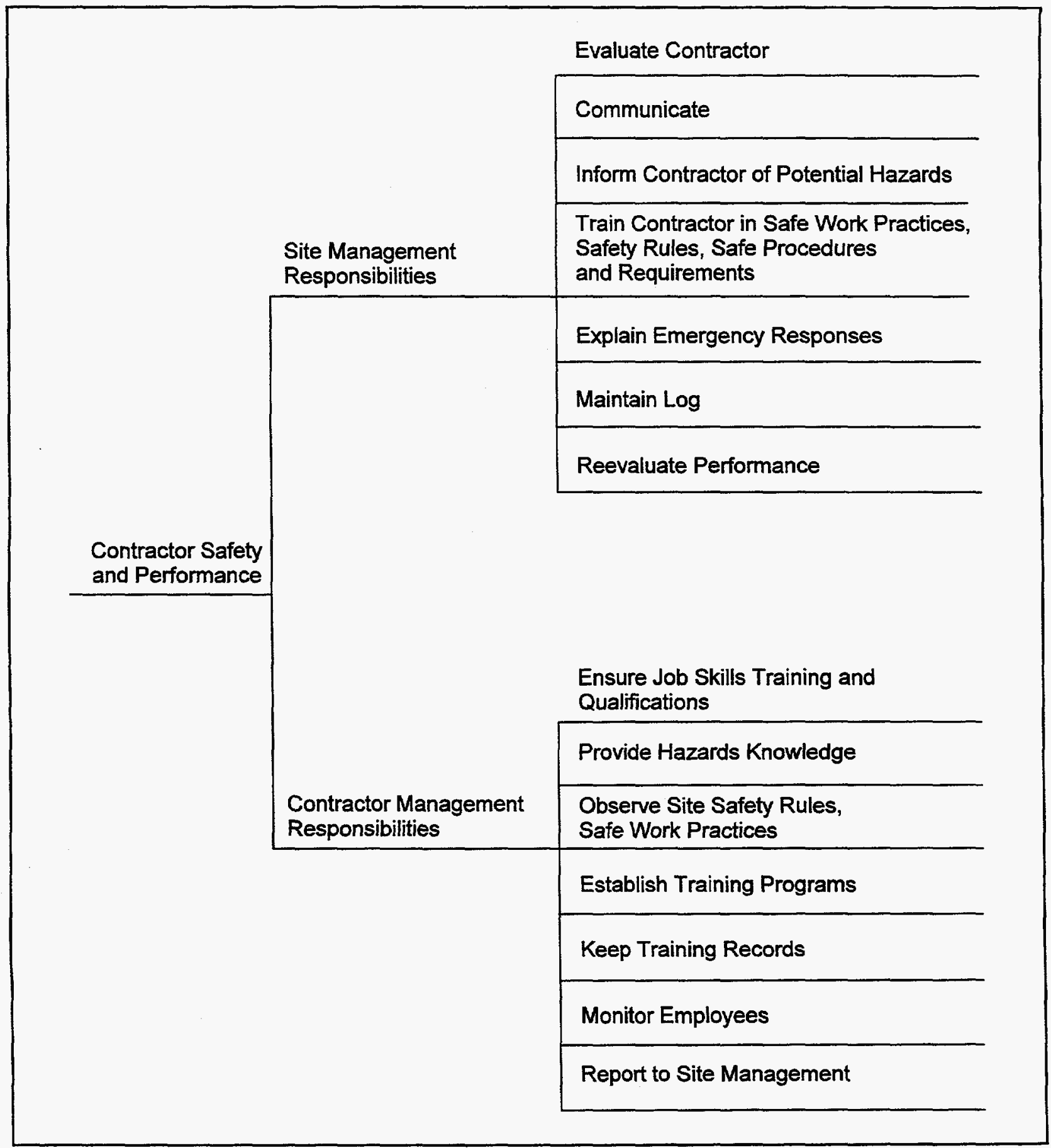

Figure 4-7. Contractor safety and performance safety subelements 


\subsubsection{Site Management}

The essential features of the site management operations should document the following-

- established criteria and guidelines to ensure minimum levels of experience and expertise are developed, validated, and maintained for supervisory and nonsupervisory positions

- scrupulous adherence to these criteria and guidelines

Records of provision of training for newly assigned personnel should include-

- $\quad$ principles and essential features of PSM

- technology specific to the operations

Records should also indicate that line supervision has demonstrated proficiency within a predetermined period and at a predetermined level. These safety subelements are shown in Figure 4-8.

\subsubsection{Incident Investigation and Communication}

\subsubsection{Principles of Safety}

Serious incidents as well as "near misses" will recur and possibly intensify unless root causes are identified and corrected. Thorough and persistent investigation of all serious incidents and "near misses" should continue to ensure continuous improvement of safety performance.

\subsubsection{Procedures, Reports, and Implementation}

Among the essential features of PSM in this regard are incident investigation procedures that

\begin{tabular}{|l|l|}
\hline \multirow{4}{*}{$\begin{array}{l}\text { Management of } \\
\text { Change (Personnel) }\end{array}$} & Minimum Level Criteria \\
\hline \multirow{4}{*}{ Minimum Level Guidelines } \\
\cline { 2 - 2 } & Velidation Data \\
\cline { 2 - 2 } & Verification Data \\
\hline & Training Records \\
\hline & Proficiency Records \\
\hline & Entry Programs \\
\hline & Documented Report \\
\hline
\end{tabular}

Figure 4-8. Management of change (personnel) safety subelements

should be developed and implemented promptly after each incident or "near miss." As a minimum, incident investigation reports should include-

- date and time of incident

- date of investigation

- description of incident/"near miss"

- basic cause and responsibilities

- factual information

- $\quad$ key factors leading to event

- identification of PSM elements needing changes or modifications

- recommendations for future avoidance that include responsibilities and timeframe 
Implementation efforts should include ensuring that-

- incident reports are reviewed by appropriate personnel

- reports are retained for the life of the process

- a follow-up/tracking system is in place and in use to ensure resolution

- communication of incidents and reports to all appropriate management and personnel at other facilities is effectively carried out

The corresponding safety subelements are shown in Figure 4-9.

\subsubsection{Emergency Planning and Response}

\subsubsection{Principles of Safety}

In-depth planning for potential emergencies is essential to ensure an effective response by site personnel, in conjunction with supporting community and emergency response organizations, should an accident or incident occur. The important objectives of this aspect of PSM include (1) mitigation of the impact on personnel, the environment, and facilities and (2) prompt control of the emergency situation.

\subsubsection{Plans and Training}

The essential features of the emergency planning and response safety subelements, shown in Figure 4-10, include the following-

- Consequence analyses should be conducted to provide key information for emergency plans.
- A well-founded and clearly written Emergency Response Plan should be developed to provide for mitigation of initial consequences of accidents or incidents and should include-

- plan activation

- authorities and responsibilities (chain of command)

- notification procedures and priority orders

- escape and evacuation routes

- personnel accounting approach

- rescue operations, including medical assistance

- designation of primary and alternate control centers

- longer term activities

- A well-founded and clearly written Release Containment Plan to terminate any hazardous materials releases and to bring any emergencies under control should be developed to include-

- emergency shutdown procedures

- authorities and responsibilities (chain of command)

- activation of emergency systems

- activation of site and/or local fire brigades

— shutdown of adjacent facilities 


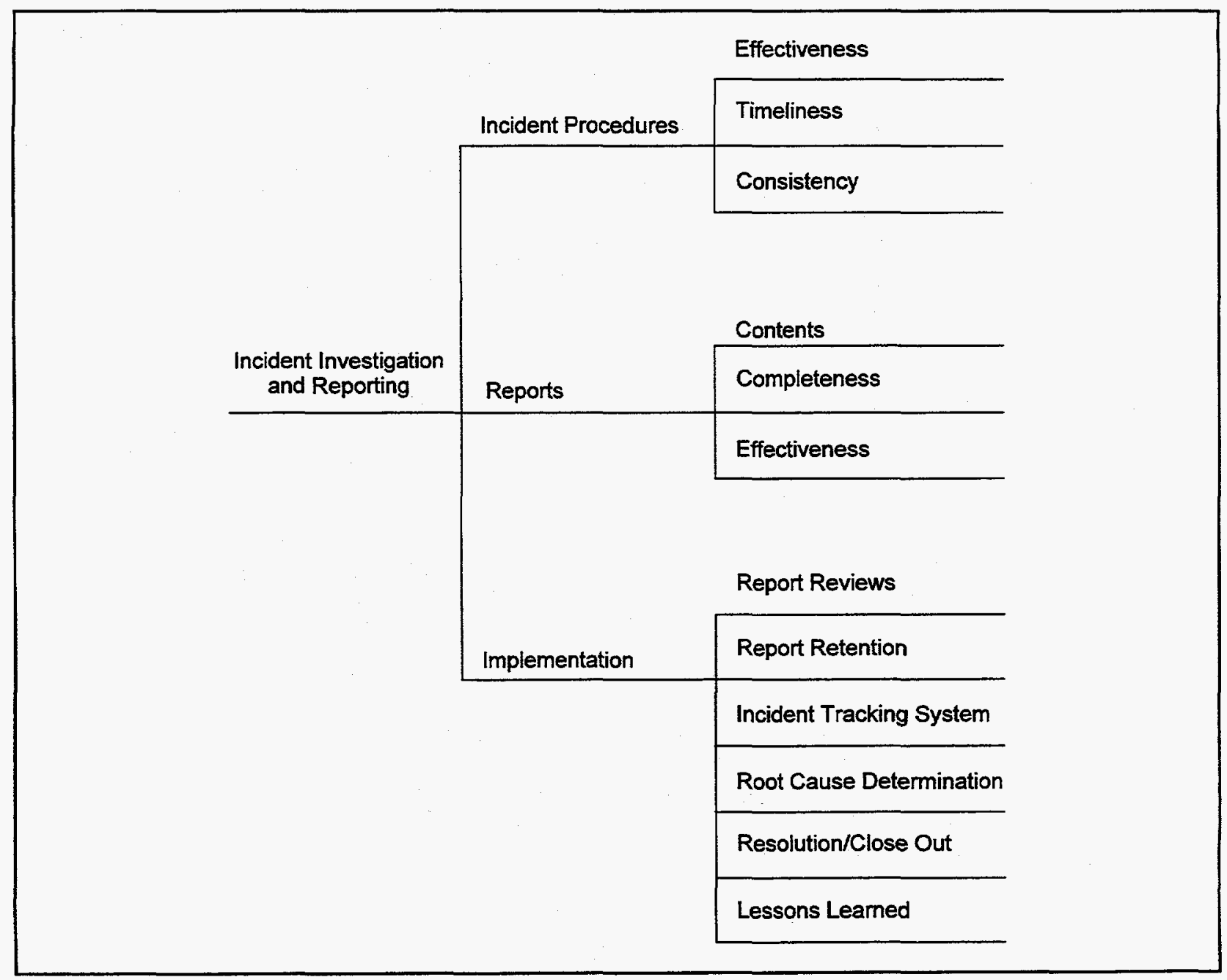

Figure 4-9. Incident investigation and communication safety subelements 


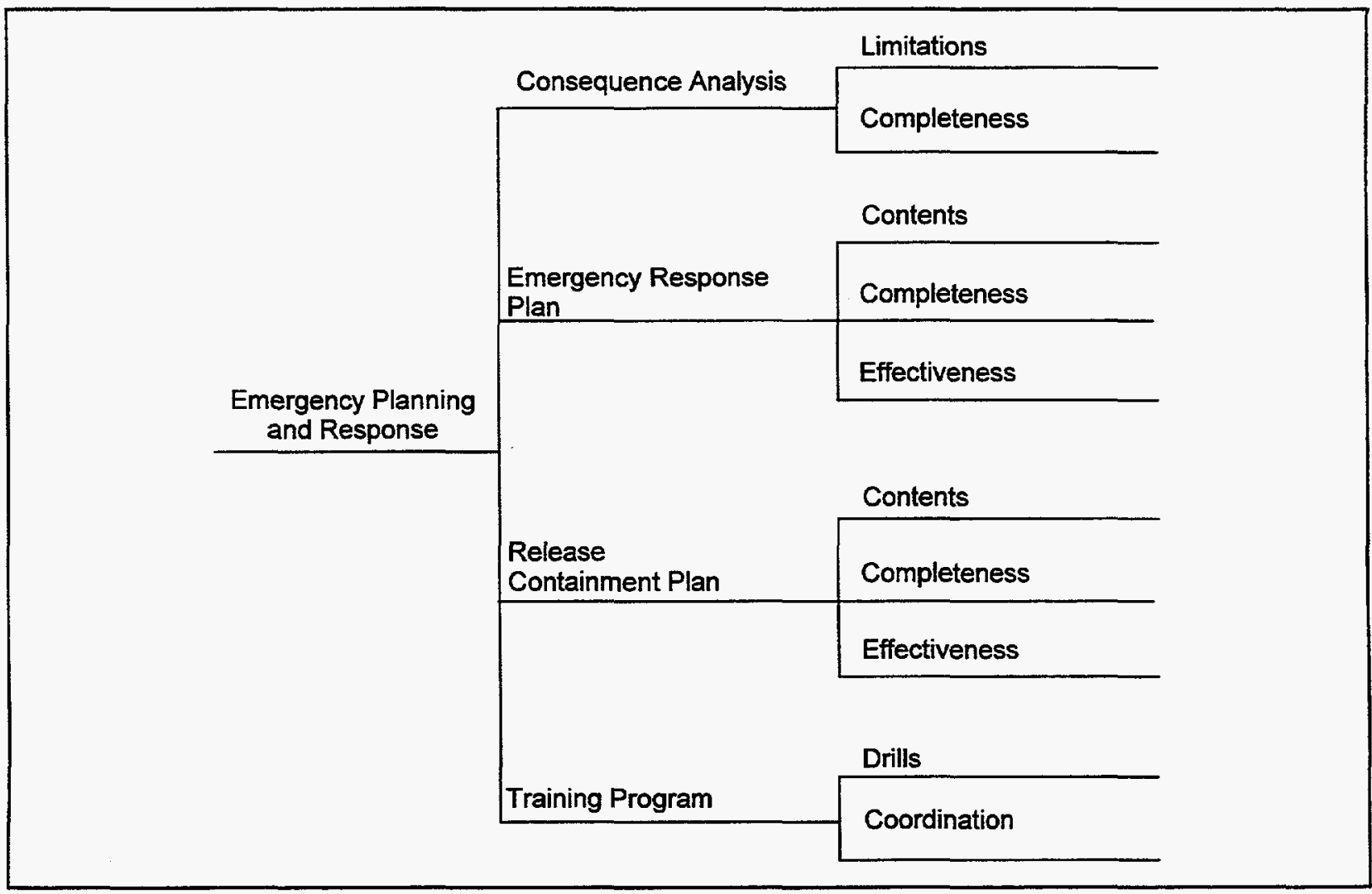

Figure 4-10. Emergency planning and response safety subelements 
— barricading/sealing off affected facilities

- activation of spill clean-up procedures

- Training of site personnel for the purpose of implementing these procedures should include periodic emergency drills and involvement of appropriate emergency response organizations.

\subsubsection{Auditing PSM}

Essential features of the auditing PSM safety subelements are most conveniently broken down into the self-audits, internal audits, and independent or external audits. These PSM safety subelements are shown in Figure 4-11.

\subsubsection{Principles of Safety}

Auditing entails comparisons of observations and measurements made on site with established standards, for the purpose of an accurate assessment of personnel operational performance and effectiveness. The complete audit process follows the classical management cycle: planning, organizing, observing, and modifying. End products of an audit include positive identification of process strengths and weaknesses as well as recommendations for improvements.

\subsubsection{Self-Audits}

Self-audits are conducted by members of the group being audited. These audits, which can be conducted on a routine schedule, permit the personnel most closely associated with the operations being audited to step back and examine their work environment. The audits should focus narrowly on one aspect of the group's operations and should cover all of the group's operations within an established frequency. The audit results should be resolved within the group and the audit process documented for management review.

\subsubsection{Internal Audits}

Adequate resources (personnel, facilities, funds) should be committed for planning, development, and implementation of procedures to compare site operations with PSM guidelines. These internal organizational audits of operations should be-

- conducted by groups of personnel who are independent of the operations being audited

- developed around prepared checklists and acceptance criteria for each PSM element

- conducted at facilities on a periodic cycle

- documented, and results reported to site management

The audit findings, observations, and recommendations should be promptly resolved internally.

\subsubsection{Independent Audits}

Adequate site resources should be provided for the support of an outside, independent organization to plan, develop, and implement procedures to compare site operations with PSM guidelines. Contract technical consultants should be adequately qualified and experienced, and headquarters staff personnel should be assigned to assist and oversee contractor activities and results. 


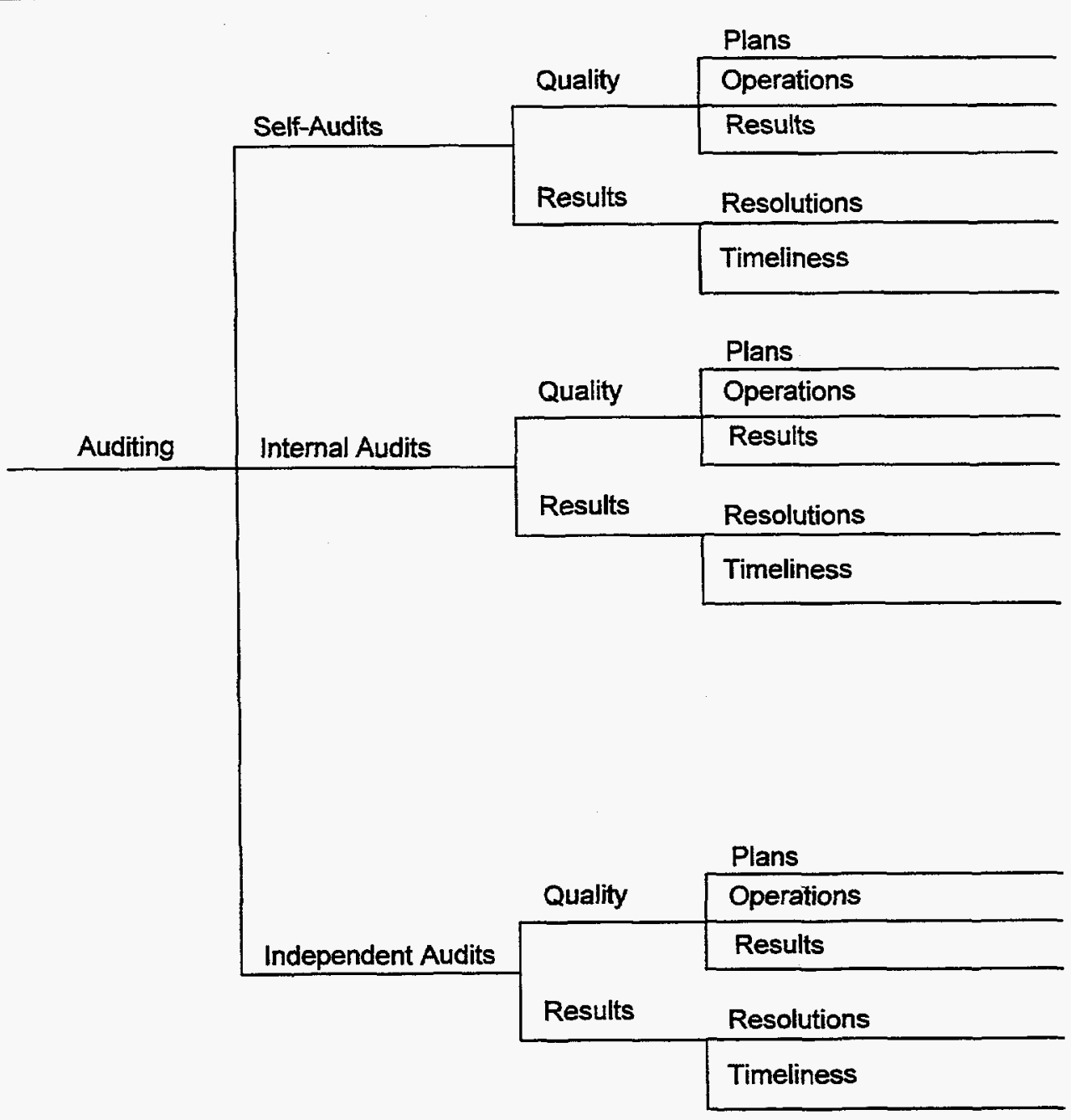

Figure 4-11. Auditing PSM safety subelements 


\subsection{Facilities Safety}

\subsubsection{Facilities Quality Assurance}

\subsubsection{Principles of Safety}

Quality assurance (QA) relative to operational facilities concerns the relationship between the design specifications and the initial operational configuration of the facilities. The QA safety subelements focus on ensuring that process equipment is-

- fabricated in accordance with design specifications

- delivered and assembled at the proper location

- installed and implemented according to the design specification

The PSM safety subelements for facilities QA are shown in Figure 4-12.

\subsubsection{Quality Assurance}

The essential features of the QA safety subelements are as follows.

(1) The design basis and design criteria should be fully documented and communicated to the operations and maintenance personnel as part of the PT package.

(2) The QA program should be developed, documented, and implemented to ensure that key process equipment is fabricated and installed in accordance with the design specifications.

(3) The QA plan should include-

- written quality control procedures
- detailed checks and inspections throughout the fabrication, construction, testing, and initial operations stages

- written event logs detailing the processes followed, the results of the assemblies and fabrications, and special circumstances and/or exceptions that may affect the safety of the equipment or facilities

\subsubsection{Facilities Mechanical Integrity}

\subsubsection{Principles of Safety}

The integrity of the facility should be maintained to ensure safety during its useful life, which ranges from the initial operational configuration through normal operations to final retirement. Mechanical integrity should be maintained by means of-

- $\quad$ proper and regular maintenance procedures

- $\quad$ properly trained maintenance personnel

- $\quad$ sound quality control procedures

- $\quad$ adequate equipment tests and inspections

- reliability engineering analyses and predictions

\subsubsection{Mechanical Integrity}

The essential subelements of the mechanical integrity safety element are shown in Figure 4-13 and include the following-

- Maintenance procedures should be established and implemented on an ongoing basis to ensure mechanical integrity of all process equipment. 
Quality Control Procedures

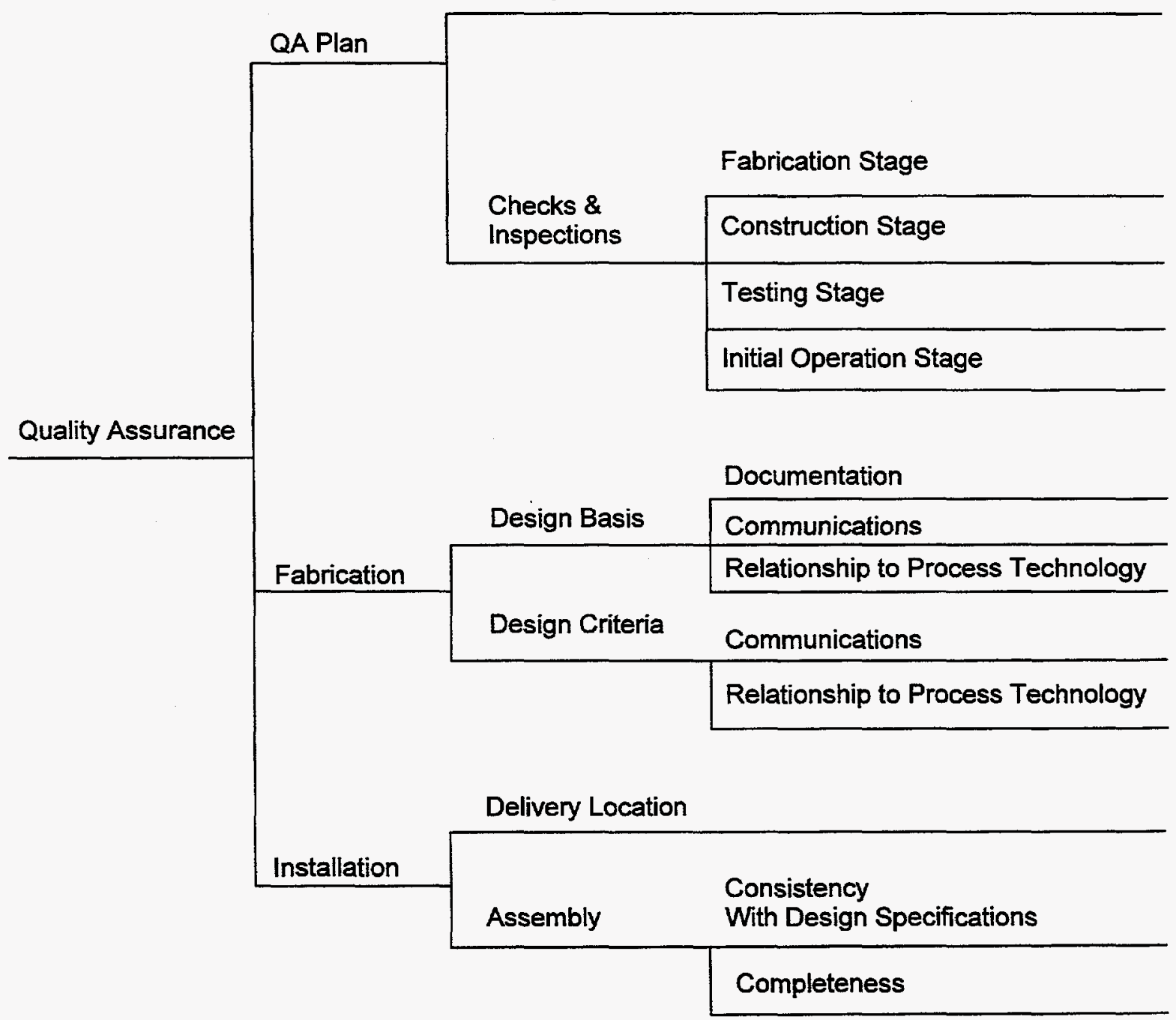

Figure 4-12. Facilities quality assurance safety subelements 


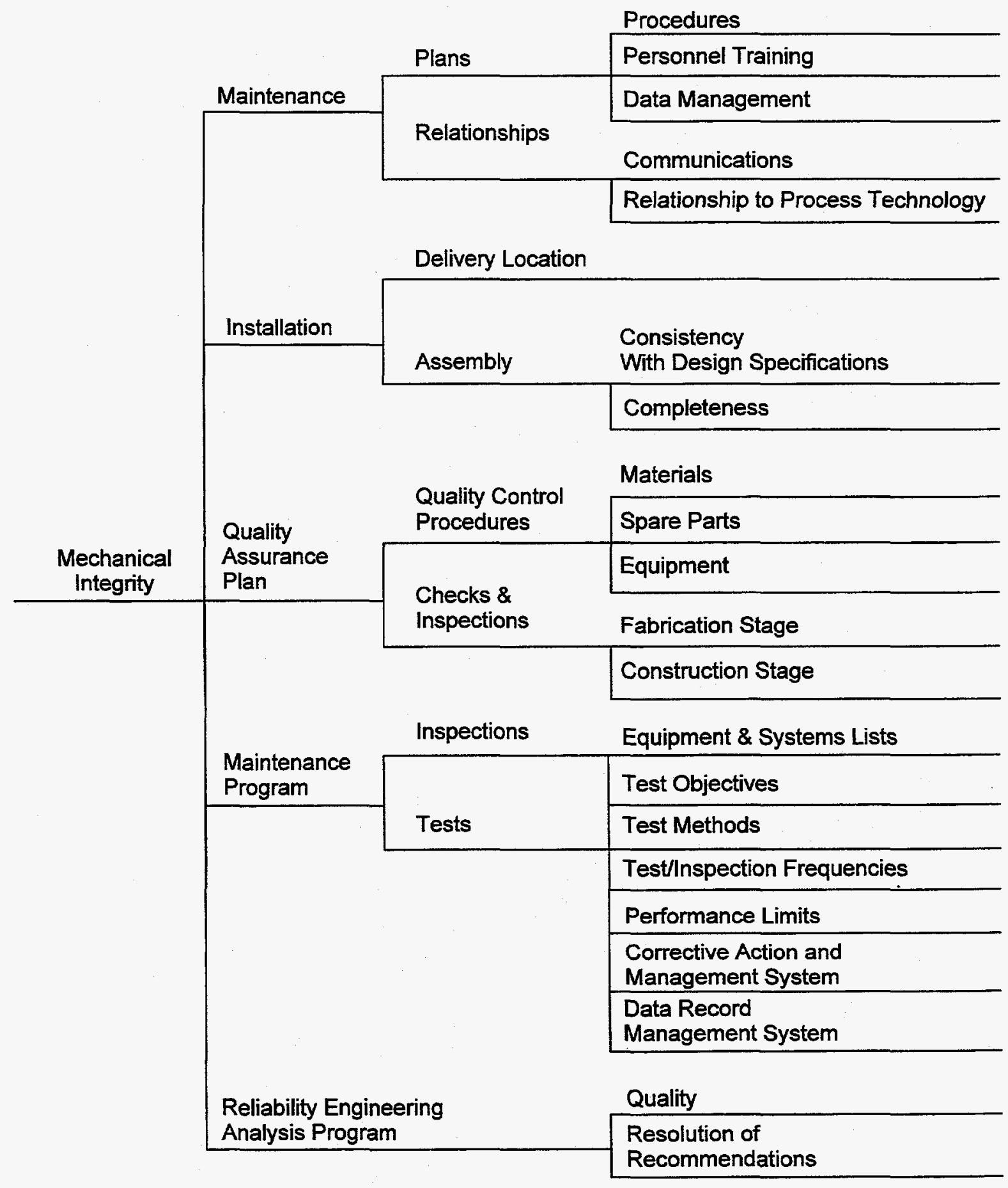

Figure 4-13. Facilities mechanical integrity safety subelements 
- Maintenance personnel should be trained in a manner and at a frequency that is consistent with the principles and procedures of the training and performance safety element.

- Quality control procedures and criteria should be established to ensure that maintenance materials, spare parts, and equipment meet design specifications and safety plan requirements.

- The maintenance program should include the following features-

- complete lists of equipment subject to inspections and tests

- documented test objectives

- documented test methods

- established test frequencies

- established performance limits

- corrective action tracking and management system

- maintenance record-keeping system for data reviews and analysis

- Ongoing reliability engineering analyses should be conducted for all safety-related process equipment and recommendations properly resolved or implemented.

- Outside safety consultants or experts should be used for adequate safety oversight.

\subsubsection{Facilities Pre-Startup Safety Review}

\subsubsection{Principles of Safety}

The pre-startup safety review safety element provides a final checkpoint to verify that all PSM safety issues in new and modified facilities and equipment have been properly and completely addressed. It is an opportunity to be sure that the safety plans and procedures have been adhered to and that the facility and/or equipment is at the same level of safety management as the rest of the operation.

\subsubsection{Safety Review}

Pre-startup safety reviews should be conducted for all new and/or modified facilities and equipment for the following purposes-

- ensure that construction/fabrication complies with the design specifications

- establish that all elements of PSM have been addressed, including-

- process technology

- process hazards analysis

- safety, operating, maintenance, and emergency procedures

- training of operations and maintenance personnel

- establishment of facility mechanical integrity systems

- establishment of configuration management system and change control documentation 
- check basic SHE considerations one last time

The ultimate purpose of the review is to certify that the facility is safe to start up and conforms to design specifications.

Pre-startup reviews are to be carried out by multidisciplinary teams. Their reviews should be fully documented and "signed off" by all review team members. An action tracking and resolution management system is needed to ensure completeness and close out of all issues and recommendations raised.

The facilities pre-startup safety review subelements are shown in Figure 4-14.

\subsubsection{Management of "Subtle" Change}

\subsubsection{Principles of Safety}

Subtle changes are defined as those changes within the documented PT that are not of the identical kind or nature as the original effect producing the change. Examples of such changes include (1) the "subtle" effects of pressure drop changes on process dynamics caused by rerouting a pipeline, (2) the "subtle" emergency response time changes caused by replacing an existing latching mechanism for a new design which, though simple, is unfamiliar to older employees, and (3) the "subtle" changes to an instrument calibration caused by replacement of thermal insulation. The PSM requirements should account for all such modifications and establish appropriate requirements for their implementation, including authorization procedures prior to initiation.

\subsubsection{Management of Subtle Change}

As shown in Figure 4-15, the subelements of the management of subtle change safety element include the following-

(1) Operational sites should establish and implement written procedures for the management of subtle changes.

(2) Site personnel should be educated/trained in regard to process changes, both technology changes and subtle changes, and the systems that have been implemented for their management.

(3) Procedures for the management of subtle changes should include (a) assessment of the SHE considerations and (b) documentation of PSM requirements (including personnel training) prior to implementing such changes.

(4) A change management and tracking system should be instituted to ensure that PSM requirements are completed prior to change implementation and to provide a permanent, documented record of the entire change process. 


\section{Design Basis Comparisons}

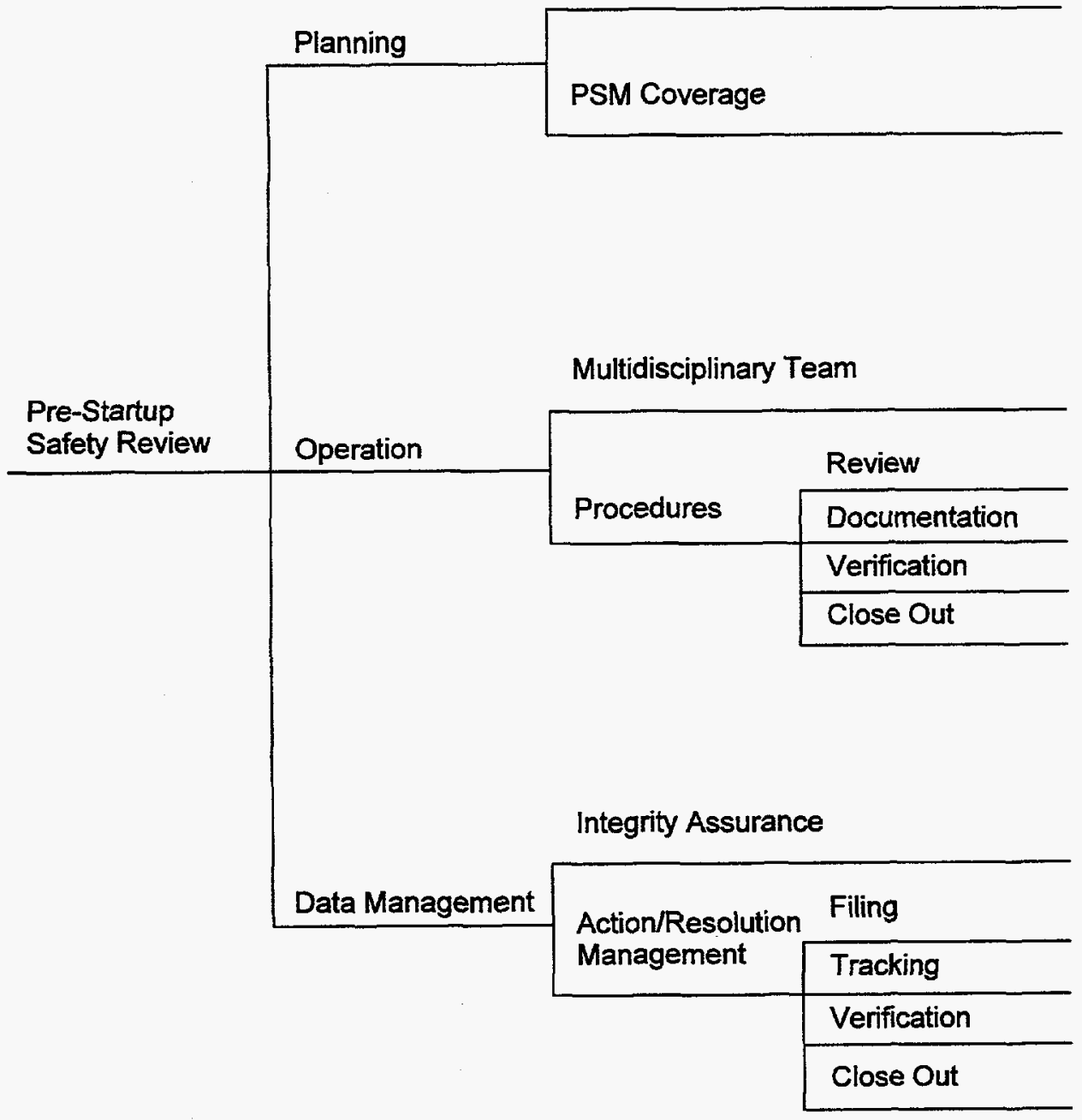

Figure 4-14. Facilities pre-startup safety review subelements 


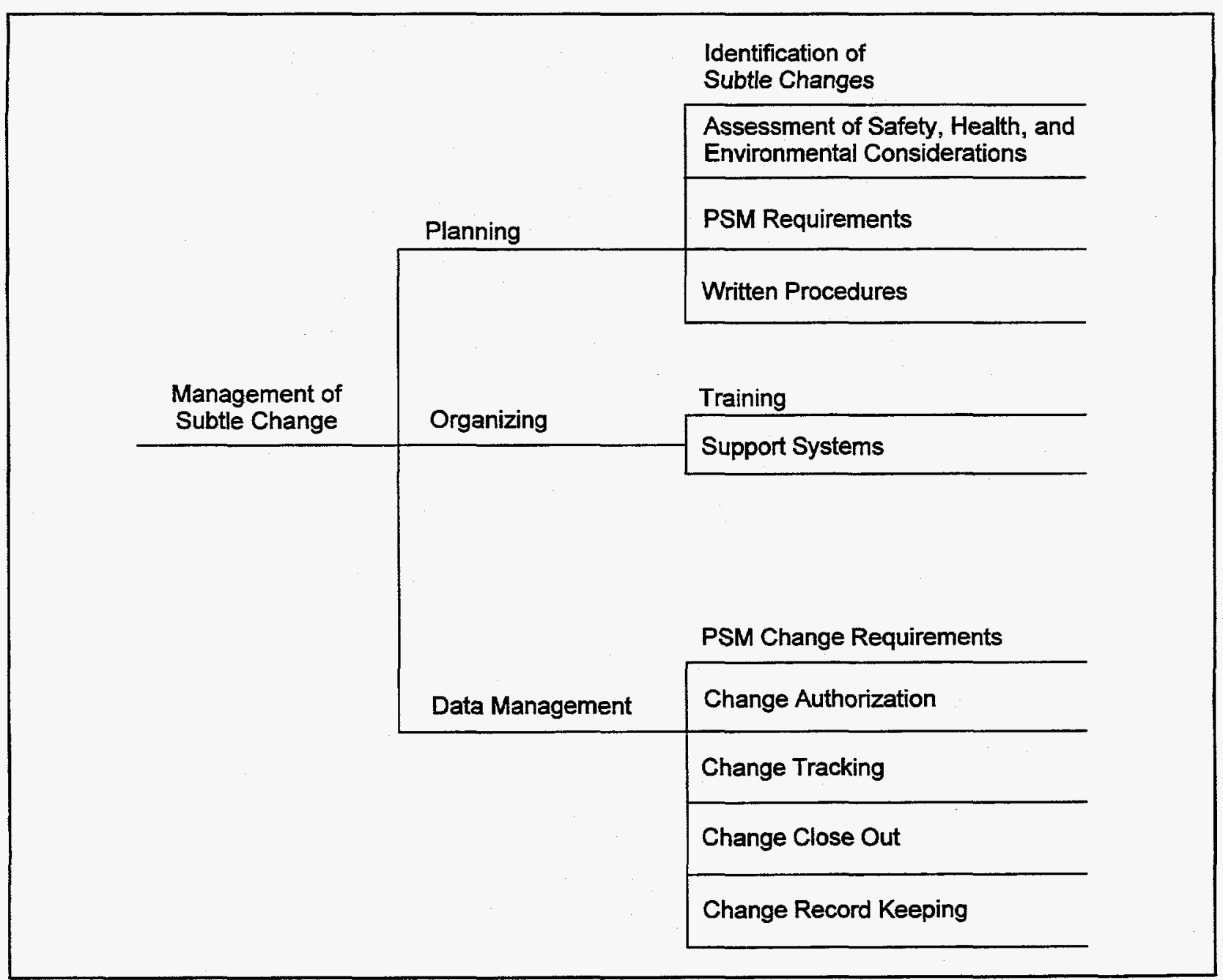

Figure 4-15. Management of subtle change safety subelements 


\subsection{Summary}

This section has covered the PSM safety elements and the issues related to the maintenance of a safe hazardous operation. Continuing analysis of PSM, especially in light of the concept of TQM, has led many hazardous industries to the position that PSM of itself is not adequate for the effective management of safety. Although PSM represents the "letter of the law" in regard to process safety, the "spirit of the law" is represented by more subtle organizational cultural and personnel attitude considerations-the subject of the next section. 


\section{SECTION 5 \\ CORPORATE ISSUES AND CONCERNS IN REGARD TO PROCESS SAFETY MANAGEMENT}

\subsection{Introduction}

Over the last several decades, professionals throughout the world have attempted to develop effective process safety management (PSM) programs in an effort to determine how to better transform safety concepts into safe, workable systems. One important factor not initially recognized by corporations or Government regulatory agencies was that of organizational culture-the beliefs and values accepted by employees and managers working within an organization. Investigation of several of the major recent process safety incidents noted in Section 4 showed that one of the primary contributing factors was related to organizational culture that did not emphasize safety. It is not enough to consider equipment, procedures, systems, and information for effective PSM. The people involved, their beliefs and values, and their relationships to one another and to safety management are also factors to weigh. The purpose of this section is to consider the organizational cultural system in order to permit assessment of a PSM program.

The DuPont Four Step Process Safety Management Program and the Chemical Manufacturers Association (CMA) Responsible Care Program are noteworthy examples of comprehensive PSM programs that have evolved in the last decades. These programs include both the technical and organizational aspects of safety management.

\subsubsection{DuPont Program}

The DuPont program, established in the mid1970 s, recognizes the following organizational factors, in addition to the more technical aspects of safety management-

(1) a solid corporate safety culture

(2) management leadership and commitment

\section{(3) overall business excellence}

DuPont found that safety management must begin with the establishment of a sound safety culture at all levels of the organization. To achieve a sound safety culture, management leadership and commitment are essential. DuPont found that excellence in general corporate program activities had an effect on the safety management program because the entire employee/management team was conscious of the importance of safety to achieving corporate excellence. Moreover, excellence in safety management and in business performance go hand in hand because both are built on employee commitment and dedication and on a team effort between workers and management. Effective assessments of PSM programs, according to the DuPont model outlined in Section 2.8 , should be based on audits and evaluations that involve the technical PSM program as well as these three organizational factors. Much of the discussion in this section follows the DuPont model for business excellence, characterized by the following factors-

- modern technology

- $\quad$ qualified and trained personnel

- $\quad$ reliable and well-maintained equipment

- effective management of change

- regular self-audits and assessments

- emphasis on doing each task right the first time 


\subsubsection{CMA Program}

The CMA Responsible Care Program was launched in the mid-1980s in response to public concern about the manufacture of hazardous chemicals. This program represents a conscious commitment by CMA members to-

- improve performance in safety, health, and environmental (SHE) quality

- listen and respond to public concerns

- assist all other member companies to achieve optimum performance

- report progress to the public

The CMA program establishes a set of codes that all members must follow. Members agree to adhere to specified guiding principles; follow specified management practices; participate in public advisory panels; conduct periodic, comprehensive safety self-evaluations; and monitor and report process safety performance.

\subsubsection{ISO-9000}

Through professional organizations and associations, important activities such as the PSM program find their way into industry standards. Such standards provide significant guidance to Government and industry with respect to both processes and products. As an example, the International Organization for Standardization (ISO) has, since the early 1980 s, been viewed by the United States as increasingly important in the standards-setting process. In 1987, the ISO issued a set of generic standards, the ISO- 9000 series, which deal with quality. The standards, which are being broadly embraced by companies worldwide, provide guidance in setting up quality management systems, which include performance, reliability, and safety. These standards apply to the elements and practice, primarily through documentation, of quality management systems but not to the specific form of implementation. The elements considered in the various ISO-9000 standards are-

- management responsibility

- $\quad$ quality system

- contract review

- design control

- document and control data

- purchasing

- control of customer-supplied product

- $\quad$ product identification and traceability

- process control

- inspection and testing

- control of inspection, measurement, and test equipment

- inspection and test status

- control of nonconforming product

- corrective and preventive action

- handling, storage, packaging, preservation, and delivery

- control of quality records

- internal quality audits

- $\quad$ training

- $\quad$ servicing

- statistical techniques 


\subsubsection{Corporate Culture}

Usually initiated through the actions of leaders within the organizational system, corporate culture is established over a long period of time. Corporate mission and philosophy statements reflect the corporate culture as further refined through specific short-term objectives and operating plans. Corporate culture, then, represents the basic beliefs and values of the organization, which in turn guide all key decisions concerning business direction, resource allocation, quality, and safety. PSM can only succeed in a corporate cultural environment that is dedicated to safety by encouraging managers and employees to promote safety practices and that commits the necessary resources-human, financial, technological, and physical-for safety performance.

In Section 4, PSM technical issues-and the related 14 safety elements-were discussed under the three main categories of Technology, Personnel, and Facilities. In this section, 13 corporate safety elements are classified under three main categories-Safety Culture, Management Leadership and Commitment, and Operating Excellence-and are discussed in conjunction with their associated subelements in the following subsections.

\subsection{Safety Culture}

PSM strongly depends on consistent dedication and commitment by all members of an organization to the principles and practices of handling hazardous materials safely. Personnel "buy-in" throughout all levels of an organization is important for a sound PSM program to succeed. It is this "buy-in" that translates the concept of safety into a safe operation. Safety is an attitude that reflects an organization's core values and basic beliefs, so that as a result safety practices are in a continual state of improvement.

\subsubsection{Corporate Mission, Objectives, and Goals}

A well-written mission statement describes an organization's primary purpose for being in business, as well as its relationship to the community at large. An organization engaged in hazardous processes should have a safety mission statement that describes its purposes in terms of safety-

- $\quad$ safe operations of its facilities

- protection of the employees

- protection of the environment

- protection of the surrounding community

A safety-conscious organization will reflect its concerns for safety in its safety mission statement so these concerns will be effectively factored into its operational and management decisions. The DuPont Company's Safety Mission Statement, as related by Burk (1993), states-

We must adhere to the highest standards for the safe operation of facilities and the protection of the environment, our people and customers, and the citizens of communities in which we do business.

These same concerns should be reflected in an organization's business objectives and in its business targets and goals. True concern for safety and the environment should, therefore, show up in an organization's business plans in the form of clear statements of purpose and intent. Otherwise, business and financial objectives and goals will ultimately force management decisions that support production and profit above safety and environmental concerns. Too great a reliance on cost-benefit analysis can cloud safety concerns.

The subelements that should be considered in a PSM program assessment of the corporate mission safety element are shown in Figure 5-1. 


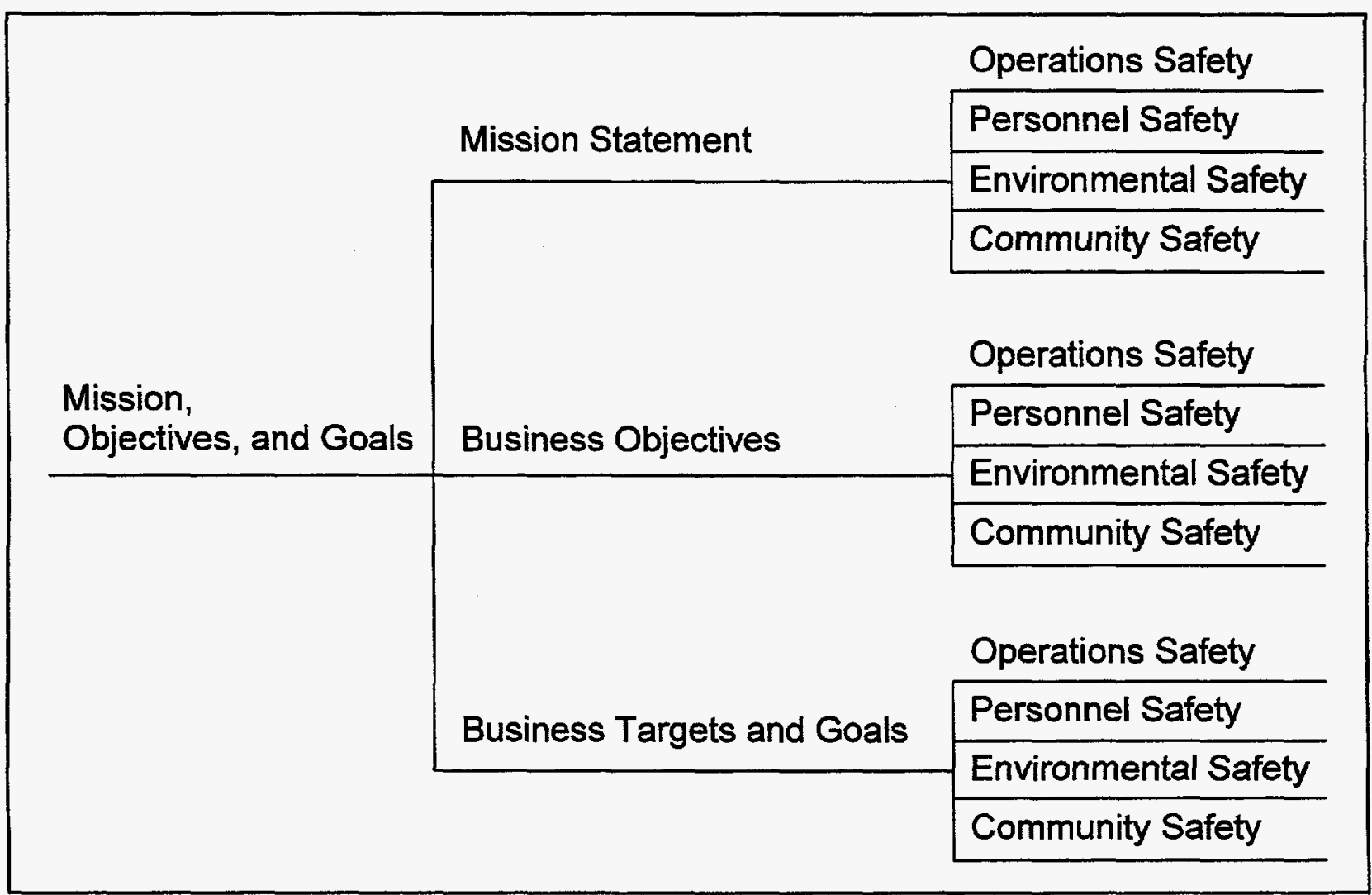

Figure 5-1. Corporate mission safety subelements 


\subsubsection{Safety Philosophy}

An organization's values in regard to safety and the environment are reflected in statements of the organization's safety philosophy. Such statements are the foundation of the corporate culture and reflect the degree of dedication to safety. To be effective, the corporate safety philosophy must deal with all aspects of organizational operations-production, handling, use, sales, transportation, and waste disposal-in terms of safety and environmental concerns. The subelements that should be considered in a PSM program assessment of the corporate philosophy safety element are shown in Figure 5-2.

\subsubsection{Safety Principles}

Organizations should document all aspects of their safety programs in their safety principles. Principles provide guidelines for activities and goals for initiatives. These principles concern every aspect of an operation and spell out what is acceptable and what is not. Safety principles, excerpted from brochures about the CMA Responsible Care Program, are shown in Table 5-1 as an example of a comprehensive set of safety principles developed and refined for use in hazardous chemical industries.

\subsection{Management Leadership and Commitment}

Effective management is the key to a successful PSM program because it is management alone that has the power to provide leadership throughout the organization and to demonstrate meaningful commitment to a safety culture. Leadership in support of the organization's goals and policies should originate with upper management and be delegated down the chain of command through the supervisory chain to positively affect the activities of every individual employee.
Management leadership is demonstrated by management actions that-

- $\quad$ establish appropriate corporate policies and operational guidelines

- commit resources necessary for PSM success

- involve knowledgeable employees in decision-making processes

- establish safety performance accountability measures

- $\quad$ establish system safety compliance measurements and controls

Management commitment is demonstrated by personal dedication, at all levels of management, to the corporate safety culture by means of consistent and visibly supportive activities, and by clear, honest, appropriate communications throughout the organization. The most effective supportive demonstrations by management are activities, because "actions speak louder than words."

\subsubsection{PSM Policies and Guidelines}

The purpose of safety policy is to define the boundaries of appropriate and acceptable activities-what is to be done-within a safety-minded culture. Management guidelines or management directives provide direction for how the policy is to be implemented.

The following issues are of importance to an assessment of the effectiveness of this corporate safety element. 


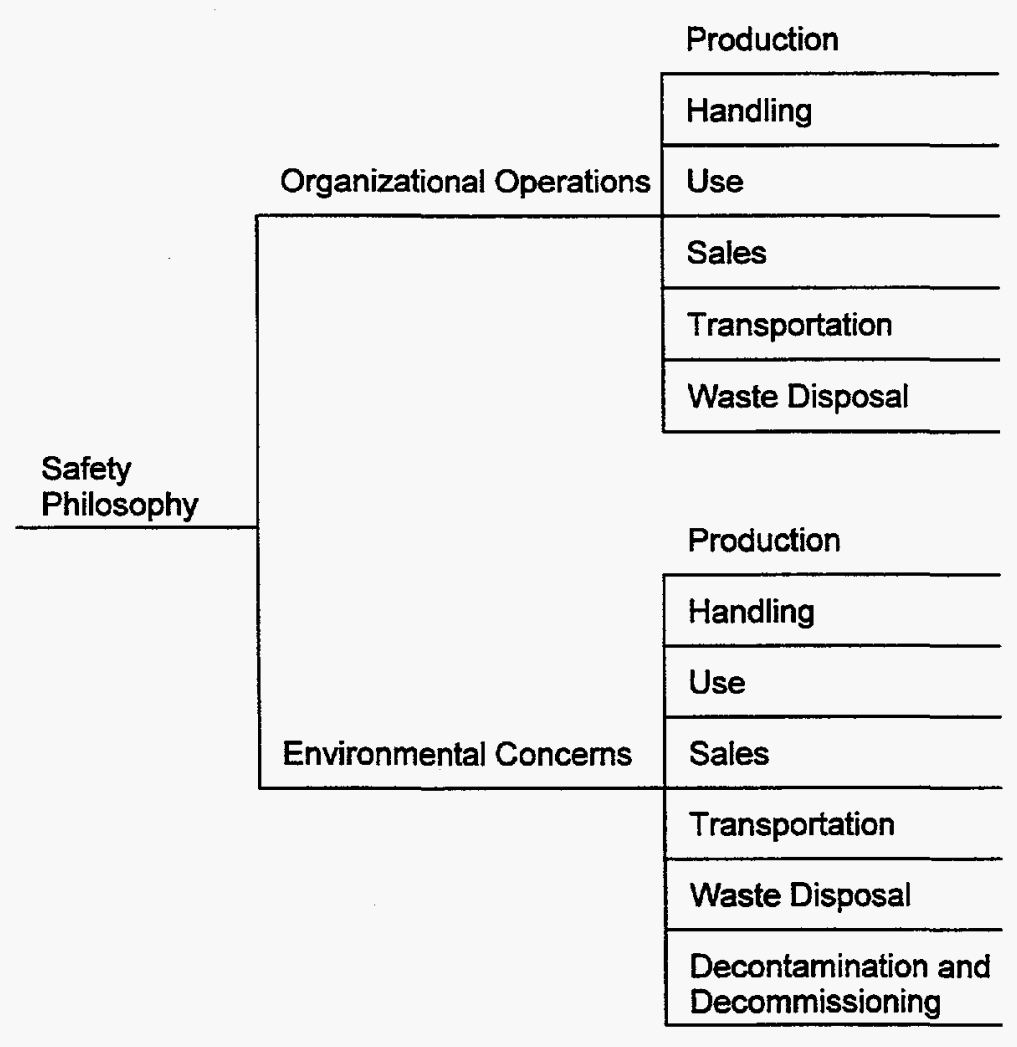

Figure 5-2. Corporate philosophy safety subelements 
Table 5.1 Chemical Manufacturers Association

\section{Safety Principles}

Recognize and respond to community concern about chemicals and our operations.

Develop and produce chemicals that can be manufactured, transported, used, and disposed of safely.

Make health, safety, and environmental considerations a priority in planning for all existing and new products and processes.

Report promptly to employees, officials, customers, and the public information on chemical-related health or environmental hazards and recommend protective actions.

Counsel customers on the safe use, transport, and disposal of chemical products.

Operate plants and facilities in a manner that protects the environment and the health and safety of the employees and the public.

Extend knowledge by conducting or supporting research on the health, safety, and environmental effects of our products, processes, and waste materials.

Work with others to resolve problems created by past handling and disposal of hazardous substances.

Participate with governments and others in creating responsible laws, regulations, and standards to safeguard the community, workplace, and environment.

Promote safety principles and practices by sharing experiences and offering assistance to others who produce, handle, use, transport, or dispose of chemicals for use in hazardous chemical industries. 
- Policies should be developed and implemented to support the corporate safety goals and objectives.

- Policies and guidelines should be clear, direct, and unambiguous.

- Policies and guidelines should be readily available to all who are required to use them.

- Effective management directives or guidelines should be developed and promulgated throughout the organization to favorably affect the safety culture.

\subsubsection{Resource Commitment}

PSM policy and guidance can become effective when properly promulgated throughout the management chain of command and when sufficient resources for implementation are committed. Commitment of human, financial, technical, and physical resources is an essential step toward transforming paper concepts into real, actionoriented programs. In the absence of adequate resources, policy and guidance amount to "lip service."

\subsubsection{Employee Involvement}

The involvement and dedication of every employee is essential for process safety for two reasons.

(1) Safety should be implemented where the action is, that is, at the personal level and with the active involvement of each member of the organization. From a management perspective, this is equivalent to delegating responsibility for safety throughout the organization.
(2) Employees, particularly those working on the shop floor, have unique expertise and hands-on process perspectives that are essential for optimum decisions in regard to the PSM program as well as process performance.

For employees to "buy in" to a PSM safety culture, they must have involvement in-

- $\quad$ process design and implementation decisions

- operations and ongoing maintenance process decisions

- the design and implementation of PSM systems

- corporate performance improvement and performance excellence programs, for both program design and reward receipt

Furthermore, employees must have the authority to stop production without penalty to address a safety concern.

Another aspect important to PSM success is personal participation by management in activities that visibly demonstrate management commitment to PSM and provide opportunities for twoway communications between the employees and management. Such activities include, for example, plant walk-through, use of personal safety equipment, and participation in appropriate safety briefings, classes, or demonstrations.

Effectiveness of this corporate safety element is based on the following-

- Interactions with and feedback from employees into the PSM program should be supported by corporate management mechanisms, such as employee panels, employee advisory groups, and suggestion boxes. 
- Employee "buy-in" for the PSM program should be encouraged and rewarded to support dedication instead of pro-forma participation.

- $\quad$ PSM program effectiveness should be judged from the perspectives of both the employees and the management.

\subsubsection{Performance Accountability}

Effective management of a PSM program depends on accountability of all involved with respect to a system of performance goals. Accountability is essential for effective management and for continuous performance improvements. It should be based on a clear understanding of responsibilities and authority, by both the managers and those being managed. There are at least two levels of performance accountability-

(1) individual (personal) accountability

(2) group or section accountability

The first deals with the assigned responsibilities and management expectations for the individuals within a group or section. The second deals with the assigned responsibilities and management expectations for the functional groups or sections within the organization. While interrelated, individual accountability is the more fundamental because PSM success depends on individual involvement and commitment.

Accountability for performance against specific goals is an important program assessment. The following issues are among those to be considered in making an assessment.

- All individuals throughout the corporation should have clear understanding of their responsibilities in regard to PSM and to process performance improvements.
- Responsibilities and the associated performance goals should accurately reflect management expectations in regard to PSM and process performance improvements.

- Responsibilities should be the outcome of interactions between employees and management.

- Communication of responsibilities should be well documented and available for review by all parties.

Figure 5-3 shows the subelements that should be considered in a PSM program assessment of the performance accountability corporate safety element.

\subsubsection{Performance Verification}

The following important aspects of a PSM program may be directly verified by audit-

- degree of implementation of PSM policies

- degree of implementation of PSM guidelines

- degree of documented achievement of PSM safety goals

- degree of documented achievement of process performance goals

In each case, performance verification should be based on clearly defined performance measurements and predefined verification methods. There are several good management reasons for having this information. Performance information, when it is based on clearly defined measures, supports management control and feedback. Information provided by performance 


\begin{tabular}{|c|c|c|}
\hline \multirow{6}{*}{$\begin{array}{l}\text { Individual and } \\
\text { Section } \\
\text { Performance } \\
\text { Accountability }\end{array}$} & \multirow{2}{*}{$\begin{array}{l}\text { Clear } \\
\text { Responsibilities }\end{array}$} & PSM \\
\hline & & \multirow{2}{*}{$\begin{array}{l}\text { Process } \\
\text { Performance } \\
\end{array}$} \\
\hline & & \\
\hline & \multirow{2}{*}{$\begin{array}{l}\text { Clear Performance } \\
\text { Goals }\end{array}$} & PSM \\
\hline & & \multirow{2}{*}{$\begin{array}{l}\text { Process } \\
\text { Performance }\end{array}$} \\
\hline & \multirow{5}{*}{ Communications } & \\
\hline & & $\begin{array}{l}\text { Interactive } \\
\text { Development }\end{array}$ \\
\hline & & Documentation \\
\hline & & Availability \\
\hline & & Adequacy \\
\hline
\end{tabular}

Figure 5-3. Performance accountability safety subelements 
verification exercises may be used for recognition of good performance or initiation of appropriate corrective actions.

The following issues are important for performance verification-

- Goals and objectives should be clearly defined in terms of parameters that are relevant, available, and measurable.

- Methodologies for measuring comparisons between goals and objectives should be verified to the satisfaction of knowledgeable personnel.

- Action plans for increasing performance verification should be documented and communicated to the appropriate, responsible personnel.

- Performance goals should be reviewed periodically, based on program priorities, to maintain their appropriateness and thus the effectiveness of the performance verification process.

Performance verification can be monitored and communicated by use of performance indicators, which visually display the numerical performance goals and historical performance toward achieving these goals.

The subelements that should be considered in a PSM program assessment of the performance verification corporate safety element are shown in Figure 5-4.

\subsection{Operating Excellence}

There is little doubt that business operating excellence and safety excellence are highly correlated; that is, organizations that succeed in one typically succeed in both. This is because both activities require the same constant dedication and commitment of management and operations personnel. In general, both represent achievements in quality and in carrying out activities the right way, every time. In fact, large successful corporations advertise their pursuit of effective PSM as one important aspect of an overall program to achieve operating excellence.

Modern management models tend to define successful organizations in terms of observable characteristics of managers and employees. Much of the information presented in Sections 2 and 3 bears this out and suggests the following characteristics as being common to successful organizational systems-

- open and active communications throughout the organization

- team spirit uniting management and employees

- common and shared values based on "buyin" at every level

Two other characteristics-(1) doing the job right the first time and (2) modifying behavior to better suit the requirements for excellence-are equally important.

Auditors should, therefore, be alert to shortcomings or omissions in any of these areas. Shortcomings or omissions could mean that the program is not grounded in the type of corporate culture necessary for excellence and may, therefore, be subject to unwanted accidents or incidents. 


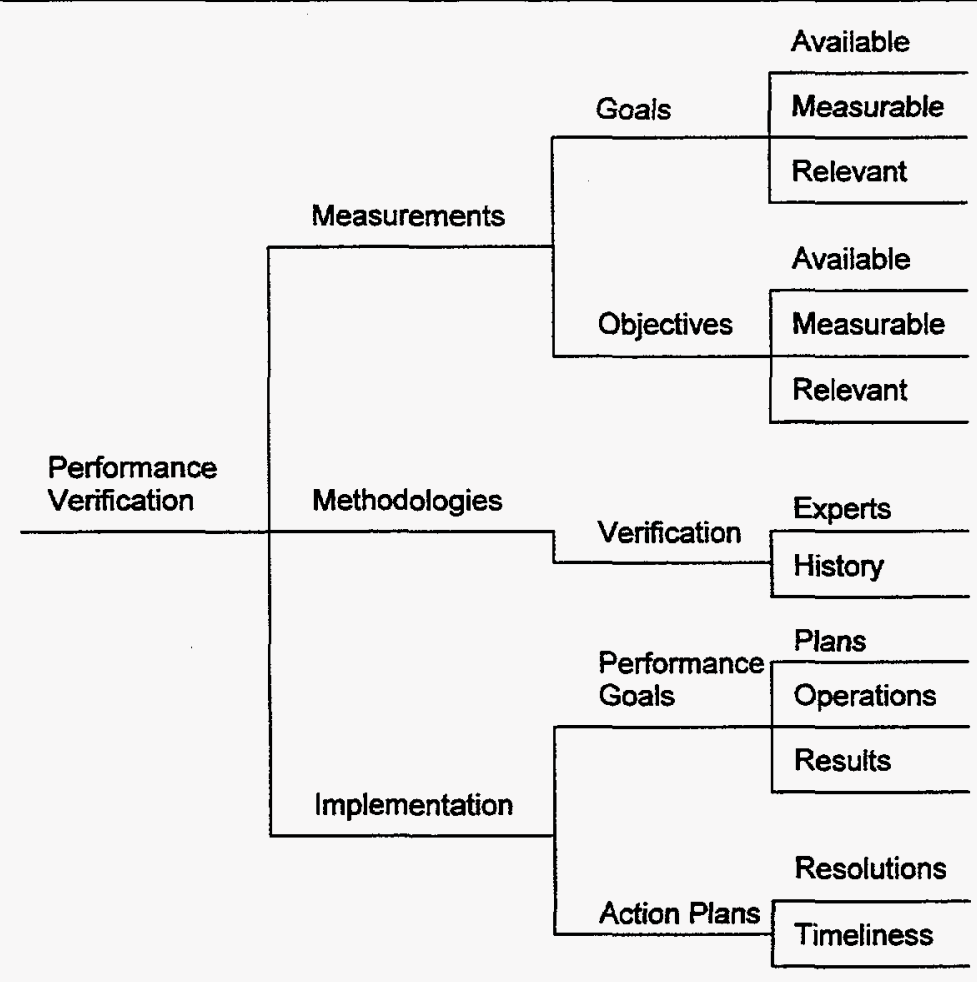

Figure 5-4. Performance verification safety subelements 


\subsubsection{Open Communications}

Communication is fundamental to human interactions and especially to interactions necessary for PSM program effectiveness and the assessment of the program by auditors. A PSM program without open, multidimensional and bidirectional communications among employees and managers is at least handicapped, and probably flawed. Openness is a characteristic of trusting relationships among individuals who respect one another and who value contributions of others. Bidirectional communications involve information flow both up and down the management chains of command, from management to employees and from employees to management. Factors that are indicative of such communications within a corporation include-

- $\quad$ high trust level

- friendly, respectful, professional relationships

- personal interactions between employees and management

- management mechanisms for communications, such as open door policy, suggestion boxes, regular participative staff meetings, and plant walk-throughs

- communications channels-types and frequencies

The subelements that should be considered in a PSM program assessment of the open communications corporate safety element are shown in Figure 5-5.

\subsubsection{Teamwork}

Teamwork is difficult to describe accurately, but easy to recognize. It is a state of harmony and cooperation that exists within and among individuals and is characterized by-

- a sense of being an important part of something of value, something bigger than each individual

- intrinsic value of each individual, each member of the team

- consistent dedication of each member to the greater whole

- commitment of each member to what is good for the whole

- $\quad$ sincere respect, personal concern, and a willingness to support one another both professionally and personally

- a sense of friendship among the members

Winning teams have these characteristics; losing teams, in general, do not. Organizations that have achieved, and continue to achieve, operational excellence and PSM effectiveness have teamwork. It is, therefore, logical and reasonable to include an assessment of organizational teamwork as an element of PSM program assessment. 


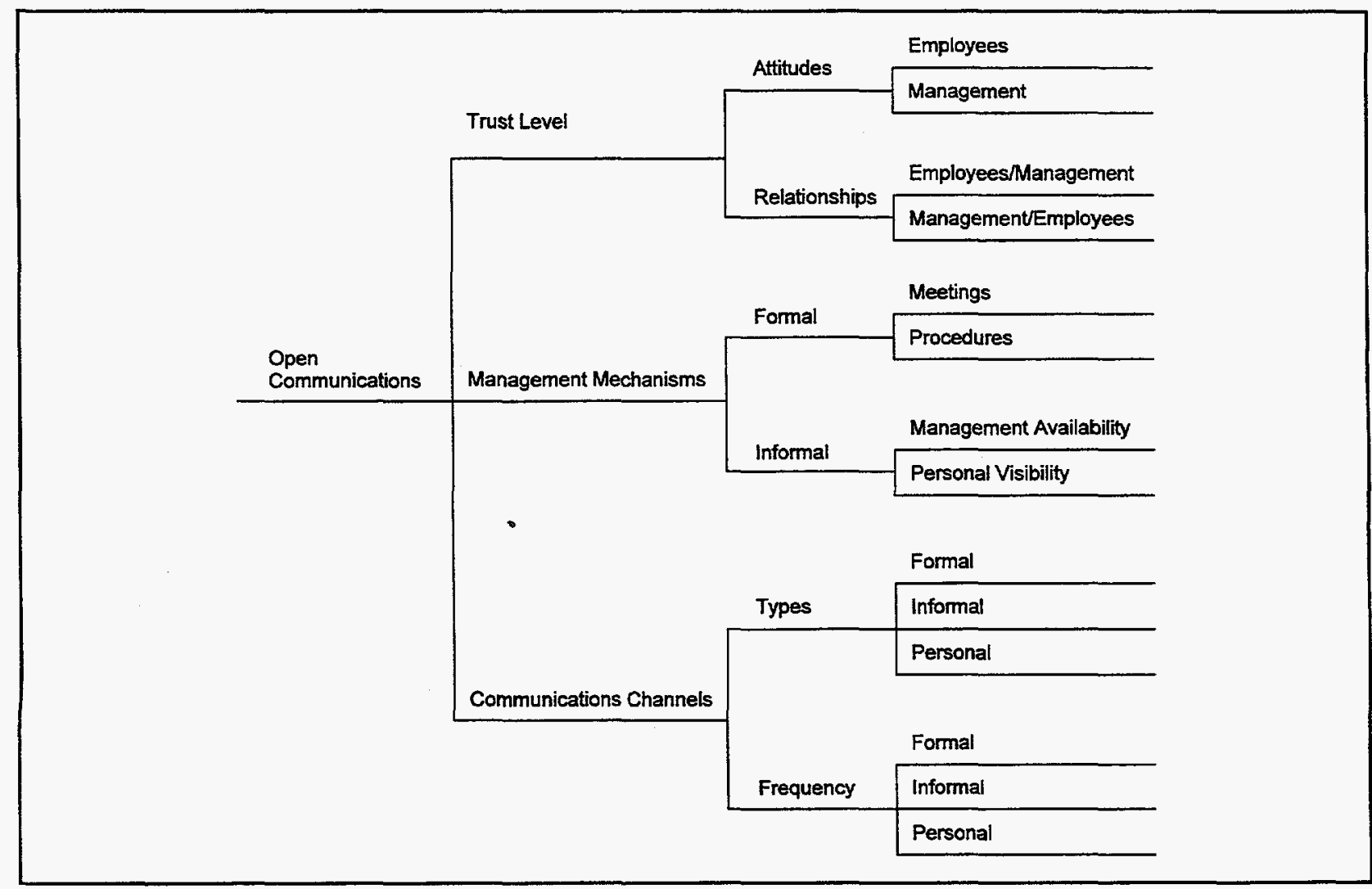

Figure 5-5. Open communications subelements 
Figure 5-6 shows the subelements that should be considered in a PSM program assessment of the teamwork corporate safety element.

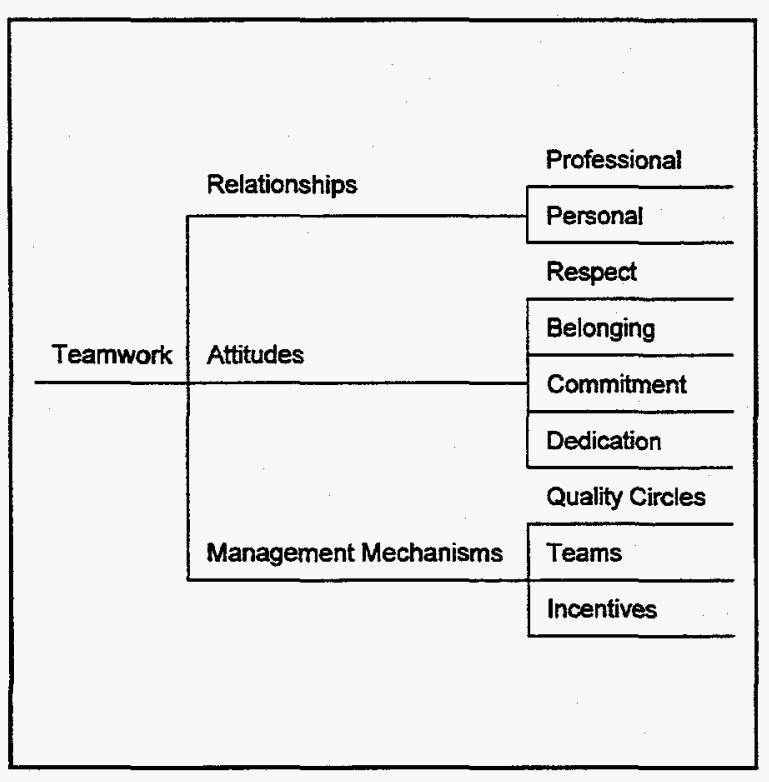

Figure 5-6. Teamwork subelements

\subsubsection{Common Shared Values}

Teamwork and integrated operations are necessary for operations excellence and for PSM effectiveness. In a team environment, adversarial relationships between operations personnel and management are replaced by cooperation and mutual support for a common cause. This is only possible if all parties share the same beliefs and values, the same dedication to the organization, to the operation and its excellence, and to the PSM safety program and its effectiveness. With a common shared set of values, individuals do what they think is best for the organization because they have "bought in" rather than because they have merely been directed to do so. Common shared values, therefore, represent an essential aspect of teamwork-a key factor in regard to a PSM effectiveness assessment.
It is difficult, however, to measure personal or group values directly. Most measurement schemes and psychological tests are based on inference rather than direct information, on choices and long-term observable behavior rather than simple testimonies. This is because what people say and really believe are often at odds. What people actually do and how they perform more often reflect real inner values and beliefs. For the purposes of PSM program assessment, this corporate safety element should be evaluated indirectly by studying the corporate culture and by identifying corporate policies and procedures designed to cultivate common shared values. These are shown in Figure 5-7, which depicts the subelements that should be considered in a PSM program assessment of the common shared values corporate safety element.

\subsubsection{Doing the Job Right the First Time}

The principles of TQM advocate the practice of doing a job right the first time. To accomplish this feat, personnel should be trained and properly equipped. Following the simple and rational concepts of TQM, many organizations have been able to realize very significant gains in process efficiency and product quality. The very same concepts, of course, apply to PSM. From the perspective of a PSM assessment, the challenge is to identify the corporate attitude in regard to quality and productivity. Corporations that are willing to cut corners to increase productivity or profit can be expected to do the same when it comes to safety. The key measures of the corporate attitudes in regard to quality and profit are built into its policies, practices, and training programs.

The following questions help illuminate the corporate attitude-

- What happens if a job is suddenly discovered to be wrong and making it right nega- 


\begin{tabular}{|c|c|c|}
\hline \multirow{5}{*}{$\begin{array}{l}\text { Common } \\
\text { Shared } \\
\text { Values }\end{array}$} & \multirow{2}{*}{$\begin{array}{l}\text { Behavior/ } \\
\text { Attitudes }\end{array}$} & Operations Personnel \\
\hline & & Management \\
\hline & \multirow{3}{*}{$\begin{array}{l}\text { Commitment } \\
\text { to Quality }\end{array}$} & Personnel Attitudes \\
\hline & & Historical Records \\
\hline & & Performance \\
\hline & \multirow{3}{*}{$\begin{array}{l}\text { Management } \\
\text { Mechanisms }\end{array}$} & Training Programs \\
\hline & & Incentive/Awards Programs \\
\hline & & Communications Channels \\
\hline & & Corporate Policy and Principles \\
\hline
\end{tabular}

Figure 5-7. Common shared values subelements 
tively affects profit or productivity measures?

- What are the corporate policies in regard to procedures and quality, especially as related to safety or the environment?

- Are there corporate records of jobs that have been stopped and processes that have been shut down in order to "do the job right"?

- What about "corner cutting"? Are personnel discouraged or even fired for following the quickest versus the safest procedure to get a job done?

- What are the corporate policies in regard to "short cuts"?

- Are there corporate records of personnel dismissals or other condemnations resulting from "corner cutting"?

- How, if at all, are these issues treated in the corporate training programs?

The answers to these questions, which can be found in corporate documents and discovered in conversations with operational personnel and management, reveal the corporate attitude concerning "doing the right job, the right way." The subelements that should be considered in a PSM program assessment of this corporate safety element are shown in Figure 5-8.

\subsubsection{Behavior Modification}

Achieving operating excellence and PSM effectiveness requires modification of behavior within an organization. The evolution of behavior is a subject of great importance, which is covered by some modern management and organizational models described in Sections 2 and 3. It is impossible to remain in the "winners circle" or

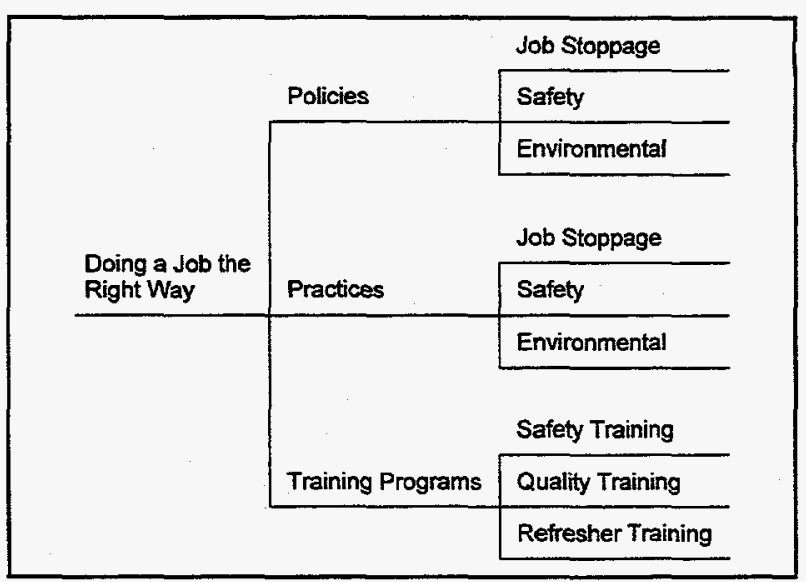

\section{Figure 5-8. Doing the job the right way subelements}

to maintain operational excellence or PSM effectiveness without changes in the way personnel operate in carrying out their jobs or in the way corporate management carries out its functions to achieve its goals and objectives. Technology, management theories, human behavioral models, and human relationships are all changing too fast and too significantly to be able to use today's solutions on tomorrow's problems. It is important to note that behavior can be changed if the affected personnel understand the changes desired and the expected benefits to themselves, their jobs, and the corporation.

There are many mechanisms for modifying behavior within the corporate environment. The challenge before a PSM assessment is to identify the change mechanisms being employed and to judge their effectiveness in regard to maintaining PSM effectiveness.

The subelements that should be considered in the behavior modification safety element are shown in Figure 5-9. 


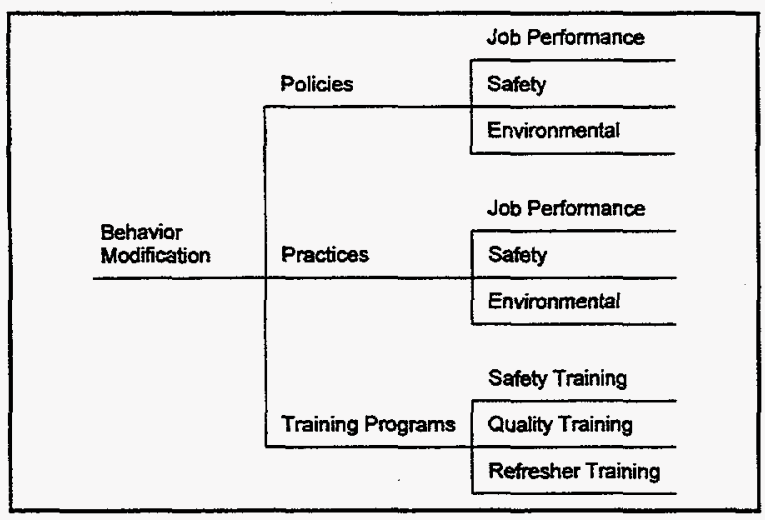

Figure 5-9. Behavior modification subelements

\subsection{Summary}

A key concept of this section-the belief that organizations that are successful in achieving overall business excellence typically also achieve PSM effectiveness-is supported by the exam- ples of many modern corporations engaged in hazardous processes or in the production of hazardous materials. As has been discussed in Sections 4 and 5, the common thread running through these successful organizations, and the many different activities they represent, is characterized by the following factors-

- use of modern technology

- $\quad$ qualified and trained personnel

- reliable and well-maintained equipment

- effective management of change, especially behavior

- effective regular self-audits and assessments

- emphasis on doing each task right, the first time

The implications for PSM assessments are simply that the organizations with the most credible safety management plans will most likely be those that strive for outstanding performance in every aspect of business and operations. 


\section{SECTION 6 EFFECTIVENESS OF MANAGEMENT CONTROL}

\subsection{Introduction}

The previous sections have reviewed modern management control theories, explored general management functions, and examined both program-level technical matters and corporatelevel safety issues. These have represented the foundation for consideration of a more formalized structure for assessing the overall effectiveness of management control of safety. This section suggests a structure for answering the following question-

How can one evaluate, in a formal and structured manner, the effectiveness of management control of safety?

This question is answered using the safety elements presented in previous sections. These elements have been arranged in two matrices - the corporate-level evaluation matrix and the PSM program-level evaluation matrix.

\subsection{Corporate-Level Evaluation Matrix}

In Section 3, five general management functions were discussed-

- planning

- organizing

- directing

- monitoring

- integrating

As these functions are implemented and exercised, management gains control over an area of particular significance to the organization. In the aggregate, these five functions cover the full range of activities necessary to exercise appropriate management control. Therefore, they represent key areas on which to focus attention.
In addition, 13 key safety elements at the corporate-organization level are important to achieving a successful safety program. Delineated in Section 5 under the three broad categories of safety culture, management leadership and commitment, and operating excellence, these key elements, and their subordinate subelements, are considered a type of "industry standard," which has evolved in attempting to understand the top-level issues in an organization that affect safety.

Together, the general management functions and key safety elements represent two important dimensions of the problem of controlling safety in an organization. On that basis, the two dimensions can be "mapped" against one another in a formal evaluation structure, as shown in Figure 6-1. This figure shows the five general management control functions as columns of a matrix and the 13 key safety elements, arranged by the three broad categories noted above, as the rows of the matrix. The matrix thus defines 65 cells. Each cell represents an area to investigate and analyze whether management is effective in controlling safety. Because these safety issues are defined at the broad corporate level, this matrix is called the corporate-level evaluation matrix.

\subsection{Process Safety Management Program-Level Evaluation Matrix}

Using a rationale that is analogous to that described in Section 6.2, it is also possible to map the five general management functions against the key safety issues at the PSM program level as defined in Section 4. This mapping is illustrated in Figure 6-2 in which the five management control functions are shown as the columns and the 14 PSM safety elements are listed as the rows, under the three categories of technology, personnel, and facilities. 


\begin{tabular}{|c|c|c|c|c|c|c|c|}
\hline & & \multirow[b]{2}{*}{$\begin{array}{l}\text { SAFETY } \\
\text { ELEMENTS }\end{array}$} & \multicolumn{5}{|c|}{ MANAGEMENT CONTROL FUNCTIONS } \\
\hline & & & 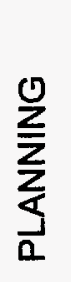 & 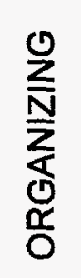 & 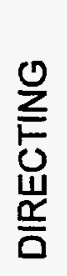 & 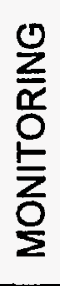 & 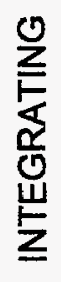 \\
\hline \multirow{13}{*}{ 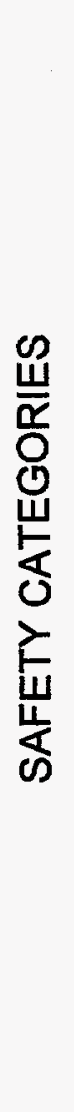 } & \multirow{3}{*}{ 岂崫 } & Mission & & & & & \\
\hline & & Philosphy & & & & & \\
\hline & & Principles & & & & & \\
\hline & \multirow{5}{*}{ 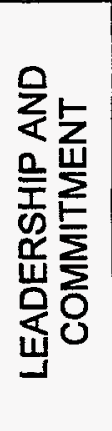 } & $\begin{array}{l}\text { PSM Policies and } \\
\text { Guidelines }\end{array}$ & & & & & \\
\hline & & Resource Commitment & & & & & \\
\hline & & Employee Involvement & & & & & \\
\hline & & $\begin{array}{l}\text { Performance } \\
\text { Accountability }\end{array}$ & & & & & \\
\hline & & Performance Verification & & & & & \\
\hline & \multirow{5}{*}{ 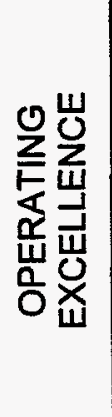 } & Open Communications & & & & & \\
\hline & & Teamwork & & & & & \\
\hline & & Common Shared Values & & & & & \\
\hline & & $\begin{array}{l}\text { Do the Job the } \\
\text { Right Way }\end{array}$ & & & & & \\
\hline & & Behavior Modification & & & & & \\
\hline
\end{tabular}

Figure 6-1. Corporate-level evaluation matrix 
The rationale for the breakdown into 14 safety elements was provided in Section 4. The resultant matrix has 70 cells, each cell representing an area in which to analyze whether management is addressing key PSM safety issues. This matrix is called the PSM program-level evaluation matrix.

\subsection{Effectiveness Evaluations}

The matrices in Figures 6-1 and 6-2 provide a means to deal with effectiveness evaluations in an organized manner. That is, by examining the combined 135 cells in these matrices, it is possible to develop procedures for assessing the effectiveness of management control of safety. The auditor carries out the evaluation by answering questions that highlight the attributes of each cell. The answers to the questions should be recorded as "adequate" or "inadequate." After addressing each of the questions, the auditor is able to make an overall judgment of how well or how poorly the organization is performing its safety responsibilities.

Tables 6-1 through 6-13 present a series of questions for each of the cells in the corporate-level evaluation matrix. The questions that address the cells in the PSM program-level evaluation matrix appear in Tables 6-14 through 6-27. The table titles distinguish the broad category in which a particular safety element is grouped. The questions in each table address the five cells in an entire row of the matrix. For example, Table 6-1 (Corporate Safety Culture/Mission) presents 18 questions to help determine the adequacy or inadequacy of the corporate mission in relation to the five management control functions.

The questions presented here are only suggestions and are subject to refinement. It is possible to delve more deeply into each of the cells in the evaluations and develop additional questions based on detailed assessments of a variety of subelements for each safety issue. Examples of such subelements were described in Section 4, which dealt with PSM program-level safety issues, and Section 5, which dealt with corporatelevel safety issues. However, to provide consistency in the assessments of differing organizations, it is recommended that a common set of questions be used to examine all organizations.

It is further recommended that the matrix structure of mapping management control functions against safety issues be maintained as the overall perspective in order to examine safety control issues in an organized and structured manner.

In assessing an organization, the auditor may determine that the organization contains a flaw that is so significant that this specific flaw surpasses all other considerations. This consideration then constitutes a critical flaw-one so serious that the organization cannot be permitted to continue operations without significant redirection. Such an event requires immediate top management attention. 


\begin{tabular}{|c|c|c|c|c|c|c|c|}
\hline & & \multirow[b]{2}{*}{$\begin{array}{l}\text { SAFETY } \\
\text { ELEMENTS }\end{array}$} & \multicolumn{5}{|c|}{ MANAGEMENT CONTROL FUNCTIONS } \\
\hline & & & $\frac{0}{\sum_{0}}$ & 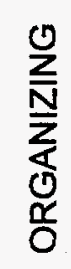 & 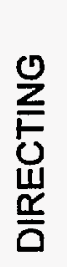 & 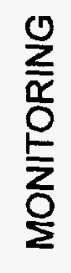 & $\begin{array}{l}0 \\
\geqq \\
\underline{E} \\
\frac{\mathbb{s}}{0} \\
\underline{W} \\
\underline{E}\end{array}$ \\
\hline \multirow{14}{*}{ 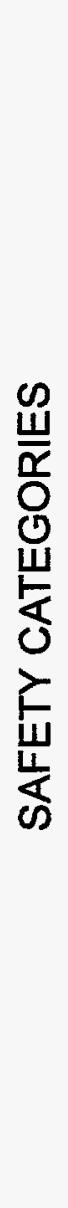 } & \multirow{4}{*}{ 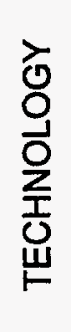 } & Process Technology & & & & & \\
\hline & & $\begin{array}{l}\text { Process Hazards } \\
\text { Analysis }\end{array}$ & & & & & \\
\hline & & $\begin{array}{l}\text { Operating Procedures } \\
\text { and Safe Work Practices }\end{array}$ & & & & & \\
\hline & & $\begin{array}{l}\text { Management of } \\
\text { Change (Technology) }\end{array}$ & & & & & \\
\hline & \multirow{6}{*}{ 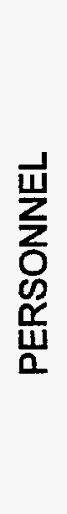 } & $\begin{array}{l}\text { Training and } \\
\text { Performance }\end{array}$ & & & & & \\
\hline & & $\begin{array}{l}\text { Contractor Safety } \\
\text { and Performance }\end{array}$ & & & & & \\
\hline & & $\begin{array}{l}\text { Management of } \\
\text { Change (Personnel) }\end{array}$ & & & & & \\
\hline & & $\begin{array}{l}\text { Incident Investigation } \\
\text { and Communication }\end{array}$ & & & & & \\
\hline & & $\begin{array}{l}\text { Emergency Planning } \\
\text { and Response }\end{array}$ & & & & & \\
\hline & & Auditing & & & & & \\
\hline & \multirow{4}{*}{$\begin{array}{l}\text { 出 } \\
\text { E } \\
\underset{\bar{\Xi}}{\mathbb{4}}\end{array}$} & Quality Assurance & & & & & \\
\hline & & Mechanical Integrity & & & & & \\
\hline & & \begin{tabular}{|l} 
Pre-Startup \\
Safety Review
\end{tabular} & & & & & \\
\hline & & $\begin{array}{l}\text { Management of } \\
\text { "Subtle" Change }\end{array}$ & & & & & \\
\hline
\end{tabular}

Figure 6-2. Process safety management program-level evaluation matrix 
Table 6-1. Corporate safety culture/mission

Planning

Organizing

Directing

Monitoring

1. Is the safety mission vested in the facility manager or higher?

2. Can each facility manager explain how he or she is organized for the safety mission?

3. Has the organization made it clear who is responsible for safety?

4. Has the organization made it clear who is responsible for environmental compatibility?

1. Does top management reiterate the corporate safety mission at least once a year?

2. Does the facility manager restate in writing the safety mission, goals, and objectives?

3. Is the corporate safety mission visible at the individual project implementation level?

4. Does the company regularly train employees with respect to its safety mission?

1. Is the company measuring safety status against mission goals?

2. Is safety part of the company's routine measurement process?

3. Does the company insist on measurement of safety at all levels in the organization?

4. Are safety trends being generated and analyzed?

Integrating 1. Is the safety mission supported by information systems?

2. Do these information systems appear to be operative and effective?

3. Are the information systems being improved in relation to changing needs? 
Table 6-2. Corporate safety culture/philosophy

Planning

Organizing

Directing

Monitoring

Integrating
1. Is the corporate safety philosophy stated clearly?

2. Is the safety philosophy environmentally sound?

3. Do project plans deal with both safety and environment?

1. Does the organization chart support the corporate safety philosophy?

2. Does the organization chart support the corporate environmental philosophy?

3. Is a group responsible for defining, updating, and promulgating a coherent safety philosophy?

4. Is there a group or person responsible for defining, updating, and promulgating a coherent environmental philosophy?

1. Does top management reiterate the corporate safety philosophy at regular intervals?

2. Do facility managers appear to know and follow the corporate safety philosophy through concrete actions and programs?

3. Is the corporate safety philosophy visible at the individual project implementation level?

4. Are management actions consistently congruent with the corporate philosophy?

1. Does management check to see if the company's safety philosophy is understood?

2. Does the company attempt to ferret out unsafe practices?

3. Does the company measure poor environmental practices?

4. Are personnel at all levels of supervision activists in terms of measuring safety and environmental compatibility?

1. Are information systems clearly a part of the company philosophy regarding safety matters?

2. Does the company philosophy concerning safety appear to convey an integrated approach?

3. Does the company philosophy appear to embrace integrated product and/or process teams?

4. Does the company clearly view safety and environment as parts of a larger system? 


\section{Table 6-3. Corporate safety culture/principles}

Planning

Organizing

Directing

Monitoring

Integrating
1. Are sound safety principles described in the company plans?

2. Are sound safety principles documented in the company's procedures?

3. Do project plans contain sound safety principles?

1. Are responsibilities for injuries and illnesses clear?

2. Is authority for corrective action clear?

3. Does top management appear to be committed to safety?

4. Is responsibility for continuous safety training clear and definitive?

1. Are deficiencies reported promptly?

2. Are deficiencies appropriately investigated?

3. Are deficiencies promptly corrected?

4. Is top management kept apprised of deficiencies and corrective actions?

1. Is deficiency status monitored?

2. Is illness and injury status monitored?

3. Are safety audits conducted?

4. Are the safety audits carried out frequently enough?

1. Is one of the principles of the safety program that a "systems" approach and perspective be maintained?

2. Is one of the principles that information systems are necessary in order to control safety levels?

3. Do the principles include the interaction between safety and environmental considerations?

4. Are integrated product and process teams suggested by the company's principles? 
Table 6-4. Corporate leadership and commitment/PSM policies and guidelines

Planning

1. Are PSM policies and guidelines documented?

2. Are PSM policies and guidelines basically sound with respect to safety?

3. Are PSM policies and guidelines basically sound with respect to environmental matters?

4. Are PSM policies and guidelines basically complete in their coverage?

Organizing 1. Is it clear as to who is responsible for PSM policies and guidelines?

2. Are responsibilities spelled out in the PSM policies and guidelines?

3. Are authority levels (i.e., chains of command) identified in the PSM policies and guidelines?

4. Do responsible parties have the authority and resources necessary to ensure proper execution of the PSM policies and guidelines?

Directing

1. Are PSM policies and guidelines distributed to all personnel?

2. Are personnel trained with respect to execution of PSM policies and guidelines?

3. Are there any penalties associated with consistent failure to comply with PSM policies and guidelines?

4. Are these penalties actually implemented?

Monitoring

1. Does management check on adherence to PSM policies and guidelines?

2. Are the management checks sufficiently frequent?

3. Do all the staff know that compliance with PSM policies and guidelines is monitored?

4. Are compliance profiles developed in a quantitative manner?

Integrating

1. Are the PSM policies and guidelines written so the PSM program is seen as an integrated whole?

2. Are information systems an important part of the PSM policies and guidelines?

3. Do the PSM policies and guidelines contain information regarding integrated product and/or process teams?

4. Do the training programs cited in the PSM policies and guidelines make safety information an integral part of the company's business? 
Table 6-5. Corporate leadership and commitment/resource commitment

Planning

Organizing

Directing

Monitoring

Integrating
1. Do corporate plans contain specific resource commitments?

2. Do facility managers' plans contain specific resource commitments?

3. Do individual project plans contain resource commitments?

4. Do resource commitments in plans appear to be sufficient?

1. Are sufficient personnel assigned to safety matters?

2. Are sufficient personnel assigned to environmental matters?

3. Are sufficient personnel assigned to injury and iliness problems?

4. Are other resources (e.g., facilities, equipment) sufficient to handle safety and environmental concerns?

1. Are sufficient personnel actually working on safety matters?

2. Are sufficient personnel actually working on environmental matters?

3. Are sufficient facilities and equipment actually employed in safety matters?

4. Are sufficient facilities and equipment actually used to deal with environmental matters?

1. Are records kept on trends regarding commitment of resources to safety matters?

2. Are records kept on trends regarding commitment of resources to environmental matters?

3. Are there periodic meetings to measure levels of resource commitment?

4. Are these meetings held frequently enough?

1. Are resource commitments made to safety activities as part of the overall resource commitments of the company?

2. Are appropriate resource commitments made to providing the necessary information systems to support safety matters?

3. Does safety appear to be a company priority as indicated by the commitment of resources to its execution?

4. Do environmental matters appear to be a company priority as suggested by the commitment of resources to them? 
Table 6-6. Corporate leadership and commitment/employee involvement

Planning

Organizing

Directing

Monitoring

Integrating
1. Do corporate plans deal with employee empowerment for safety?

2. Do the facility managers' plans deal with employee empowerment for safety?

3. Do project plans deal with employee empowerment for safety?

4. Do plans indicate the role of integrated cross-functional teams?

1. Are all levels in the organization involved in achieving corporate goals and objectives?

2. Are suggestion boxes utilized to obtain employee ideas and inputs?

3. Does the organizational development strategy include participative management skills?

4. Are management and supervisory personnel trained to encourage participative management and support?

1. Do employees generally feel that they are brought into problemsolving activities?

2. Do employees generally feel that they have the power to accomplish their tasks?

3. Are the results of team efforts generally listened to by management?

4. Are employees encouraged to keep up with and participate in professional society activities?

1. Are employees brought into measurement processes?

2. Are employee teams responsible for defining monitoring methods and procedures?

3. Are employees aware of whether the company is meeting safety and environmental goals?

4. Are employees encouraged to report out-of-spec or unsafe conditions?

1. Are employees asked for inputs regarding the information systems that support the safety programs?

2. Are employees asked for inputs regarding cause and effect relationships with respect to safety?

3. Are employees, other than managers, asked to participate in integrated product and/or process teams?

4. Do rank-and-file employees participate in discussing integrated views of safety and environmental issues and solutions? 


\section{Table 6-7. Corporate leadership and commitment/performance accountability}

Planning

Organizing

Directing

Monitoring

Integrating
1. Do corporate plans deal with performance accountability with respect to safety and environment?

2. Do facility managers' plans deal with performance accountability with respect to safety and environment?

3. Do project plans deal with performance accountability with respect to safety and environment?

4. Are the levels of coverage in these plans adequate?

1. Do all levels of the organization include performance accountability in personnel evaluations?

2. Is feedback on performance, or lack thereof, a standard operating procedure?

3. Is training for performance assessment and accountability carried out across all levels of the organization?

4. Are levels of responsibility and authority commensurate so as to facilitate performance accountability?

1. Is on-the-job performance part of the periodic employee evaluation process?

2. Is performance accountability part of the company's monthly measurement processes?

3. Are the safety goals of the company measurable and are they measured?

4. Are the environmental goals of the company measurable and are they measured?

1. Is company performance regarding safety measured quantitatively?

2. Is this measurement carried out frequently enough?

3. Is individual performance regarding safety measured quantitatively?

4. Are individual performance measurements made frequently enough?

1. Is performance accountability supported by information systems?

2. Are these information systems accurate and responsive?

3. Do these information systems provide correlated data dealing with many aspects of safety and report the status?

4. Does performance accountability deal with all relevant aspects of safety and environment? 
Table 6-8. Corporate leadership and commitment/performance verification

Planning

Organizing

Directing

Monitoring

Integrating
1. Do corporate plans deal with performance verification?

2. Do facility managers' plans deal with performance verification?

3. Do individual project plans deal with performance verification?

4. Do the levels of verification cited in the plans appear to be adequate?

1. Are responsibilities for performance verification clear?

2. Are authorities for performance verification commensurate with these responsibilities?

3. Are chains of command for performance verification well defined?

4. Does performance verification involve multifunctional teams?

1. Does the company have specific compliance goals and objectives?

2. Are people held accountable for achieving the specific compliance goals and objectives?

3. Are there any incentives or penalties for achieving or failing to achieve compliance?

4. Does the company act quickly to verify performance compliance?

1. Are compliance levels measured quantitatively?

2. Are trend lines established from these measurements?

3. Are compliance reports part of the company's monthly measurement process?

4. Is compliance reporting sufficiently frequent?

1. Is performance verification supported by modern information systems?

2. Are these systems accurate and responsive?

3. Is performance verification related to all other significant elements of safety?

4. Are tradeoffs between safety compliance and performance normally carried out? 
Table 6-9. Corporate operating excellence/open communications

Planning

Organizing

Directing

Monitoring

Integrating
1. Do corporate plans stress the need for open communications?

2. Are planning processes themselves generally participative?

3. Do facility managers' plans encourage open communications?

4. Do all plans recognize the need for open communications both vertically and horizontally in the organization?

1. Does the company convey messages from top management to the staff in a consistently clear and acceptable manner?

2. Does the company encourage and accept messages from the staff to higher levels of management in a clear and acceptable manner?

3. Do human resources personnel assist the processes of open communications?

4. Are cross-functional and integrated product and process teams employed to achieve open communications?

1. Does top management respond to inputs from the staff?

2. Is there a management "open door" policy and is it generally exercised?

3. Do the rank and file generally feel that management is listening?

4. Does the human resources group have a concrete program to assist in open communications in the company?

1. Are all levels in the company encouraged to provide inputs regarding potentially unsafe conditions?

2. Can employees report anonymously on potentially unsafe conditions?

3. Are trends and statistics regarding safety made available to all personnel?

4. Are trends and statistics regarding environmental conditions made available to all personnel?

1. In communications with the staff, does management stress relationships between various aspects of safety and performance?

2. Are these communications effective?

3. Do these communications request feedback and response?

4. Are all areas related to safety and environment subject to open and direct communications from the rank and file to various levels of management? 


\section{Table 6-10. Corporate operating excellence/teamwork}

Planning

Organizing

Directing

Monitoring

Integrating
1. Does the corporate strategic plan stress teamwork and team building?

2. Are plans developed through team efforts?

3. Do plans for explicit team building exist?

4. Do individual project plans include cross-functional and integrated team efforts?

1. Does the company consistently operate through the employment of high-performance teams?

2. Are these teams prevalent in the line organization?

3. Do these teams also include multifunctional and quality circle teams?

4. Are the results of team efforts considered authoritative solutions to problems or are they simply advisory?

1. Does the company encourage the use of teams for problem-solving activities?

2. Are these teams highly functional?

3. Is there a training program whose purpose is to establish highperformance teams?

4. Do highly functional teams receive some form of appreciation for a job well done?

1. Are teams employed to develop appropriate monitoring and measurement procedures?

2. Are the results produced by the teams consistently considered and carried out?

3. Are teams utilized to perform important audits of safety and environmental conditions?

4. Are team members trained in various monitoring and measurement techniques?

1. Are teams often cross-functional to obtain an integrated view of a problem area?

2. Are teams or team leaders trained to apply the systems approach?

3. Are information systems available to standard and specialpurpose teams?

4. Are these information systems effective and responsive? 
Table 6-11. Corporate operating excellence/common shared values

Planning

Organizing

Directing

Monitoring

Integrating
1. Does the company strategic plan convey the value system of the company with respect to safety?

2. Does the company strategic plan convey the value system of the company with respect to environmental matters?

3. Are common shared values evident in managers' plans?

4. Are the common shared values described in the plans adequate and comprehensive with respect to safety and environment?

1. Is there evidence that various organizational elements and groups have the same common shared values?

2. Do the various organizational elements contribute to the definition and promulgation of common shared values?

3. Does the human resources group accept at least partial responsibility for promulgating common shared values?

4. Is there evidence that top management consistently promulgates the common shared values of the organization?

1. Can personnel articulate the common shared values of the company with respect to safety?

2. Can personnel articulate the common shared values of the company with respect to environmental matters?

3 . Is there a training program that has as an objective the conveyance of the company's common shared values?

4. Are common shared values reinforced through policies and procedures as well as internal communications, such as newsletters?

1. Is continuous measurement and improvement of safety part of the company's common shared values?

2. Is continuous measurement and improvement of the environment part of the company's common shared values?

3 . Is the monthly measurement process part of the company's common shared values?

4. Is quantitative analysis and meeting quantitative goals and objectives part of the company's common shared values?

1. Do the company's common shared values include the integrated systems approach to problem solving?

2. Do the company's common shared values include the use of the most modern information systems?

3. Do the company's common shared values support the use of integrated product and/or process teams?

4. Do the company's common shared values emphasize the effective interaction between different functional parts of the organization? 
Table 6-12. Corporate operating excellence/do the job the right way

Planning

Organizing

Directing

Monitoring

Integrating
1. Does the corporate strategic plan emphasize doing the job the right way?

2. Do facility managers' plans emphasize prevention rather than correction?

3. Are plans in evidence that would promote doing the job the right way?

4. Do plans exist that train personnel in doing the job the right way?

1. Do organizational units responsible for prevention of problems dominate the units responsible for correction of problems?

2. Are trouble-shooting teams put together to solve important problems and encourage new and sound processes?

3. Are these trouble-shooting teams listened to in terms of the solutions they recommend?

4. Does the company have active, continuous improvement and business process reengineering initiatives and teams?

1. Is the "right way" to perform various jobs made clear through supervisors and on-the-job training?

2. Is the "right way" to perform various jobs made clear through formal training programs?

3. Are personnel evaluated on the basis of their consistent use of correct and appropriate methods?

4. Is there any special recognition given to personnel who consistently perform tasks the "right way"?

1. Does the company keep statistics and trends on error rates and unsafe conditions?

2. Are statistics or other records kept on individual performance, both good and bad?

3. Are errors or out-of-condition situations part of the monthly measurement process at all levels in the company?

4. Is the company president kept informed about out-of-spec conditions in a timely manner?

1. Are cross-functional teams employed to solve problems?

2. Are resources made available that highlight "lessons learned"?

3. Is training available that reinforces proper methods?

4. Is this training of high quality? 
Table 6-13. Corporate operating excellence/behavior modification

Planning

Organizing

Directing

Monitoring

Integrating
1. Does the company's strategic plan make it clear as to how the company wishes to make changes with respect to safety?

2. Is there a safety improvement plan in evidence in the various line organizations?

3. Is there an environmental improvement plan in evidence in the various line organizations?

4. Do business process improvement plans contain sections on safety and environment?

1. Is reorganization utilized as a means of behavior modification?

2. Is empowerment down the line organization utilized as a means of behavior modification?

3. Are personnel able to move within the organizations to encourage individual and group behavior modification?

4. Is there evidence that the company has responded to chronic problems by changing organizational structures?

1. Are the company priorities with respect to behavior modification made clear?

2. Do continuous improvement programs exist with respect to improving safety-related behavior?

3. Are these programs generally successful?

4. Is the company making appropriate investments each year into changing behavior with respect to safety?

1. Are there concrete attempts to modify behavior with respect to quantitative measurement processes?

2. Are there attempts to modify behavior with respect to continuous improvement methods and techniques?

3. Are there attempts to modify behavior with respect to individual responsibility regarding safety assessments?

4. Are incentives and penalties part of the behavior modification activities?

1. Can the company be considered a "learning organization"?

2. Are integrated product and/or process teams involved in behavior modification?

3. Are these teams considered successful?

4. Are appropriate information systems available to support behavior modification? 
Table 6-14. Program technology/process technology

Planning

Organizing

Directing

Monitoring

Integrating
1. Do corporate plans explicitly contain a section on process technology?

2. Is this section considered adequate?

3. Do corporate plans deal explicitly with process technology for environmental compatibility?

4. Are these plans considered adequate?

1. Are specific organizational elements clearly responsible for acquiring and improving process technology?

2. Do these organizational elements have the authority commensurate with their responsibility?

3. Is the chain of command responsive to the needs for improvement in process technology?

4. Do the organizational units have access to the necessary expertise in all aspects of safety and environment?

1. Is the company making appropriate investments with respect to acquiring new and improved process technology?

2. Is this technology brought online quickly?

3. Are personnel being trained to utilize the new technology correctly?

4. Is there evidence that the new technology is actually improving safety or environmental performance?

1. Is the operating status of process technology continuously monitored?

2. Are out-of-spec conditions with respect to process technology immediately reported to management?

3 . Is the status of process technology part of the monthly measurement process?

4. Are measurements of the status of process technology made frequently enough?

1. Do information systems routinely support process technology?

2. Are these information systems effective and responsive?

3. Is the process "technology base" viewed in an integrated fashion?

4. Do cross-functional teams routinely work with the company's process technology? 
Table 6-15. Program technology/process hazards analysis

Planning

Organizing

Directing

Monitoring

Integrating
1. Do the facility managers' plans incorporate process hazards analysis?

2. Do individual projects exist that deal with process hazards analysis?

3. Are standards spelled out on how to accomplish process hazards analysis?

1. Is there a special organizational unit with expertise in process hazards analysis?

2. Who has the authority to make changes when a process hazards analysis indicates that a safety problem exists?

3. Is training in process hazards analysis carried out mainly through in-house expertise and capabilities?

4. Do all line organizations have at least one person with expertise in process hazards analysis?

1. Is process hazards analysis being continuously carried out?

2. Are the results of process hazards analysis being used to modify unsafe procedures or practices?

3. Do business process reengineering or total quality management activities include process hazards analysis?

1. Is process hazards analysis part of a continuous measurement process?

2. Are assessments made periodically as to the adequacy and completeness of process hazards analyses?

3. Are process hazards analyses consistently focused on high-risk areas?

4. Is process hazards analysis part of a program to determine whether the company is meeting quantitative goals?

1. Are hazards viewed in terms of their complex interactions?

2. Do integrated teams work routinely on process hazards analyses?

3. Do hazards cover both safety and environmental issues? 
Table 6-16. Program technology/operating procedures and safe work practices

Planning

Organizing

Directing

Monitoring

Integrating

1. Do plans exist for the acquisition of technology that would improve operating procedures and safe work practices?

2. Do plans exist for the in-house development of technology that would improve operating procedures and safe work practices?

3. Do these plans indicate that funding is available and budgeted for technology applications?

4. Do specific safety improvement plans evidence the use of the most modern and effective technology?

1. Are all line organizational units responsible for having the necessary technology for sound operating procedures and safe work practices?

2. Is the investment in appropriate technology for safety a key issue on the corporate agenda?

3. Is the investment in appropriate technology for safety a key issue on the agendas of the facility managers?

4. Are appropriate investments in technology being made by all organizational units in order to ensure safe operations?

1. Are appropriate operating procedures and safe work practices well documented and disseminated?

2. Are people following proper operating procedures and safe work practices?

3. Is there a training program that reinforces appropriate operating procedures and safe work practices?

4. Are there any goals with respect to the effective employment of proper operating procedures and safe work practices?

1. Does the company measure the adequacy of operating procedures and safe work practices with respect to technology?

2. Are these measurements made frequently enough?

3. Do the operating procedures and safe work practices include trends and methods of statistical process control?

4. Is the staff encouraged to report out-of-spec conditions with respect to technology, whenever they find them?

1. Are relationships between operating procedures and safe work practices described?

2. Are operating procedures and safe work practices supported by modern information systems?

3. Are these information systems complete and responsive?

4. Do operating procedures and safe work practices mandate the consistent use of modern computer-based tools? 


\section{Table 6-17. Program technology/management of change technology}

Planning

Organizing

Directing

Monitoring

Integrating
1. Do corporate plans show investments in management of change (MOC) technology?

2. Do plans show specific timetables for the employment of MOC technology?

3. Do individual project plans exist for the acquisition and employment of MOC technology?

4. Do these plans appear to be comprehensive and forward-looking?

1. Are responsibilities clear regarding MOC technology?

2. Are authorities commensurate with responsibilities with respect to MOC technology?

3. Can the chain of command be clearly identified with respect to MOC technology?

4. Are spans of control appropriate with respect to managing MOC technology?

1. Is the company program with respect to MOC technology clear to all employees?

2. Are training programs in evidence with respect to MOC technology?

3. Is the utilization of MOC technology considered effective?

4. Does MOC technology cover both safety and environmental issues?

1. Is any MOC technology focused on developing better measurement techniques?

2. Is MOC technology sufficient to support the company's needs with respect to monitoring and measurement?

3. Does MOC technology support audit procedures?

4. Does MOC technology help in determining when and where auditing is necessary or desirable?

1. Does MOC technology integrate the existing technology?

2. Does MOC technology provide views of the company's operation or the effectiveness of that operation?

3. Does MOC technology deal with integrating safety information?

4. Does MOC technology allow different functional groups in the company to communicate and work better together? 
Table 6-18. Program personnel/training and performance

Planning

Organizing

Directing

Monitoring

Integrating
1. Does the corporate strategic plan stress personnel training in safety matters?

2. Does the corporate strategic plan stress personnel training in environmental matters?

3. Are the company's training plans comprehensive?

4. Do plans for personnel training cover every person at least once a year?

1. Are responsibilities for training of personnel clear?

2. Does the responsible unit have the authority to carry out appropriate training programs?

3. Does the responsible unit have sufficient funding to carry out a training program?

4. Does the training program for safety and environment appear to be coherent and comprehensive?

1. Do training programs exist with respect to safety?

2. Do training programs exist with respect to environmental matters?

3. Are these training programs effective?

4. Do training programs consider both safety and performance matters and the potential conflict between them?

1. Are periodic status reviews held with respect to training and performance?

2. Are these reviews held frequently enough?

3. Are these reviews comprehensive and do they include both safety and environmental matters?

4. Do training programs emphasize methods of measurement and monitoring?

1. Are personnel trained to view the various operations in the company as an interactive system?

2. Are personnel trained to interact with other functional groups within the company?

3. Are personnel trained with respect to operating as part of integrated product and/or process teams?

4. Is this training frequent enough and effective? 
Table 6-19. Program personnel/contractor safety and performance

Planning

Organizing

Directing

Monitoring

Integrating
1. Do corporate plans cover contractor safety and performance (CS\&P)?

2. Do the facility managers' plans cover matters of CS\&P?

3. Are there specific project plans for CS\&P?

4. Are contractors involved in the planning processes that deal with CS\&P?

1. Are firm contractual relationships in place with respect to all contractors?

2. Are contractual authorities identified and clear?

3. Are contractual responsibilities identified and clear?

1. Is there a specific program in effect to ensure contractor safety?

2 . Is there an appropriate dialogue between the company and its contractors with respect to safety and performance?

3. Are corrective actions consistently taken when contractor safety is considered to be inadequate?

1. Does the company perform contractor audits of safety and performance on a periodic basis?

2. Are these audits carried out with sufficient frequency?

3. Are these audits comprehensive and do they deal with both safety and environmental matters?

1. Do the contractors train their personnel on all aspects of safety and how to meet safety standards?

2. Is the safety performance of contractors handled by integrated information systems? 
Table 6-20. Program personnel/management of change personnel

Planning

Organizing

Directing

Monitoring

Integrating
1. Do corporate plans explicitly identify the need for management of change (MOC) personnel?

2. Have MOC personnel been specifically identified in corporate-level and facility-manager-level plans?

3. Have MOC personnel drawn up specific plans for change and improvement?

4. Do plans indicate the skills required in order to qualify and acquire MOC personnel?

1. Does the organizational structure show units responsible for analyzing and evaluating possible needs for change?

2. Does the MOC personnel function have a clear and documented charter?

3. Can specific cases of change management in the past year be clearly cited?

1. Are there company "champions" who are designated as MOC personnel?

2. Are these personnel effective in doing their jobs?

3. Are change goals and objectives clear?

4. Is there any evidence that the change goals are being met?

1. Are MOC personnel trained with respect to appropriate methods of monitoring and measurement?

2. Are MOC personnel involved in periodic status reviews?

3. Are MOC personnel encouraged to establish new and improved methods of measurement?

4. Are MOC personnel significantly contributing to the monitoring and measurement processes of the company?

1. Do MOC personnel address problems of process interactions?

2. Do MOC personnel deal with improvements in information flow and access?

3. Are MOC personnel trained as change agents in a systems context?

4. Are MOC personnel taking on leadership positions with respect to the operations of integrated product teams? 
Table 6-21. Program personneVincident investigation and communication

Planning

Organizing

Directing

Monitoring

Integrating
1. Do corporate strategic plans stress the element of incident investigation and communication (II\&C)?

2. Do the facility managers' plans stress the element of II\&C?

3. Do project-level plans explain the procedures that are to be carried out with respect to II\&C?

4. Are these plans considered adequate in terms of scope and effectiveness?

1. Are responsibilities for $\| \& C$ explicitly identified?

2. Do II\&C personnel have the necessary autonomy to carry out investigations without corporate intervention?

3. Do II\&C personnel have the authority to make changes where they consider it necessary to do so?

4. Do II\&C personnel appear to have the appropriate influence in the company?

1. Are the procedures for incident investigation clear and well documented?

2. Are these procedures followed?

3. Is incident investigation carried out in a timely manner?

4. Are the results of incident investigation appropriately communicated?

1. Are periodic reviews held with respect to the results obtained from incident investigations?

2. Are these reviews held frequently enough?

3. Are incident investigations comprehensive and do they cover both potential safety and environmental impacts?

4. Are incident investigators trained to deal with quantitative measurements and trending?

1. Is there evidence that incident investigations take the whole system and internal interactions into account?

2. Are incident investigators trained to obtain necessary data from any and all parts of the organization?

3. Are incident investigators able to retrieve related data from an automated database in most situations?

4. Are incident investigators successful in communicating with any and all necessary personnel in the company? 
Table 6-22. Program personnelemergency planning and response

Planning

Organizing

Directing

Monitoring

Integrating
1. Does the corporate strategic plan stress the element of emergency planning and response (EP\&R)?

2. Do the facility managers' plans stress the element of EP\&R?

3. Do individual project plans exist that deal with EP\&R procedures and practices?

4. Are these plans considered adequate with respect to scope and effectiveness?

1. Is the EP\&R function shown on the company organization chart?

2. Is EP\&R carried out by one or more teams?

3. Do these teams have a clear charter?

4. Does the charter delineate both responsibilities and authorities?

1. Are emergency response procedures practiced?

2. Have prior emergency responses been adequate?

3. Is the staff at large aware of what they are supposed to do in emergency situations?

4. Have suggested emergency responses been sufficiently analyzed to ensure that they minimize possible negative consequences?

1. Are periodic status reviews carried out with respect to the effectiveness of EP\&R?

2. Are these reviews carried out frequently enough?

3. Are these reviews comprehensive?

4. Are these reviews quantitative?

1. Are EP\&R activities supported by information systems?

2. Are these information systems effective and responsive?

3. Are EP\&R teams composed of representatives from all the various functional areas in the company?

4. Is there evidence that these EP\&R teams take a systems approach to developing EP\&R plans and actions? 
Table 6-23. Program personnel/auditing

Planning

Organizing

Directing

Monitoring

Integrating
1. Does the corporate strategic plan emphasize the importance of periodic auditing?

2. Do plans define the level and scope of auditing processes?

3. Do plans define how training for auditing is to be carried out?

4. Are these plans considered to be adequate in scope and effectiveness?

1. Is auditing generally carried out as an independent function?

2. Is auditing the sole function of at least some organizational units?

3. Does auditing cover both safety and environmental matters?

4. Do auditing organizational units maintain audit trends and statistics?

1. Are personnel tested on a periodic basis to ensure that they are able to carry out safety-related tasks?

2. Are personnel tested on a periodic basis to ensure that they are able to carry out environment-related tasks?

3. Is there a cadre of "independent" auditors in the company?

4. Is this cadre doing an effective job?

1. Is the auditing process carried out on a periodic basis?

2. Are auditing processes carried out with sufficient frequency?

3. Are audits comprehensive?

4. Do audits yield quantitative information?

1. Are audits based on a systems view of the company and its activities?

2. Are audits supported by an information system?

3. Are auditors readily able to obtain information regarding the results of previous audits that might be related?

4. Are auditor team members drawn from a variety of company disciplines? 
Table 6-24. Program facilities/quality assurance

Planning

Organizing

Directing

Monitoring

Integrating
1. Is there a corporate-level plan for quality assurance?

2. Are there facility managers' plans for quality assurance?

3. Do plans for quality assurance indicate the use of the most modern methods of quality assurance?

4. Do plans for quality assurance appear to be sufficiently broad in scope and focused on prevention?

1. Is quality assurance carried out at least in part by independent organizational units?

2. Do quality assurance personnel report results at an appropriately high level in the organization?

3. Are quality assurance responsibilities clearly specified?

4. Is quality assurance authority commensurate with assigned responsibility?

1. Is equipment for carrying out quality activities calibrated and maintained?

2. Are facilities for quality assurance at the leading edge of the stateof-the-art?

3. Are personnel trained to use quality assurance facilities in the best possible way?

4. Is there a continuous improvement program that includes quality assurance facilities?

1. Are periodic status reviews held with respect to the quality assurance program and its effectiveness?

2. Are these reviews held frequently enough?

3. Are these reviews comprehensive?

4. Are quality assurance procedures quantitative in nature, consistently incorporating such items as statistical process control?

1. Are quality assurance methods consistently supported by information systems?

2. Are quality assurance teams cross-functional in makeup?

3. Are statistical methods utilized as standard procedures?

4. Are results of quality assurance audits, findings, tests, and methods kept in an historical record? 
Table 6-25. Program facilities/mechanical integrity

Planning

Organizing

Directing

Monitoring

Integrating
1. Do the facility managers' plans deal with how to achieve mechanical integrity?

2. Do project plans cover the full scope of facilities and equipment?

3. Do plans for mechanical integrity show specific goals that are to be achieved?

4. Do plans show how these goals are to be achieved?

1. Is there an organizational unit responsible for mechanical integrity of facilities?

2. Does this unit have the necessary authority to ensure mechanical integrity?

3. Do other parts of the organization know who to go to when they observe that mechanical integrity may be compromised?

4. Does mechanical integrity maintenance include facilities that enhance both safety and environment?

1. Is there a training program to ensure mechanical integrity of facilities?

2. Are the facilities in fact maintained at a high level of mechanical integrity?

3. Is there a program that focuses on continuous improvement of mechanical integrity?

4. Are funds allocated each year to ensure mechanical integrity?

1. Are periodic reviews of mechanical integrity carried out?

2. Are these reviews held with sufficient frequency?

3. Are these reviews comprehensive?

4. Are quantitative measurements consistently used to assess mechanical integrity?

1. Are operating and safety models of mechanical facilities routinely developed and utilized?

2. Are mechanical facility records kept in an automated form?

3. Are man-machine interactions studied from the point of view of meeting safety goals? 
Table 6-26. Program facilities/pre-startup safety reviews

Planning

Organizing

Directing

Monitoring

Integrating
1. Are adequate safety plans for all facilities in place?

2. Are adequate plans for operating the facilities in place?

3. Are adequate maintenance plans in place?

4. Are adequate emergency response plans in place?

1. Is a specific organizational unit responsible for safety reviews of these facilities?

2. Does this unit have the necessary resources to carry out the safety reviews?

3. Does the unit have adequate independence?

4. Does the unit have the requisite authority to carry out the safety reviews?

5. Does this unit report to an appropriate level in the overall organization?

1. Is construction in accordance with specifications?

2. Have operating personnel been trained?

3. Have safety reviews for these facilities been carried out?

4. Have previous reviews indicated high levels of safety?

1. Are safety reviews comprehensive?

2. Are safety reviews held frequently enough?

3. When problems are found, are the results fed back quickly so that corrective action may be taken?

4. Are pre-startup safety reviews part of the normal measurement process?

1. Are safety reviews supported by information systems?

2. Are these information systems complete and responsive?

3. Are the results of previous safety reviews accessible through some type of record system?

4. Are the safety review teams drawn from all appropriate functional areas? 
Table 6-27. Program facilities/management of "subtle" change

Planning

Organizing

Directing

Monitoring

Integrating
1. Do plans indicate the way in which subtle change occurs with respect to facilities?

2. Do plans track the levels of subtle degradation that may occur with certain classes of facilities?

3. Do plans indicate the way in which subtle change with respect to facilities is to be managed?

4. Are these plans considered adequate with respect to scope of coverage, effectiveness, and investment levels?

1. Is there an organizational unit responsible for the management of subtle change with respect to facilities?

2. Does this unit have the necessary authority to manage these changes?

3. Does this unit have the budget and overall resources necessary to keep all facilities in a safe condition?

4. Do other personnel in the organization know who to go to if they believe that there is a degradation in facilities?

1. Is the company responsive to out-of-spec condition assessments of facilities?

2. Does the company have an adequate maintenance and readiness program?

3. Does the company have an incentives program for maintenance of facilities at the highest levels?

4. Does the company have enough personnel assigned to the tasks of maintenance of facilities?

1. Are monitoring programs specifically designed to detect subtle degradations in facilities and equipment?

2. Are these programs consistently quantitative?

3. Are measurements made with sufficient frequency?

4. Do corrective action messages consistently flow from out of condition situations that are detected?

1. Is the measurement of facility status supported by information systems?

2. Is the future status of facilities with respect to performance and safety routinely predicted?

3. Do integrated process teams periodically examine the safety of all significant facilities? 


\subsection{Summary}

This section integrated the results of the previous sections by formulating two matrices, one dealing with a corporate-level assessment of safety and the other considering safety at the PSM program level. These matrices provide an organized structure for the overall effectiveness evaluation of management control of safety.

By answering questions in each of the cells of the matrices, it is possible to develop effectiveness assessments that provide a quantitative "view" of how well management is controlling safety. These views are developed cell by cell and in the aggregate they offer an increasingly comprehensive picture of management control of safety.
- Views across rows deal with specific safety elements.

- Views down columns deal with management functions.

- Views both across rows and down columns yield overall results for each matrix.

- Views that combine the results of each matrix provide a total effectiveness evaluation.

The suggested procedure may be expanded and modified by adding or refining illustrative questions and/or changing the rating system used by the auditors. Further applications of the procedures suggested will lead to notions regarding expansion and modification possibilities. 


\section{SECTION 7 ISSUES FOR PUTTING THEORY INTO PRACTICE}

\subsection{Introduction}

The previous section set forth a technique for evaluating management effectiveness with respect to controlling safety. The process enables one or more auditors to develop responses to a series of questions and thus derive a measure of management effectiveness. There are, however, some issues that are not necessarily revealed through a formal effectiveness assessment. These additional issues are addressed in this section.

\subsection{Management Commitment}

The corporate-level safety assessment included "leadership and commitment" as a major category, under which five safety elements were discussed (see Section 5.3 and Figure 6-1). Corporate commitment to meeting rigorous safety goals is viewed as an overriding necessity for any practical and viable safety program. Companies may espouse commitment with all the appropriate rhetoric but may not ultimately support their words with plans and actions. In the suggested evaluation procedure, the auditor should, through investigation, examination, and observation, consider-

- the thoroughness of PSM policies and guidelines

- the extent of resource commitment

- the degree of employee involvement

- the measures for performance accountability

- the extent of performance verification

Positive evaluations for these five safety elements provide only a partial determination of a company's real commitment to safety. True commitment is difficult to determine, but without top-level commitment, lower level safety programs and initiatives are not likely to be sustainable or successful.

\subsection{Management Awareness}

If management is to be considered seriously committed to safety, the following three general conditions should be satisfied-

(1) Management should know, in some sense, the various costs of potential lack of safety (see Section 2.9).

(2) Management should be able to ascertain the "safety status" of its company.

(3) Management should understand that, in the long run, performance is not sacrificed by active and effective safety programs.

Given the above, management has the necessary awareness to understand that safe and environmentally sound operations are good for business. Furthermore, these three conditions imply that monitoring and measurement programs are effective, convincing, and supported by appropriate resource levels and budgets. This type of management awareness is a precursor to a steady and long-range commitment to safety.

\subsection{Management Policies}

One of the key instruments for gauging management's commitment and awareness is its set of PSM policies and guidelines, another safety element grouped under "leadership and commitment." Management implements its programs through official policies and guidelines that are uniformly promulgated and enforced. Enforcement is implemented through effective systems of reward, reinforcement, and penalties. For these basic reasons, PSM policies and guidelines 
deserve special emphasis and therefore should be given significant weight in any refined evaluation process.

\subsection{Procedures and Procedure Control}

The next step with respect to PSM policies and guidelines is to spell out specific procedures that implement these policies and guidelines. Such procedures, as a general rule, are not going to be developed by top management. They will be defined by lower level personnel in the company and be based on the statements of policy by top management. This means that such procedures should be-

- checked that they accurately reflect the PSM policies and guidelines

- checked to confirm that they are sound and complete

- followed faithfully

Experience shows that a large percentage of safety problems are caused not by the absence of a proper procedure, but by a series of events that resulted in the procedures not being followed. Therefore, procedure control should be rigorous to ensure that personnel do not violate, nullify, or degrade safe procedures. Procedure control also entails ensuring that procedures are updated to incorporate all new conditions, such as the installation of modified or new facilities or equipment.

A company moves from corporate level commitment, awareness, and policies to detailed procedures for the control of safety. This "chain" of activities can be broken at any point with weak links that could lead to unsafe conditions. It is the job of management to assure that implementing procedures and procedure control, at the level of hundreds of safety-related tasks, do not repre- sent weak links in the chain of safety control measures.

\subsection{Control Methods}

Another dimension of the control of safety and the appropriate implementation and control of procedures concerns the specific methods that might be employed. These can be through performance verification and utilization of "standardized" methods.

Performance verification is yet another safety element grouped under the "leadership and commitment" category of key corporate-level safety concerns. It is not enough for management to ensure that all procedures are in place and complete; management should also insist on performance verification. Such verification usually requires that independent checking for compliance be part of the process. When a failure to comply has potentially serious safety consequences, many levels of checking may be entailed.

With respect to standardized methods, a variety of such methods can be drawn, at least by analogy, from the theories of total quality management and those of quality assurance and control (see Section 2). Such methods include, but are not necessarily limited to-

- $\quad$ statistical process control

- quality function deployment

- Pareto analysis and charting

- design of experiments

- Taguchi methods

- Ishikawa diagramming

- $\quad$ process-oriented computer simulation tools

- trend analysis and prediction

- plan-do-check-act procedures

- scatter diagrams

These methods, when appropriately applied, can be used effectively in the domain of safety assur- 
ance. It is the ultimate responsibility of management to ensure that the most modern and effective tools are utilized. By implication, management should provide (1) support for training so that these methods are employed optimally and

(2) budgets for any related capital expenditures.

\subsection{Integrated System Approach}

The Learning Organization (TLO) was described in Section 2 as one of the significant management control theories. The "fifth discipline," a central theme of TLO, was "systems thinking." Indeed, TLO is largely a treatise on systems thinking and the systems approach. Although a complete explanation of these matters is beyond the scope of this report, it is important to restate the view that systems thinking is "the discipline that integrates the disciplines, fusing them into a coherent body of theory and practice" (Senge, 1990, p. 12). In the domain of safety control and safety assurance, the following aspects of systems thinking are of special importance-

- creating models of safety operations and of causes and effects

- implementing the necessary information systems to bring together accurate information on a timely basis

\subsubsection{Models}

Models of safety operations allow prediction of the effects of actions and to test new policies and procedures before they are implemented. Models that can simulate new processes are of special importance and can often be constructed by using off-the-shelf and inexpensive computer-based tools. Models also represent powerful training mechanisms that provide a common basis for employee understanding of how systems operate and behave as well as how degraded operations may lead to safety problems. Models thus play a central role in developing mental models and achieving systems thinking in a continuously learning organization.

\subsubsection{Information Systems}

In today's world, information systems can be the lifeblood of an organization. Ranging over a variety of domains, as described in Section 3.6, information systems were not explicitly listed as safety elements in discussions of corporate- or PSM program-level safety issues. They are, however, integral to the effective control of safety. Basically, all the documentation and reporting that is part of any safety program usually finds its way into a computer-based information system.

In an overview context, three aspects of information systems are key-

(1) completeness

(2) accuracy

(3) responsiveness

Completeness refers to the matter of scope: Does the information system capture and represent all of the desired data needed at the various management levels? Accuracy deals with the correctness of the information. An organization can get into major difficulties if it bases decisions on incorrect data. Finally, the required information should reach the right people as quickly as possible. Response times are especially important when out-of-spec situations are detected and should be remedied quickly. The "safety status" of any organization should be discernible from the information that resides in its information bases and systems. 


\subsection{Configuration and Records Management}

Information systems include the components of configuration and records management. Organizations that allow their configuration and records management processes and systems to fall into disarray are likely to face serious safety problems to which they are unable to respond within desired reaction times.

The classical features of a configuration management system have been described as-

- identification

- control

- $\quad$ auditing

- $\quad$ status accounting

- traceability

Handwritten and computer-based records support all configuration management systems and document the status of various configurations. Records of all system characteristics should be kept to allow for status determination and to assist in such activities as trend analysis, hazards analysis, performance accountability, and performance verification. Essentially all records management systems should be automated to facilitate these activities. And because records accumulate over a period of time, they should be made easily retrievable through automation.

\subsection{Safety Committees}

Safety committees are a crucial part of management control of safety. They should, however, be set up so as to maintain safety responsibilities but not violate principles of chain of command and equality of responsibility and authority. In today's world, many of the theories of modern management control point to the increasing use of cross-functional and integrated teams as well as general principles of teamwork. Safety committees should be composed of experts who will address problem areas from a systems perspective, utilizing knowledge from all relevant parts of the organization.

Special safety committees can also be used to establish new initiatives in essentially all of the safety elements shown in the corporate- and PSM-level evaluation matrices. Here again, modern theory would argue that all functional area groups should be represented in such committees.

\subsection{Performance, Financial, and Safety Management}

Performance, finance, and safety represent three interdependent aspects of the operation of a company. Resources are allocated to each of these three functions and they should be kept in balance for a company to succeed. A company under pressure from a performance and/or financial perspective cannot, however, view the safety area as one that can be compromised in order to improve performance and financial conditions. This is not only potentially dangerous but also bad business practice. In the long run, safety should be viewed as the one company activity that cannot and should not be compromised. Various past experiences have shown that safety problems have led to performance and financial disasters.

\subsection{Checks and Balances}

Another important perspective that should be present in all safety programs is that of checks and balances. This shows itself in at least two dimensions-

(1) maintaining a balance between business and safety matters

(2) checking and rechecking safety operations 
With respect to the first, a company that is consistently "out-of-balance" is likely to ultimately fail. Poor business performance can lead to insufficient investments in safety matters. Conversely, if safety is the only concern, then eventually there will not be enough resources available to sustain a company's financial health. Then the safety programs will be affected, and a downward spiral may be established.

An example of the second point-checking and rechecking-is in the area of performance verification. In safety matters, it is inadvisable to assume compliance has occurred. It should be verified. In general, high levels of safety can only be ensured through verification of all safety-related procedures and practices. In cases that are particularly significant from a safety point of view, performance verification often entails multiple levels of checking and rechecking. Thus, a question that should be answered from management's perspective is, How can we be sure that performance has been achieved? This same question can be rephrased with respect to all the safety elements in the corporate- and PSM-level sets of safety categories.

\subsection{Priorities}

Essentially all of the issues discussed so far are reflected in the priorities that management gives to various aspects of operating a company. Analysis of budgets and resources will reveal explicit priorities given by management to various business and safety operations. Norms for resources and budgets are not easy to establish, but trending can be used effectively to determine whether more or less resources should be allocated, year by year, to business and safety operations. Thus, the reviewer of a company should also be in a position to analyze budgets and resources over a period of time to see if trends are positive or negative. Although budget and resource audits do not reveal the efficiency of these expenditures, they are indicators of man- agement priorities with respect to the various ways in which resources are expended.

\subsection{Business and Regulator Perspectives}

The overall perspective of this report views safety from the point of view of the regulator. In the suggested evaluation procedures, safety is the primary concern and other business operations are not explicitly considered. The companies should take public safety as a primary goal as verified by the regulator. All other business issues are secondary and should be left to the companies. However, as discussed above, safety assurance is also good business practice. Unsafe operation will cause loss of public confidence in a company which can lead to degraded business performance. As with most regulation charters, high levels of safety should be considered inviolate in keeping with the maintenance of public safety responsibilities.

\subsection{Summary}

This section has briefly covered some important issues that are not necessarily revealed through the formal effectiveness assessment suggested by the two evaluation matrices in Section 6. These issues have been concerned with-

- management commitment and awareness

- management policies, procedures, and procedure control

- control methods

- the integrated system approach

- information systems, including configuration and records management

- $\quad$ safety committees 
- $\quad$ performance, financial, and safety manage- - priorities ment 


\section{SECTION 8 SUMMARY}

This report has examined safety issues from the point of view of how well management deals with such issues. The central focus of the report was the development of a structure to evaluate the effectiveness of management control of safety. The recommended evaluation process takes the form of two matrices: one maps general management functions against corporate-level safety elements and the other maps general management functions against PSM program- level safety elements. These matrices provide a basic structure for an overall evaluation, but they are subject to modification and refinement, both through application and through development of additional questions. It is hoped that the suggested evaluation procedure will form the basis for an assessment of how well the management of organizations in the nuclear industry is able to plan, organize, direct, monitor, integrate, and thus control their safety programs. 



\section{REFERENCES}

Burk, A.F., "Achieving Excellence in Process Safety Management," paper presented at International Conference and Exhibition on Safety, Health and Loss Prevention in the Oil, Chemical and Process Industries, Singapore, 15-19 February 1993.

Chemical Manufacturers Association, Process Safety Code of Management Practices, Responsible Care Program, Washington, D.C., 1990.

Crosby, P., Quality Without Tears, New American Library, 1984.

DuPont, Inc., DuPont's Process Safety Management Program, Safety, Health and Environmental Management Center, Wilmington, Del., 1979.

Eisner, H., "Leadership Imperatives: Do They Support Creativity and Innovation?" paper presented at American Society for Engineering Management Annual Conference, Dallas, October 22-25, 1993.

Feigenbaum, A., Total Quality Control, McGraw-Hill, New York, 1991.

Hammer, M., and J. Champy, Reengineering the Corporation, Harper Business, New York, 1993.

Imai, M., Kaizen, McGraw-Hill, New York, 1986.

Ishikawa, K., What Is Total Quality Control-The Japanese Way, Prentice-Hall, Englewood Cliffs, N.J., 1985.

International Organization for Standardization, "Quality Management and Quality Assurance Standards: Guidelines for Selection and Use," ISO-9000, The International Organization for Standardization, Geneva, 1987.

Juran, J., Juran on Leadership for Quality, The Free Press, New York, 1989.

Kezsbom, D., D. Schilling, and K. Edward, Dynamic Project Management, John Wiley, New York, 1989.

Military Standard 2173 (AS), "Reliability-Centered Maintenance," AMSC No. N3769, Department of Defense, Washington, January 21, 1986.

Mondy, R., and S. Premeaux, Management-Concepts, Practices and Skills, Allyn and Bacon, Englewood Cliffs, N.J., 1993.

Roy, R., A Primer on the Taguchi Method, Van Nostrand Reinhold, New York, 1990. 
Senge, P., The Fïth Discipline, Doubleday Currency, New York, 1990.

Walton, W., The Deming Management Method, A Perigee Book, Putnam Publishing Group, New York, 1986. 


\section{BIBLIOGRAPHY}

American Institute of Chemical Engineers, Guidelines for Auditing Process Safety Management Systems, Center for Chemical Process Safety, New York, 1992.

American Institute of Chemical Engineers, Plant Guidelines for Technical Management of Chemical Process Safety, Center for Chemical Process Safety, New York, 1992.

American Institute of Chemical Engineers, Proceedings of the International Conference on Safety, Health and Loss Prevention in the Oil, Chemical and Process Industries, Vol. 18, Center for Chemical Process Safety, New York, 1994.

American Institute of Chemical Engineers, Proceedings of the International Conference on Safety, Health and Loss Prevention in the Oil, Chemical and Process Industries, Vol. 17, Center for Chemical Process Safety, New York, 1993.

American Institute of Chemical Engineers, Proceedings of the International Conference on Safety, Health and Loss Prevention in the Oil, Chemical and Process Industries, Vol. 16, Center for Chemical Process Safety, New York, 1992.

American Petroleum Institute, Recommended Practice \#750: Management of Process Hazards, Washington, D.C., 1989.

Archibald, R., Managing High-Technology Programs and Projects, John Wiley, New York, 1976.

California, Risk Management and Prevention Program, Sacramento, 1985.

Chemical Manufacturers Association, Community Awareness and Emergency Response Code of Management Practices, Responsible Care Program, Washington, D.C., 1989.

Chemical Manufacturers Association, Employee Health and Safety Code of Management Practices, Responsible Care Program, Washington, D.C., 1992.

Chemical Manufacturers Association, Evaluating Process Safety in the Chemical Industry: A Manager's Guide to Quantitative Risk Assessment, Washington, D.C., 1990.

Chemical Manufacturers Association, Process Management Safety: Control of Acute Accidents, Washington, D.C., 1990.

Chemical Manufacturers Association, Product Stewardship Code of Management Practices, Responsible Care Program, Washington, D.C., 1992.

Chemical Manufacturers Association, Resource Guide for Implementing the Process Safety Code of Management Practices, Responsible Care Program, Washington, D.C., 1989.

Delaware, Risk Management Program for Extremely Hazardous Substances, Wilmington, 1988. 
Department of Energy, Environment, Safety and Health Progress Assessment of the Mound Plant, DOE/EH-0285, Assistant Secretary for Environment, Safety and Health, Washington, D.C., 1992.

Department of Energy, Nuclear Safety Analysis Reports, DOE Order 5280.23, Washington, D.C., 1992.

Department of Energy, Performance Objectives and Criteria for Technical Safety Appraisals at Department of Energy Facilities and Sites, DOE/EH-0135, Assistant Secretary for Environment, Safety and Health, Washington, D.C., 1990.

Department of Energy, Report on the Department of Energy Occupational Safety and Health Program Review of the Portsmouth Gaseous Diffusion Plant, DOE/EH-0281, Assistant Secretary for Environment, Safety and Health, Washington, D.C., 1992.

Department of Energy, Technical Safety Appraisal: Reference Manual, Vols. 1 \& 2, DOE/EH-0090, Assistant Secretary for Environment, Safety and Health, Washington, D.C., 1989.

Frame, J., Managing Projects in Organizations, Jossey-Bass, San Francisco, 1987.

Institute for Nuclear Power Operations, Institutional Plan, Atlanta, Ga., 1993.

Institute for Nuclear Power Operations, Performance Objectives and Criteria for Corporate Evaluations, INPO 90-020, Atlanta, Ga., 1990.

Institute for Nuclear Power Operations, Performance Objectives and Criteria for Operating and Nearterm Operating License Plants, INPO 90-015, Atlanta, Ga., 1990.

Kreitner, R., Management, Houghton Mifflin, Boston, 1986.

New Jersey, Toxic Catastrophe Act, Trenton, 1986.

Nuclear Regulatory Commission, Guidance on Management Controls/ Quality Assurance, Require ments for Operation, Chemical Safety, and Fire Protection for Fuel Cycle Facilities, Proposed Guidance to Applicants and Licensees, Federal Register, Vol. 54, No. 53, Washington, D.C., March 21, 1989.

Nuclear Regulatory Commission, Standard Format and Content of Safety Analysis Reports for Fuel Reprocessing Plants, Regulatory Guide 3.26, Washington, D.C., 1975.

Occupational Safety and Health Administration, Process Safety Management of Highly Hazardous Chemicals, 29 CFR 1910.119, Washington, D.C., 1992.

Stephenson, J., System Safety 2000: A Practical Guide for Planning, Managing, and Conducting Systems Safety Programs, Van Nostrand Reinhold, New York, 1991. 
2. TITLE AND SUBTITLE

Management Concepts and Safety Applications for

Nuclear Fuel Facilities

\begin{tabular}{|l|c|}
\hline 3. & \multicolumn{1}{|c|}{ DATE REPORT PUBLISHED } \\
\hline MONTH & YEAR \\
MaY & 1995 \\
\hline $\begin{array}{l}\text { 4. FIN OR GRANT NUMBER } \\
\text { J5030 }\end{array}$ \\
6. TYPE OF REPORT \\
TeChnica 1 \\
\hline 7. PERIOD COVERED inclusive Dates)
\end{tabular}

H. Eisner, R. S. Scotti, The George Washington University

W. S. Delicate, The KEVRIC Company, Inc.

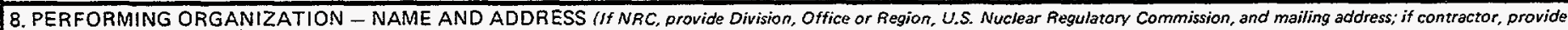
name and mailing address.

The George Washington University

School of Engineering and Applied Science

Center for International Training and Education Washington, DC 20052
Under Contract to:

The KEVRIC Company, Inc.

8401 Colesville Road, Suite 610

Silver Spring, MD 20910

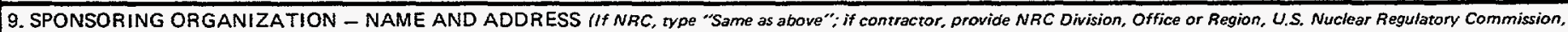
and mailing address.).

Division of Fuel Cycle Safety and Safeguards

Office of Nuclear Material Safety and Safeguards

U.S. Nuclear Regulatory Commission

Washington, DC 20555-0001

10. SUPPLEMENTARY NOTES

11. ABSTRACT (200 words or less)

This report presents an overview of effectiveness of management control of safety.

It reviews several modern management control theories as well as the general functions of management and relates them to safety issues at the corporate and at the process safety management (PSM) program level. Following these discussions, a formal and structured technique for assessing management of the safety function is suggested. Seven modern management control theories are summarized, including business process reengineering, the learning organization, capability maturity, total quality management, quality assurance and control, reliability centered maintenance, and industrial process safety. Each of these theories is examined for. its principal characteristics and implications for safety management. The five general management functions of planning, organizing, directing, monitoring, and integrating, which together provide control over all company operations, are discussed. Under the broad categories of Safety culture, Leadership and Commitment, and operating Excellence, key corporate safety elements and their subelements are examined. The three categories under which PSM program-level safety issues are described are Technology, Personnel, and Facilities.

12. KEY WORDS/DESCR!PTORS (List words or phrases that will assist researchers in locating the report.

Assessment

Evaluation

Management Control theories

Safety Management

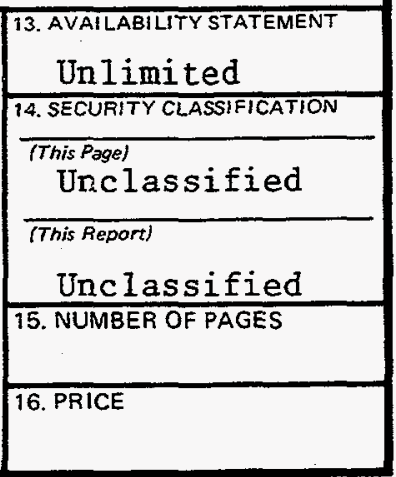

